Illinois State University

ISU ReD: Research and eData

Theses and Dissertations

$5-28-2020$

\title{
(Dis)Ability Discourse And The Mediation Of Disabled Identity In Young Adult Literature And Television
}

Daniel Freeman

Illinois State University, danielfreeman92@gmail.com

Follow this and additional works at: https://ir.library.illinoisstate.edu/etd

Part of the English Language and Literature Commons

\section{Recommended Citation}

Freeman, Daniel, "(Dis)Ability Discourse And The Mediation Of Disabled Identity In Young Adult Literature And Television" (2020). Theses and Dissertations. 1285.

https://ir.library.illinoisstate.edu/etd/1285

This Thesis is brought to you for free and open access by ISU ReD: Research and eData. It has been accepted for inclusion in Theses and Dissertations by an authorized administrator of ISU ReD: Research and eData. For more information, please contact ISUReD@ilstu.edu. 


\section{(DIS)ABILITY DISCOURSE AND THE MEDIATION OF DISABLED IDENTITY IN YOUNG ADULT LITERATURE AND TELEVISION}

\section{DANIEL FREEMAN}

\section{Pages}

The primary aim of literary (and media) disability studies scholarship has been to examine the rhetorical effects of the various representations of disability that are found throughout literature, television, and other cultural sites of inquiry. The Internet has helped to facilitate this aim, opening these types of discussions to the general public. Social media has given individuals the power, agency, and voice to assert their ideas about disability identity, and (dis)ability (as a system; see Schalk, Bodyminds Reimagined) more broadly to the world, and in doing so, has radically altered the author-text-audience relationship. My project examines the authorial choices of JK Rowling, John Green, and Scott Silvestri (and other writers) in regard to how they think, write, and talk about (dis)ability and disability identity within and outside the story-world of the Harry Potter series (1997-2007), Turtles All the Way Down (2014), and the television show, Speechless (2016-19). Analysis of these works is especially focused on where the authors aligned their (dis)ability discourse with and within larger ideological systems, and how this alignment mediates disabled identity to readers/viewers. My intervention, however, is to juxtapose these discourses of (dis)ability with how fans/audiences are taking them up in digital spaces. The choices that individuals make about these systems, identities, and ideologies in their own day-to-day lives provides a new understanding between the nexus of identity, media, and 
literature, as individuals interact with the models for thinking, writing, and talking about (dis)ability and disability identity— such as cripped narratology—that authors put forth.

KEYWORDS: Young Adult literature, Disability Studies, John Green, disability identity, cripped narratology, social media 
(DIS)ABILITY DISCOURSE AND THE MEDIATION OF DISABLED IDENTITY IN YOUNG ADULT LITERATURE AND TELEVISION

\author{
DANIEL FREEMAN
}

\author{
A Thesis Submitted in Partial \\ Fulfillment of the Requirements \\ for the Degree of \\ MASTER OF ARTS \\ Department of English \\ ILLINOIS STATE UNIVERSITY
}


(C) 2020 Daniel Freeman 
(DIS)ABILITY DISCOURSE AND THE MEDIATION OF DISABLED IDENTITY IN YOUNG ADULT LITERATURE AND TELEVISION

DANIEL FREEMAN

COMMITTEE MEMBERS:

Katherine Ellison, Chair

Mary Jeanette Moran 


\section{ACKNOWLEDGMENTS}

I could not have succeeded in this project without the expert wisdom and guidance of my committee, Dr. Katherine Ellison and Dr. Mary Moran. You both have inspired me to take risks with this project, and in doing so, have helped me grow as a scholar. My parents, Anne and David Freeman, deserve much more gratitude than I could ever put here; their many years of support for this path, this dream, mean so much to me. I have likewise been the beneficiary of so much support, love, and guidance from my friends as I have undertaken this task: Keely Doyle, Mike Horky, Nicole Tauster, Haley Conger, Sam Bertram, Lauren Tarbutton, Kyle Scott, Zoe Edwards, Erin Poppe, Samuel Trent McGee, Marissa Germann McGee, and Jennifer Smith—you all have my heart. To my Master's cohort and PhD buddies: thank you for challenging me every day, and more importantly, for making me feel at home. Katy Lewis, you get a special shout out for mentoring me throughout my Master's in English—your joy is only matched by your intellect, and that, my friend, is a gift to us all. I would be remiss if I did not also thank a few other folks. Dr. Krystal Cleary started me on this path, and I am always grateful for that. I have learned so much from \#DisabilityTwitter and \#AcademicTwitter, but a special mention goes to Dr. Travis Chi Wing Lau, who has modeled what it means to be a disabled academic in this precarious times: thank you for your Internet presence, you do extremely valuable work.

And finally, I must thank Molly Cockerham, who has been by my side through all the late nights writing, researching, and pontificating about the intersections of disability, young adult literature, and social media. I am so glad I get to do life with you. (And Scooby).

D. F. 


\section{CONTENTS}

$\begin{array}{lll}\text { Page } & \\ \end{array}$

ACKNOWLEDGMENTS

CHAPTER I: INTRODUCTION 1

$\begin{array}{ll}\text { Review of Literature } & 10\end{array}$

$\begin{array}{ll}\text { Disability Studies Theory } & 10\end{array}$

Disability and Children's/ Young Adult Literature $\quad 12$

Disability and Media Studies $\quad 16$

$\begin{array}{ll}\text { Methodology } & 19\end{array}$

$\begin{array}{ll}\text { Defining Mediation } & 25\end{array}$

CHAPTER II: AUDIENCE REACTION TO DISABILITY IDENTITY

IN HARRY POTTER ON SOCIAL MEDIA 26

(Dis)ability Discourse and Rowling's Writings on Disability in the Wizarding World 32

Harry Potter and the Analysis of Audience Reception to (Dis)ability Discourse 39

Doing Disability Identity Differently

CHAPTER III: HOW CRIPPED NARRATOLOGY INFORMS DISABILITY IDENTITY

DISCOURSE IN TURTLES ALL THE WAY DOWN \& THE BROADER NERDFIGHTERIA

$\begin{array}{ll}\text { COMMUNITY } & 60\end{array}$

Initial Narratological Concerns: Narrative Voice and Character $\quad 65$

Focalization as Indicator of OCD $\quad 71$

$\begin{array}{ll}\text { Cripped Narratology } & 73\end{array}$

Nerdfighteria and (Dis)ability Discourse $\quad 83$ 
CHAPTER IV: SPEECHLESS AND (DIS)ABILITY DISCOURSE: TOWARD NEW

$\begin{array}{ll}\text { UNDERSTANDINGS OF DISABILITY IDENTITY } & 94\end{array}$

$\begin{array}{ll}\text { Episode Analysis } & 97\end{array}$

$\begin{array}{ll}\text { Social Media Engagement with Speechless } & 110\end{array}$

$\begin{array}{ll}\text { Facebook } & 111\end{array}$

$\begin{array}{ll}\text { Twitter } & 117\end{array}$

$\begin{array}{ll}\text { YouTube } & 119\end{array}$

$\begin{array}{ll}\text { CHAPTER V: CONCLUSION } & 125\end{array}$

$\begin{array}{ll}\text { Limitations } & 131\end{array}$

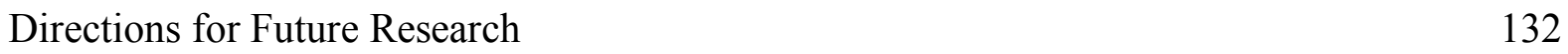

$\begin{array}{ll}\text { WORKS CITED } & 134\end{array}$ 


\section{CHAPTER I: INTRODUCTION}

Youth culture has not always been synonymous with "popular culture"; however, the trends in young adult (YA) literature suggest a movement in that direction, as movie, television, and theatrical adaptations of these texts are all on the rise. We can look to the success of series like Harry Potter (1997-2007) and The Hunger Games (2008-2010) as well as adaptations of popular stand-alone novels such as The Fault in Our Stars (2012) and 13 Reasons Why (2007) as evidence for this phenomenon. Other forms of media - such as television, podcasts, and theater-have also taken up creating content specifically directed at adolescents, in part because of the opportunity to seek out new audiences that these literary franchises created.

In the last ten years especially, the industry has tried to diversify itself. Organizations like We Need Diverse Books, which was founded in 2014 ("Our Story”), have been at the forefront of calls for more diverse authors, characters, and stories within YA texts. Yet, Melanie D. Koss and William H. Teale, and the Cooperative Children's Book Center, have shown that disability representation across all forms of media — including the YA literature industry — is still behind that of other identity groups ("What's Happening in YA Literature? Trends in Books for Adolescents"; CCBC Blog). Similarly, the publishing house Lee and Low Books conducted a study of the diversity found within the publishing industry in both 2015 and 2019; the 2015 survey found that $92 \%$ of the industry is able-bodied, while the 2019 study found that $89 \%$ percent of the industry is able-bodied ("2015 Baseline Survey," "2019 Baseline Survey"). These figures may inform the lack of available disability YA texts on the market as a result of disabled voices being largely absent from the production of YA texts. Of course, this is not to say that such representation is nonexistent, for as David Mitchell and Sharon Snyder point out, "disability 
is pervasive in literature" and likewise, so is it in other forms of media and culture (Narrative Prosthesis: Disability and the Dependencies of Discourse, 47-8).

In this vein, disabled adolescents' bodies resist constructions of adolescence and their embodied identities may "produce a [more] complex picture of what it means to be [a teenager]" (Hintz and Tribunella, Reading Children's Literature: a Critical Introduction, $2^{\text {nd }}$ edition, 14). An embodiment of disability in adolescence changes the ways in which that individual can experience adolescence. To be clear, here I am referring to the reader/viewer, who is potentially an adolescent with a disability who, by watching that representation, then perceives limited ways of experiencing their own embodiment. However, I am also arguing that disability, as an embodiment, pushes the limits of storytelling conventions, creating specific types of narratological sequences and discourses by which a character might experience their own identity. At the same time, these specific strategies can hinder how disability identity is experienced if disability identity is not complexly imagined and conveyed. Clearly, disabled teens' bodies (the characters and those of viewers/readers) resist constructions of able-bodied adolescence, but if able-bodied constructions of adolescence are all we have to consider (including unrealistic, stereotyped, or normalizing representations of disabled bodies), what does that mean for representations of disability that are produced in YA literature and media featuring adolescent disabled bodies?

Thus, my thesis examines representations of adolescent disability in The Harry Potter series, by JK Rowling, Turtles All the Way Down, by John Green, and the television show, Speechless, created by Scott Silveri, and how they engage in dominant discourses of disability through various narratological and rhetorical moves. I chose these texts because of their cultural capital; each text has had a large audience for its original iteration, which only continues to grow 
on social media. However, these texts were also chosen precisely because of ways that their creators leverage the power that comes with such high cultural capital. Gauging how audiences react to that level of control over the various discourses of disability that are put forth in the original texts, as well as externally on social media by the authors/creators themselves, is paramount to understanding how disability identity is mediated to readers/viewers.

In the first chapter on Harry Potter, I interrogate Rowling's insistence on rhetorically tying two adult characters, Alastor "Mad Eye" Moody and Remus Lupin, to disability through an essay she published on her social media platform, Pottermore, while not doing so for Harry, whom multiple scholars have identified as disabled. I trace the effect of Rowling's "able-bodied discourse of disability" on the ways that Potter fans talk, think, and write about disabled identity. In the second chapter, I look at how John Green intentionally creates a "disabled discourse of disability" within his text and online community, building on his own experiences living with OCD. Green's innovative use of narratological conventions (including the routine breaking of them) moves me to propose "cripped narratology" as a way of better understanding how disabled identity is mediated in literature, and how this narratological framework, when combined with Green's own openness about his OCD, creates an inclusive disability discourse in online spaces for Nerdfighters. In the third chapter, I break down the "mixed disability discourse" that the TV show Speechless employs to cater to able-bodied and disabled audiences alike. My focus on audience response in this chapter examines how the mixed disability discourse transfers over to audience engagement with disability identity. "Able-bodied disability discourse," "disabled disability discourse," and "mixed disability discourse" refer to the experiences that are privileged by these discourses, with "mixed" alluding to the combination of able-bodied and disabled experiences as informing the discourse that Speechless employs. 
Each chapter prioritizes social media responses from fans/viewers to show how social media has redefined the relationship between authors, texts, and audiences, and how this continually changing relationship influences (dis)ability discourse to various degrees. I find that social media responses to and commentary on these mainstream depictions of disability in recent popular YA narratives are not only engaging in dominant disability discourse but also providing a counternarrative to them. This emerging counternarrative constructed by viewers through their participation in discourse communities, allows disabled adolescents' bodies to resist normative constructions of them and, in turn, is influencing how disability is represented in novels and film.

My approach to the intersection of identity, media, and literature is informed by the work of Maria Nikolajeva, Julie Passanante Elman, and Robert McRuer; their theories greatly influenced my research questions, as well as the criteria by which I will be evaluating texts. According to Maria Nikolajeva, aetonormativity questions the power dynamics of how we read children's literature by examining the power structures at work in analyzing texts meant for children but written by adult authors (and sometimes read by adults, too) (8). Nikolajeva cites Roberta Trites's work as foundational to this line of thinking, as Trites's examination of power in young adult fiction distinguishes the mechanisms by which adolescents grapple with power in young adult texts, almost always settling for "[one of] two choices...: to perish or to become repressive himself" (7). Nikolajeva remarks that Trites's study lays bare the cycle of power inherent in adolescent texts that ultimately reifies existing adult-oriented and -mandated status quos (7). Furthermore, Nikolajeva, adapting queer theory's meaning of "norm" and carnival theory, argues that:

Children are allowed, in fiction written by adults for the enlightenment and enjoyment of children, to become strong, brave, rich, powerful, and independent—on certain 
conditions and for a limited time. The most important condition is the physical

dislocation and the removal, temporary or permanent, of parental protection, allowing the child protagonist to have the freedom to explore the world and test the boundaries of independence. (10, emphasis in original)

One of the arguments I am making in this thesis extrapolated from Nikolejeva's writing is that the disabled adolescent body disrupts many of the conventions that Nikolajeva mentions above. Disabled adolescents must negotiate the power dynamics of adult versus child as well as the dynamics of being able-bodied versus being disabled. These dichotomies are overly general and do not fully represent the capaciousness of either adolescents or disabled folk, but my point is that negotiations of norms and normativity (as Nikolajeva says) are immensely less straightforward for these types of characters. This assertion about the lack of straightforwardness that adolescent characters experience when negotiating norms and normativity works in a similar manner when thinking about the narratives that disabled adolescents are allowed to exist in, for disabled "boundaries of independence" may look different, and as a result, demand alternative ways for thinking about their engagement in a narrative.

Nikolajeva's astute observation that children's literature is usually written by adults (10), leads me to my next extrapolation of children's literature theory, as one of the central questions in children's and young adult literature is "who is it for?" Theorists such as Barbara Wall, Linda Alcoff, and Nikolajeva have all attempted to answer this question. The question's relevance for this project can be adjusted slightly, as my consideration is not "are these texts for children" but rather, "what kind of young adults are these texts for"-i.e. are these texts for able-bodied audiences or disabled audiences? This question is meaningful as it addresses the discourse on disability that an audience may be entering by reading or viewing the text. Likewise, as Alcoff 
has suggested, it is also important to consider whether a text is speaking with a particular group's needs and views rather than over them ("The Problem of Speaking for Others," 5-32). This is especially important to consider with books about disabled adolescents as Beth Haller has noted that disabled voices rarely have control over their own stories (Representing Disability, 1-25, 115-136).

These questions get much coverage in Chronic Youth: Disability, Sexuality, and U.S. Media Cultures of Rehabilitation by Julie Passanante Elman. In this work, Passanante Elman demonstrates how society, particularly in the 1980's and 90's, constructed adolescence itself as a disabling condition, unpacking the ramifications that such a construction of adolescence had on creating a culture of rehabilitation in the US, and not just in US media, but also, in US government and other facets of everyday American life. In her chapter on the "sick-lit" of Lurlene McDaniels, Elman describes young adult literature as "discursively [producing] an imagined teenager, constituted at the nexus of publishing market demand, adults' nostalgia about their own teen experiences, and cultural hopes and expectations of what a 'healthy' reading experience might produce in teen readers as proto-citizens" (98). One of Elman's central arguments in this chapter is that "able-bodied audiences want to feel pain, but not experience it for themselves" (Freeman 5). Furthermore, Elman argues that sick-lit thrives upon this performance of sadness, going so far as to claim that it is "the functional feeling that must be exchanged between able-bodied and disabled characters" (103-5).

I do not focus on "sick-lit" in my thesis. However, the concepts from Elman's work not only reify the above questions of "who is young adult literature for" and "who is the intended audience of these books about disability and young people" but also point to the system by which audience, author, and text interact, and how they do so in a specific discourse when engaging in 
texts that feature disability as a central component of the story world. Specifically, Passanante Elman makes clear that the type of discourses that able-bodied individuals have about disabled bodies tend to be drastically different than those conducted by and for disabled people. These discourses, as she demonstrates, are frequently invoked, not only in everyday media messaging, but also in messaging at the state and global levels, too. And this point brings me to Robert McRuer's concept of "compulsory able-bodiedness."

McRuer's theory highlights how systemic barriers and attitudes inform the choices that disabled individuals are allowed to make, even though the reality is that most of the time, the choices are already made for them, and typically, are centered on able-bodied views of disability rather than the opposite. Harry Potter presents a good example of this idea, as Remus Lupin's lycanthropy is presented to the reader as a disabling condition; Wizarding society refuses to accommodate Lupin's embodiment to the extent that he can hardly find a job. It is not until Severus Snape and Albus Dumbledore provide Lupin with a potion that mutes the effects of Lupin's lycanthropy that Lupin is allowed to participate in society in a significant way. Thus, even in the Wizarding world, able-bodiedness is presented to Lupin as a choice he is making to give himself a better life, when in reality, it is the only choice if he is to participate in society at all. Furthermore, however, McRuer — in part building off the work of Judith Butler-is articulating the notion that even if one's only choice is to perform able-bodiedness so as to abide by these rules, this performance is still an impossibility, precisely because "[compulsory ablebodiedness] depend[s] on a disabled existence that can never quite be contained" (Disability Studies Reader, 375). Moreover, McRuer acknowledges that this hegemonic framework can never truly be iron-clad due to the fact that "able-bodied status is always temporary" (374). 
This application of McRuer's theory extends back to my arguments concerning Nikolajeva's work and promotes a new line of thinking by suggesting that disabled adolescent characters attempt to create their own systems of choice in regard to disabled identity development, but really, they typically wind up fulfilling a disabled identity that is chosen for them by someone else, rather than by themselves. Moreover, this setup encourages audiencesespecially able-bodied ones - to engage in specific types of disability narratives over others, such as "sick-lit," as Elman points out.

In bringing the work of Maria Nikolajeva, Julie Passanante Elman, and Robert McRuer together, and building from their theories, I identify three main problems in the representation of disabled teen bodies in YA literature:

1. (Perhaps able-bodied) assumptions are made by authors, creators, and producers about disabled teen bodies;

2. these assumptions, in turn, construct disabled adolescence in literature and media as either adhering to able-bodied notions of disability or as disability that does not actually function as disability (either as narrative prosthesis or as other manifestations);

3. and this dichotomy creates a false choice regarding disability representation in literature and mainstream culture and often leads audiences to identify with disability representation that is "Other," but not so Other as to alienate the reader or viewer.

These assumptions and dichotomies do not define every text in which a disabled character exists; however, each text I examine reflects these assumptions and dichotomies, demonstrating that the concept of adolescence (and its various models) has been highly debated, and so too, has 
disability. When they are considered together, the convergence of these identities creates a unique set of problems for scholars and audiences alike.

In recent years, these problems have been brought to the fore by audience responses to the spectrum of disability representation that has appeared across literature and other forms of media. These discussions - usually held online in places like Twitter, Reddit, and Facebook as well as in publications like Bustle, the blog Disability in Kidlit, and The New York Times' disability opinion section and in books such as The Pretty One by Keah Brown-reify the material consequences of the creative process as it imagines the disabled body. These conversations have begun to create counter-narratives of disability, mediating identity in ways that better serve the capaciousness of disability and the real lives of disabled people. Moreover, understanding these counter narratives helps us to understand the types of assumptions that are consistently made about disabled bodies_ — not to mention children. By analyzing these core texts against their immediate, crowd-sourced audience reactions through real-time social media, I am demonstrating new ways that readers and viewers of these narratives are not only receiving these discourses, but also co-constructing disability discourse and forming new versions of these narratives that imagine disabled bodies differently. Furthermore, this project captures how the author-text-audience relationship is continually changing, and moreover, how that relationship informs the ways in which we think, talk, and write about disabled adolescents and their identities, especially in online spaces. 


\title{
Review of Literature
}

\author{
Disability Studies Theory
}

Clare Barker and Stuart Murray note that the field of disability studies arose out of the humanities and became increasingly focused on literary and cultural representations of disability in prominent texts and their rhetorical effects (The Cambridge Companion to Literature and Disability 1-16). Studies on disability in visual media have largely focused on photography and/or art (see Alan Gartner and Tom Joe, 1987; Tobin Siebers, 2010; Robert Bogdan, 2012, as cited in Barker \& Murray, 2018, xii-1), highlighting how, over history, disabled bodies have been positioned as non-normative, "freaks," and medical marvels, such as in Extraordinary Bodies (1997) by Rosemarie Garland-Thomson. David Mitchell and Sharon Snyder have long contributed to disability theory; their work Narrative Prothesis: Disability and the Dependencies of Discourse (2000) has been highly influential in shaping literary disability theory. Their definition of narrative prothesis is that disability functions in literature and literary discourse "as a stock feature of characterization and, second, as an opportunistic metaphorical device" (47). Mitchell and Snyder clarify what they mean here by writing "Disability lends a distinctive idiosyncrasy to any character that differentiates the character from the anonymous background of the "norm"' and that "Physical and cognitive anomalies promise to lend a 'tangible' body to textual abstraction" (47-8). Mitchell and Snyder have since moved on to contribute much work about the cultural and political implications of disability. Michael Bérubé's work has also been integral to literary disability theory, as his work combines narratology, literary theory, and disability studies to examine how disability functions across genre (Secret Life of Stories, 2015). Also influential to thinking about disability, literature, and cultural theory has been the work of 
Lennard Davis, especially his book Enforcing Normalcy: Disability, Deafness, and the Body (1995), which centered "normalcy" as a topic of debate and analysis for disability studies. This topic, of course, is not unique to disability studies, as Robert McRuer has demonstrated in his work on the intersections of queer studies and disability studies (see Crip Theory: Cultural Signs of Queerness and Disability, 2006). Other theorists and life writers, such as Eli Clare, Susan Wendell, and G. Thomas Couser have also taken up this debate in various ways in their work. Disability studies and feminist analysis has also been a longstanding coupling of theoretical orientation in the field. Prominent scholars using these frameworks in conjunction with one another include Kim Q. Hall, Alison Kafer, Rosemarie Garland-Thomson, Ellen Samuels, and Sami Schalk, among others. The work of these scholars generally seeks to use this combination of theoretical frameworks to push the limits of each discipline's analytical toolbox, thereby deepening and challenging historical and cultural understandings of identity and the power structures that govern them, sometimes within literature and sometimes not (such as in Fantasies of Identification by Samuels). Another trend within disability studies is the coupling of disability theory and rhetoric studies. Margaret Price (Mad at School), Melanie Yergeau (Authoring Autism), Julia Rodas (Autistic Disturbances) and Jay Dolmage (Disability Rhetoric) have been among the leading voices in this subfield, and their work continues to frame discussions about (dis)ability discourse as it applies to both public and academic spheres. Their work is important to include here because all four scholars question the role of rhetoric in shaping perceptions of disability among and across different institutions, identities, and systems. The intersection of disability studies and rhetoric studies will be explored more deeply in the second chapter of my thesis, as I propose "cripped narratology" as a new mode for thinking about how disabled characters tell audiences their stories, especially with regard to how disabled 
characters break and buck narratological conventions in order to more fully convey authentic representation of their disabled bodyminds.

\section{Disability and Children's/ Young Adult Literature}

There is a growing pool of children's and YA literature that deals with disability, although it is still rather small. According to a 2009 study of fifty-nine young adult titles published between 1999 and 2005 (which were consolidated from a larger pool of 370 titles)

conducted by Melanie D. Koss and William H. Teale, "There were significantly more titles with disabilities than we expected" ("What's Happening in YA Literature? Trends in Books for Adolescents," 567). Approximately $25 \%$ of the 59 titles they studied featured a character or characters with a disability (566). In addition, Koss and Teale's study found that "[o]ver half of the disabilities represented were mental illness" and that "disabilities represented in the remaining titles were evenly split between books that centered on physical disabilities and books in which a character had a disease that caused the disability" (567). Moreover, Koss and Teale noted that "most characters with disabilities [in these texts] were main characters" (567). While the Cooperative Children's Book Center (CCBC) does not have any explicit data on disability in young adult literature, in a 2017 study of 698 picture books, they found that "[a] child with a disability appeared in only 21 picture books, and only 2 of those were main characters. Most others appeared in background illustrations" ("CCBC Blog"). While disability is more represented in YA literature than picture books, a complex imagining of disability is still needed within the YA industry, as a select few disabilities are centered and others are ignored. 
There have been two major works concerning the study of children's and young adult literature and disability completed in the last ten years: Handiland: The Crippiest Place on Earth by Elizabeth Wheeler (2018) and Disabling Characters: Representations of Disability in Young Adult Literature by Patricia Dunn (2015). These studies share the common denominator of looking at how disability functions in children's and young adult literature, but ultimately, Wheeler and Dunn are examining different qualities about the literature, for different purposes. Wheeler's book "explores how national politics and laws, everyday life experience, and literature collaborate and clash with each other in the project of reimagining young people as full members of society" (3). To this end, Wheeler is not only concerned with how politics have shaped children and children's literature, but vice versa. Therefore, Wheeler looks at texts within the umbrella of children's and young adult literature from a variety of genres, including picture books, although special attention is paid to realistic fiction and fantasy (especially Harry Potter). Likewise, while Wheeler situates most of her analysis on work done in the UK and USA, her analysis also includes authors from across the globe, including "Ghana, Venezuela, and Japan" (Wheeler 3) The range of disabilities that Wheeler includes in Handiland is also worth noting, as Wheeler's comprehensive approach to being inclusive of physical, mental, emotional, and other disabilities (such as chronic illness) lends itself toward capturing the systemic issues in literature and culture that Wheeler is concerned with.

Wheeler's work questions how social justice/social activism fits into the work of children's literature as both entities specifically pertain to disabled populations. Throughout her book, Wheeler interrogates how the aims of social justice and disability activism have butted against the laws governing disabled persons and children alike, and what influence, if any, this conflict has had on the subsequent literature that has been produced. Moreover, Wheeler's 
research approach that combines interviews and other qualitative evidence from disability community members (including herself) on online platforms, through stories, and other avenues is a methodological attempt at combatting such ableist structures. In this vein, Wheeler explains that the intended audience of the book is "parents, educators, therapists, doctors, policymakers, and everyone else whose work, ideas, and hands touch young people with disabilities" (Wheeler, 4. Kindle Edition). In essence, Wheeler's work is for everyone who deals with disability, but not necessarily for disabled people themselves. This is a trait that the book shares with Dunn's work. Dunn's book primarily takes a literary analysis approach to dealing with disability and young adult literature. However, a large component of the work is Dunn's inclusion of teaching guides for the texts that she covers - the book is in part meant for English teachers as well as scholars interested in the intersection of disability and young adult literature (Dunn 4). The inclusion of these materials is specifically intended to better understand what "shape[s] reader's understandings of these fictional pieces," especially their understandings of how disability functions within them (Dunn 4). Like Wheeler, Dunn's text explores a vast array of genres. Yet, a large difference between Dunn's data set and Wheeler's is that Dunn more explicitly includes novels by disabled authors that also feature disabled protagonists. Dunn is also primarily concerned with dominant discourses and narratives of disability that appear in fiction such as disabled characters' agency, identity, and etiquette as well as how able-bodied individuals in these texts experience those discourses and narratives.

Dunn's orientation to her work is thus different from Wheeler's in that it seeks to move inward rather than outward by examining the major themes and modes of representation that are associated with depictions of disability in young adult literature. It ultimately seeks to understand the connection between the reader (specifically, the implied reader) and the representation of 
disability that is occurring on the page, and how each influences the other. And in turn, the book seeks to articulate what this cycle means for a larger, cultural understanding of disability. This is the clearest indication of where Wheeler's framework for her book and Dunn's align.

Of course, the work of these two authors is not the only work done on the intersection of these two fields. In 2004, an entire issue of The Disability Studies Quarterly was devoted to discussing disability and children's literature. Important articles from that issue are "What Teachers Never Taught and Writers Feared to Write: Disability in African American Children's Literature" by Kapria Daniels; "The Treatment of Disability in 19th and Early 20th Century Children's Literature" by Ann Dowker; and "What Disability Studies can do for Children's Literature" by Kathy Saunders. In similar ways to my own project, these three articles unpack areas of disability studies and children's literature studies that focus on the ways that our particular subjectivities complicate existing understandings of each discipline. My project adds to this conversation by examining the impact of authorial choices in regard to how they think, write, and talk about disability and disability identity within and outside the story-world of their fictions. Through the analysis of social media, I also uncover the choices that individuals make about these systems, identities, and ideologies in their own day-to-day lives and how that affects engagement with the various models and ideas about disability and disability identity that Rowling, Green, and Silvestri espouse in their work.

Still other avenues of research on disability in children's and young adult literature exist, but by way of public scholarship. Perhaps most prominent of these other avenues is the blog called Disability in Kidlit. Run by disabled authors for disabled readers, the blog details what books represent disability well and includes reviews, discussions, and other resources ("Disability in Kidlit"). Other public scholarship on disability and young adult literature also 
sometimes occurs on the \#CripLit chats that Alice Wong (and others) host on Twitter. The \#CripLit chats therefore bring together disabled authors, publishers, and other constituents into a discussion about disability representation in literature. To this end, following disabled authors on Twitter is another way to engage in the conversations that are happening in the industry about disabled representation in young adult literature. Twitter is also a great place for connecting with other disabled individuals, as well as more generally connecting with people who share same interests: there are multiple "Twitters" such as \#BlackTwitter, \#FilmTwitter, \#AcademicTwitter, etc. Twitter is therefore a platform that contains a multitude of discussions, but some of the most prominent discussions on the site are about media and media representation.

\section{Disability and Media Studies}

The media and disability—like literature and disability—have long held a relationship to each other. Beth Haller has tracked disability representation in many forms of media, including television, newspapers, advertising, and film; her findings suggest an increasing amount of content being created by disabled people for disabled people—especially online—as well as more traditional programming (such as TV and film) creating more inclusive content specifically to reach disabled consumers (Representing Disability in an Ableist World, v-vii). Julie Passanante Elman's work on the intersections of disability, sexuality, and media suggests a media and national culture keen on ideologically tying bodily deviance to adolescence through policy and cultural products alike (Chronic Youth). The recent edited collections The Image of Disability: Essays on Media Representations (eds. JL Schatz and Amber E. George, 2018) and Disability Media Studies (eds. Elizabeth Ellcessor and Bill Kirkpatrick, 2017) both contribute 
new understandings of the ways that disability is mediated in popular culture. The latter collection features numerous essays that blend critical textual analysis with media studies methodologies, including an emphasis in general on audience as well as considering the value of audiences' participation in online spaces related to media (see Ellcessor; Kido Lopez; Cleary; Oren, in Ellcessor and Kirkpatrick, 2017). Other notable authors operating in disability and media studies include Katie Ellis and Gerard Goggin. The two scholars frequently work on projects together, perhaps most notably Disability and the Media (2015). The two scholars are a part of a larger group of mostly UK and Australian researchers who are developing interdisciplinary approaches to studying the intersection of media and disability. The uptick in recent disability media studies scholarship is important not only because it covers the changing nature of media landscapes or how and why more disabled people are utilizing these tools and platforms, but also because this scholarship actively explores the evolution of disability identity and its representation across multiple types of media and the material effects this has on disabled people.

When it comes to more singular studies of disability on television, Bradley Bond notes in a content analysis of over 400 episodes of children's TV programming that disability representation is sparse; generally the disabled characters are older and male, and their disabilities have little to no bearing on the plot of the series ("The Invisible Minority: Portrayals of Physical Disability on Children's Television Programming," 2). David Kociemba traced how Glee's depiction of its disabled character, Artie Abrams, played by the able-bodied actor Kevin McHale, fit into preexisting stereotypes about disability (“'This Isn’t Something I Can Fake’: Reactions to Glee's Representations of Disability," para 2.1-2.3); furthermore, Kociemba interrogated the responses to this character in forums populated by the Glee fan community, 
importantly noting that viewers seemed to lack the knowledge about disability to have a critical debate about the show's handling of the topic (para 3.3). Peter Wayne Moe looked at the rhetorical discourse behind Michael J. Fox's Parkinson's diagnosis, from its public unveiling to how it was incorporated onscreen in some of Fox's characters. One of the key arguments put forth was whether the dueling nature of Fox's public dialogues on Parkinson's could affect the viewer's outlook on/relationship to Fox's fictional characters who also had the disease ("Revealing Rather Than Concealing Disability: The Rhetoric of Parkinson's Advocate Michael J. Fox, " 452-3).

In the study perhaps most correlated with the general research aims of this paper, Lingling Zhang and Beth Haller analyze the ways in which media representations of disability impact disabled viewers' perceptions of their identity ("How mass media impact the identity of people with disabilities", 2013.). Key findings of the study include a reminder of the prevalence of negative disability stereotypes in mass media as well as the fact that even positive representation has its problems (339-330). The authors did not conduct in-depth interviews with respondents; they note that this might be an area for future research on the link between media consumption and identity development and/or shaping (331). Zhang and Haller's study (and its assessments) contextualizes my project by establishing the loose connection between media consumption and identity development, with specific attention paid to the ways in which disabled people embody and react to the representation of disability. In fact, Zhang and Haller's finding that even positive representation has its problems is an indicator of just how individualized disability identity is, as each person they talked to likely reacted in different ways to the representation given to them. The study also points to disability's functioning as a system 
and how the media routinely facilitates representations of disability identity for typically ablebodied audiences which do not speak to the lived experiences of disabled individuals.

\section{Methodology}

There is a long history of disability entangling itself with and within literature (Mitchell and Snyder 47-8). Michael Bérubé has postulated "disability as motive.....as the condition for possibility for the text and its apprehension by readers" (Kindle Location 1116). While Bérubé is specifically writing about mental disabilities and their application to genres such as fantasy and science fiction that deal with changes in time, he is also calling attention to how disability, as a "narrative strategy," "becomes a vehicle for literary techniques that open onto radical forms of alterity" not only with concepts and genres such as time, fantasy, and science fiction, but also as applied to imaginings of disabled people and what narratives do with them (Kindle Location 1116). Mitchell, Snyder, and Bérubé have written at length about the myriad ways in which disability is deployed in literature and, also, in culture to certain ends. However, this latter assertion about the interplay between culture and disability begins to get at the tension that disability evokes, not only as subject matter, but also as a system to be interrogated. In this vein, in her book Bodyminds Reimagined: (dis)ability, Race, and Gender in Black Women's Speculative Fiction, Sami Schalk uses the term "(dis)ability" to "[highlight] the mutual dependency of disability and ability to define one another" as well as in reference to "the wider social system" (Kindle Location 193-212). Schalk contends that "disability without the parenthetical adjustment merely references disability and impairment” (193-212). In Bodyminds Reimagined, Schalk specifically calls attention to the ways in which (dis)ability has intersected 
with other identities and their histories, institutions, and the attending political, social, and cultural dynamics that have grown with the development of discourses on (dis)ability and disabled persons and their "material effects" (193-237).

One of Schalk's criteria for using this term is that "in speculative fiction the function and meaning of (dis)ability does not necessarily comply with our realist understanding of what constitutes ability and disability and therefore must be explained for each text" (206). While this project does not explicitly cover speculative fiction or the intersection of race and disability, my aim in following Schalk's terminology is to likewise name and unpack how each text explains the systemic functions of (dis)ability, as well as disability as impairment. Moreover, my aim is to call attention to how "our realist understandings of what constitutes ability and disability" especially how authors understand and communicate those terms to their readers-influence the relationship between author, text, and audience. Using "(dis)ability" and the attendant "(dis)ability discourse" also points to interrogating the archetypal narratives about disability that are systemic in our culture, and furthermore, are re-created within fan discourses about these texts in online spaces. For these reasons, I will be following Schalk's distinction between disability and (dis)ability to better attend to the goals of this project and the nuances of disability representation in YA literature and television.

To this end, to carry out my research and contextualize it within past, current, and perhaps future discourses on disability, the chapters that follow utilize Jan Grue's framework of disability discourse analysis to capture not only how the primary texts create and engage in disability discourse, but also how (and whether or not) their audiences do as well. I am taking this approach precisely because, as Ria Cheyne writes, "[t]he narratives circulating in popular culture play a significant role in shaping disability and impairment" (117). Grue notes that his 
approach is based upon Critical Discourse Analysis (CDA), which Grue defines as "[being] about the way in which language use shapes the world, and vice versa. It is an attempt to tease out power relations, power use, and power abuse from the source material of text" (Disability Discourse Analysis, 22). Importantly, Grue also acknowledges that "[a] major premise of [his] book is that stories and representations also constitute arguments, whether implicitly or explicitly, and so come to express something not only about how the world is, but about how it should be" (7).

Grue's main assumptions about the connection between discourse and disability are as follows:

My initial assumption is that disability theory qualifies as such by hypothesizing about what disability is and how it is produced...It is possible to articulate a theory of disability which restricts itself only to individual bodies and their physiology, although such a theory would be alien to almost everyone who has any experience with disability and disabled people. My second assumption is that disability theory, as relevant to Disability Studies, hypothesizes about what disability is and how it is produced, in social, cultural, and historical context. (29, emphasis author's own)

What Grue is suggesting in this passage is that disability appears in various contexts, but disability theory does not always have ways to adequately address how disability is taken up in and by them, a line of thinking that Schalk also covers in Bodyminds Reimagined. However, Grue establishes two key ideas about discourse on (dis)ability: first, that disability's capaciousness renders much of disability theory impractical and second, that (dis)ability has specific relationships to specific contexts, and thus, maintains specific discourses related to those relationships that have developed over time. 
As such, Grue notes that (dis)ability discourse, and related disability studies research in the United States, has typically fit into the "minority model" of disability, "in which disability is theorized partly as a form of cultural otherness" (37). Moreover, Grue argues that the minority model can be referred to as "a social model" (36); however, for clarity, the minority model label refers to the discourse surrounding disability, rather than the actual type of theoretical model being used to theorize disability, i.e. the social model of disability. Yet, Grue acknowledges how the social model of disability, which postulates that societal and attitudinal conditions are what make people disabled, is often tacitly apparent in the functioning of the minority model of disability, especially in disciplines that "explore disability as a motif or narrative device, albeit one with social and political ramifications" (36-9). Thus, Grue writes that: "If there are to be multiple points of identification for disability narratives, this requires the critical examination of prominent representations of disabled people - not for the purpose of dismissing them as unsatisfactory or unfit, but for the traditional purpose of critique: examining the grounds on which they come into being, and their alternatives" (108). Following this train of thought, Grue homes in on two questions that govern his rhetorical analysis of disability in media contexts: what is being valued and what is it for? (101-109) These questions, which stem from thinking about disability as a type of rhetorical situation, are immensely useful to thinking about my topic, as they frame the narratives I am studying in a way that allows me to ask the following research questions:

RQ1: What narratives about disability identity do these texts promote, engage in, or combat?

RQ2: How are these narratives conveyed to the audience? 
RQ3: To what extent do audience members engage with these narratives outside the story world, especially in online platforms?

In essence, I am examining the ways in which these texts take up (dis)ability discourse as unique social practices inherent to their fictional story worlds, and how those social practices are interpreted in "real life" by audiences. Therefore, I am applying Grue's conception of disability discourse analysis to examine the implicit and explicit arguments about (dis)ability/disability that these texts mediate to readers and viewers, and how these arguments construct a discourse on (dis)ability that runs counter to some of the dominant stereotypes that Grue and others, such as Beth Haller and Rosemarie Garland-Thomson, have articulated.

Thus, for the first and second research questions, I will be undertaking a rhetorical analysis of the texts to examine the (dis)ability discourses that they are promoting and/or engaging in. For the third research question, I will be analyzing audience responses to these texts on social media platforms, primarily Facebook, Twitter, and YouTube, although other platforms, such as fan-forum sites and Reddit, are also examined. Frederic Jameson defines genre as “essentially literary institutions, or social contracts between a writer and a specific public, whose function is to specify the proper use of a particular cultural artifact" (106). Each of these texts, as a fictional representation of "real-life" discourses on disability, presents itself as a particular type of work about disability and adolescence, with the resulting (dis)ability discourses that are created by authors, producers, and creators for their "specific publics" necessitating different types of responses to the (dis)ability discourse. The relationship between authors, texts, and audiences - through the proliferation and use of social media — is much like a genre, as audiences must form discourse communities to participate in fandom and attendant (dis)ability discourse 
that the texts evoke. John Swales identifies six primary characteristics of discourse communities:

A discourse community has a broadly agreed set of common public goals; A discourse community has mechanisms of intercommunication among its members; A discourse community has its participatory mechanisms primarily to provide information and feedback; A discourse community utilizes and hence possesses one or more genres in the communicative furtherance of its aims; In addition to owning genres, a discourse community has acquired some special lexis; A discourse community has a threshold level of members with a suitable degree of relevant content and discoursal expertise. (Writing about Writing: A College Reader, 2011, 471-473)

The Internet has proven an apt tool for fans to connect to others who are similarly interested in texts, films, etc. The Internet has also allowed fans access to additional authorial evidence that comes forth about these works, giving them a front row seat to interact with and across multiple platforms and in various modes. As such, fan communities meet many of Swales' criteria for discourse communities. This is especially evident in my analysis of Nerdfighteria - the fan community attributed to John Green and his brother, Hank (also an author). The actual makeup of these fan discourse communities is not homogenous, and therefore, my project takes into consideration a very general slice of the population. I am interested in this more general audience specifically because I want to better understand how discourses around (dis)ability in the media are engaged with by both able-bodied and disabled people alike. Throughout my thesis, I will be employing purposive sampling "because of the unique position of the sample elements," which speak to the (dis)ability/disability discourses that these texts employ and the readers/viewers' responses to the texts on social media (Russell Schutt, Understanding the Social World, 75). 
Purposive sampling generally refers to the notion that a researcher is subjectively selecting the members of a population they need to participate in a study; here, I am using it to convey the thought that I am subjectively selecting the social media responses that best speak to the (dis)ability/disability discourses that these texts employ.

\section{Defining Mediation}

The approach to the study of mediation I will be utilizing comes from Disability Media Studies (2017), edited by Elizabeth Ellcessor and Bill Kirkpatrick. Ellcessor and Kirkpatrick call for a disability media studies approach that "consider[s] more thoroughly how media representations are connected to systems of structure and agency, better accounting for economic and material institutions and forces, social and political contexts of media production and reception, technological limitations and affordances, and the ways that audiences negotiate meanings" (17). Ellcessor and Kirkpatrick also propose that "a disability media studies might produce scholarship that radically rethinks received knowledges about the workings of culture, society, and identity," with particular attention to how the body and (dis)ability disrupts, challenges, and creates these knowledges, including policies, histories, and economies as well as other cultures and material conditions (19).

Thus, through the application of these theories and methodologies, I interrogate how disability works to upend conventional narratological formats of mediating identity, and therefore, also reconfigures the audience relationship to (dis)ability discourse, if not altogether changing (dis)ability discourse altogether. 


\section{CHAPTER II: AUDIENCE REACTION TO DISABILITY IDENTITY IN HARRY POTTER ON SOCIAL MEDIA}

Since the publishing of the first Harry Potter book in 1997, there have been significant changes in the ways that individuals consume media. The most notable of these changes has been the proliferation of the Internet; its development and subsequent permeating presence, particularly through social media, continues to change and shape culture, politics, and other avenues of public and private life in beneficial and detrimental ways. Harry Potter has experienced a plethora of changes, beneficial and detrimental, within its now young-adult-aged life. The Internet was highly influential in the early forming of fan communities, as Melissa Anelli details in Harry, A History (77-100). Moreover, as the books and, eventually, movies continued to be released, the Internet became a place where "Potterheads" 1 " could find a home. They found online spaces dedicated to subjects such as Wizard rock, parody musicals, and other Potter-inspired theater, fan art, and more. Rowling has likewise found the Internet to be an effective tool for continuing to grow the Wizarding world and has actively participated in online discussion about the texts, including how the texts treat (dis)ability in the series. Because this conversation persists - along with Rowling's involvement and her fans' reactions to it-more attention is needed to fully unpack how online spaces are changing the nature of the author-fan relationship, as well as how online spaces are allowing for discussions of (dis)ability and disability identity to take place within the Harry Potter fandom.

This chapter cannot grasp the complete force that is Harry Potter; its status as a global, corporate conglomerate precludes that from taking place. Other scholars, such as Tammy Turner-

\footnotetext{
1 "Potterheads" refers to the name of the Harry Potter fan community. There is no definitive source for the original coining of this name.
} 
Vorbeck (“Pottermania: Good, Clean Fun or Cultural Hegemony?") have started to cover the impact of the Harry Potter phenomenon. Still, scholarly and public discussions about the franchise's engagement with (dis)ability in both the original texts and films have yet to fully reckon with Rowling's and fan reactions to Potter's (dis)ability discourse on social media and in other online conversations. This is especially true when looking at how these interactions create spaces for fans to explore disability identity as part of a larger discourse on embodiment and identity that the books facilitate. In fact, one of the things that made the series so special to so many, including myself, was its ability to connect with the reader on an individual level, to make them feel that Harry's struggles were their own, and furthermore, that Hogwarts - and everything it contained — was home. Thus, the discussion of (dis)ability discourse in the Harry Potter series is not merely limited to what is on Rowling's pages; however, my analysis begins there to better understand how a cultural phenomenon like Harry Potter contributes to the on-going, constantly changing connections among its author, readers, their identities, and the characters in the novels and films which may serve as "mirrors, windows, or sliding glass doors" to not only fans' embodied realities, but also, the overarching (dis)ability discourses and systems that exist in our world today (Rudine Sims Bishop, ix-xi). Because of the power of social media, disabled readers can now address the intersections of (dis)ability and Harry Potter in ways that give them agency and control (individually), but also power (systemically), as social media allows disabled individuals to dissect the (dis)ability discourses at work in the series (and in real life) for large audiences. Amplification, in the context of social media use by disabled individuals, is a critical tool that allows for the possibility of disabled voices, which have routinely not been included in discussions about (dis)ability in the series, to become not only normalized, but centered. The exclusion of disabled voices in the (dis)ability and Harry Potter conversation is concerning 
because - to paraphrase James Charlton in Nothing About Us Without Us: Disability Oppression and Empowerment - the discourse is about them, yet, happening without them, and therefore, the exclusion of disabled voices allows for able-bodied discourses of disability to take hold (3$18)$.

Other scholars, in fields such as psychology, are also examining the implications of readers' relationships to texts with the cultural capital of Harry Potter and what the act of reading these texts tells us about readers' identities. In 2015, Loris Vezzali, Sofia Stathi, Dino Giovannini, Dora Capozza, and Elena Trifiletti published a study in The Journal of Applied Social Psychology entitled, “The Greatest Magic of Harry Potter: Reducing Prejudice.” This study quickly garnered mainstream attention, as the study's key finding that reading the series "improves attitudes toward stigmatized groups" (105) formalized, in a sense, the idea that these books develop a certain kind of reader. According to Vezzali et al's study, that reader is a more empathetic one (115). However, the study did not include an analysis of readers' attitudes toward disabled people, choosing instead to focus on "immigrants, homosexuals, and refugees" (105). This project addresses the omission of (dis)ability in Vezzali et al's study, as my work is centered upon understanding reader's attitudes toward disabled people, but also, their understanding of (dis)ability and disability identity. This project also demonstrates the importance of reading texts within the social, historical, and other contexts under which they were produced, as Vezzali et al's study does not examine Rowling's role in creating and maintaining discourses about stigmatized groups outside of the novels themselves.

My work blends rhetorical analysis, media studies, and disability studies approaches to demonstrate how the author-text-audience relationship is continually changing, and moreover, how that relationship informs the ways in which we think, talk, and write about disabled 
adolescents and their identities. Throughout the scholarly study of Harry Potter, there have been numerous explorations by scholars on the series' treatment of politics, race, gender, and other issues $^{2}$, but fewer scholarly pieces have explicitly dealt with disability, not to mention the specific issue of disabled adolescence. Those that have done work on disability in the series include Karen Brown's Prejudice in Harry Potter (2008), Roslyn Weaver's “Metaphors of Monstrosity: The Werewolf as Disability and Illness in Harry Potter and Jatta" (2010), Marc Napolitano's "War, Trauma, and Disability in the Harry Potter Series" (2015), and Robin Aronsonn's “Making the Muggle: A Study of Processes of Othering in J.K. Rowling's Harry Potter and how Teachers Can Use the Novels to Work with Issues of Ableism" (2016). This list is not exhaustive: there are many more articles, chapters, and books that specifically deal with other facets of disability in the series; still, much of the focus on the study of disability in these works is focused on interrogating the way that disability functions solely within the story-world of the series. However, Michael Berube and Elizabeth Wheeler's respective book sections analyzing the Harry Potter series have largely moved out of the practice of analyzing literal representation of disability in the Wizarding World, asking instead, "what is that representation doing?"

\footnotetext{
${ }^{2}$ See "The Politics of Terror: Rereading Harry Potter" by Courtney Strimel (2004); "Heteronormative Heroism and Queering the School Story in JK Rowling's Harry Potter Series” by Tison Pugh \& David L. Wallace (2006); "Harry's Girls: Harry Potter and the Discourse of Gender" by Meredith Cherland (2008); "Harry and the Other: Answering the Race Question in J. K. Rowling's Harry Potter" by Jackie Horne (2010); The Politics of Harry Potter by Bethany Barratt (2012); "Representations of Gender and Agency in the Harry Potter Series" by Sally Hunt (2015); Peace and Resistance in Youth Cultures: Reading the Politics of Peacebuilding from Harry Potter to The Hunger Games by Siobhan McEvoy-Levy (2017); and The dark fantastic: Race and the Imagination from Harry Potter to the Hunger Games by Ebony Elizabeth Thomas (2019).
} 
For Bérubé, the primary concern is the function of disability in literary narrative, as he extends the work of Ato Quayson (aesthetic nervousness) and David Mitchell and Sharon Snyder (narrative prothesis) in his own exploration of mental disability in literary narratives. Bérubé begins The Secret Life of Stories by discussing the character of Albus Dumbledore and his sister, Ariana. Bérubé asserts that "Rowling is installing intellectual disability at the heart of a narrative that includes no direct representation of a character with intellectual disabilities" (Secret Life of Stories, Kindle Location 571-76). Rather quickly, Bérubé's theory of “disability as motive.....as the condition for possibility for the text and its apprehension by readers" (Kindle Location 1116), comes to the fore as "the reason" for at least part of the Harry Potter narrative. One could extend this argument to the whole of the series, as Bérubé does by arguing that Albus Dumbledore's manipulation of Harry serves as an explanation for much of the series' plot (Kindle Location 594). But this is not what concerns Bérubé. Rather, Bérubé asks us to consider not only the question of "What does the study of disability tell us about the practices of reading?", but furthermore, what it means when "narratives have been disabled".

Bérubé clarifies what he means by "narratives becoming disabled," writing that these cases appear when "some features of narrative have been disabled, such that the text prevents, defers, or eludes readerly comprehension" precisely because of the intervention of intellectual disability: this intervention, Bérubé argues, influences how "readers [expect] texts [and narrative] to behave" because of "characters' relation(s) to narrative- the specific narrative they inhabit, and to narrative as such" as well as how "disability... sets the terms for readers' engagement with the text (with regard to form)" (Kindle Location 588-94, 820, 906). Ultimately, Bérubé uncovers much about the way that readers assume texts to function, and similarly, how 
our real-world notions of the function of (dis)ability become intertwined with the function of narrative - only for the combination of the two to disrupt our approaches to reading altogether. If readers do not understand that the narratives they are reading have been disabled in the way Bérubé describes, then it stands to reason that they will likewise misunderstand the functioning of (dis)ability in the narrative itself. Additionally, readers may also miss the various ways that disability identity is mediated by these works, especially if it is a text like Potter where disability is not made explicit nor is immediately central to Harry's development. Yet, if readers are clued into how disability affects narratives, they might also be more apt to notice how disability identity is mediated through them, as Elizabeth Wheeler demonstrates in Handiland: The Crippiest Place on Earth.

Wheeler's work on Harry Potter is vital to include here, as it begins to question the role of disability in fandom. However, this is not where her work on the series starts; Wheeler begins with an exploration of the series and its treatment of depression and chronic illness as disability (163). Wheeler's stance on Rowling's inclusion of disability in the series is that “J. K. Rowling's fantasy metaphors refute the stigmas surrounding invisible conditions and do justice to the ethical struggles at the core of chronic pain" (164, Kindle Edition). In this chapter, I will argue that the (dis)ability discourse that Rowling engages in - through textual metaphors and, importantly, overt references and world-building — does the opposite work that Wheeler suggests here. My close reading of Rowling's work shows how her treatment of physically disabled characters, informed by able-bodied discourses of (dis)ability, leans into the stigmas surrounding physical impairments, and, to a lesser extent, the often-unethical representations of physically disabled people that appear in literature and other media. I do agree with the central method of Wheeler's chapter, which is to "analyze the Harry Potter fandom... [and how fans] have used 
[the series] for fashioning their own identities and exploring what it means to be part of a community," but I question the validity of her claim that the Potter fandom is inclusive of disabled bodies (164, Kindle Edition). My analysis of the Harry Potter series suggests that disabled people may find it difficult to continue to engage in a fandom that does not privilege disabled bodies because of Rowling's commentary and the Harry Potter canon, and moreover, the (dis)ability discourse that ableist fans use to talk about characters like Alastor "Mad Eye" Moody and Remus Lupin.

The gap that I see between Rowling's cross-medium (dis)ability discourse and fan reactions to this discourse, with specific attention paid to the two most visible, physically disabled characters in the books, Alastor Moody and Remus Lupin, has significant implications for how disability identity is mediated through literature. I focus my analysis of the text - and the audience reaction — on these two characters in part because of Rowling's continued dialogue on these issues, but also because physical disability is extremely underrepresented in the series. Likewise, as I will demonstrate later in the chapter, Rowling explicitly does not qualify Harry as a disabled character. Consequently in the vein of Bérubé and Wheeler, I am asking, "what does that disability representation (or lack thereof) do?" especially as it envisions an implied reader of the text and the subsequent implications for the real fans interacting with the series' (dis)ability discourse and the mediation of disabled identity.

\section{(Dis)ability Discourse and Rowling's Writings on Disability in the Wizarding World}

Jan Grue explains how different discourses around disability have developed over time within specific socio-cultural contexts; (dis)ability discourse - and related disability studies 
research — in the United States has typically fit into the "minority model" of disability, "in which disability is theorized partly as a form of cultural otherness" (Disability and Discourse Analysis, 37). However, Grue notes that "The British social model has proved particularly valuable in focusing attention on the systemic factors that shape the meaning of disability, particularly those that have to do with political economy, without necessarily targeting individual bodies. It has been considerably less successful in theorizing impairment as a bodily and embodied phenomenon" (34-36). Grue's research contextualizes the discourses on (dis)ability that might frame the disabled representation in Harry Potter in a very specific way: while the US, UK, and even the Scandinavian models of disability have similarities, they emphasize different things (25-50). The US/UK division, simplified above, provides a general but critical framework to discuss the (dis)ability discourses that Rowling employs to ground disabled identity in her books and other complementary Potter materials.

Rowling has documented her own struggles with depression, noting that the dementors of the Harry Potter series are, in part, a manifestation of her own experiences (Wheeler, 166). And through her website, thewizardingworld.com (formerly Pottermore), she has elucidated more about her own creative processes and how she imagines the Wizarding world—including disability and illness in Harry Potter. Susan Wendell has addressed the distinction between these two categories in "Unhealthy Disabled: Treating Chronic Illnesses as Disabilities" (2001), arguing that while there are biological and social differences between disability and chronic illness, the social model of disability encompasses chronic illness as disability (19-21). However, in her discussion of passing as able-bodied, Wendell never explicitly discusses the various ways that systems and other actors mediate disabled identity other than the fact that able-bodiedness is the goal to aspire to, and that passing as healthy disabled allows for certain privileges that 
unhealthy disabled folks do not receive (28-30). Thus, Rowling conflating these categories in her essay, "Illness and Disability," is ultimately confusing because the distinction between "magical accidents," "magical illnesses" and "disabilities" is never made clear. In turn, this lack of clarity, and a more general use of the terms, allows Rowling to rhetorically traffic in (dis)ability discourse that not only imagines disabled (and chronically ill) bodies less complexly but also imagines bodily difference and disease as Other, with the only descriptors available becoming those used by able-bodied persons to describe those who appear not to be.

This kind of able-bodied discourse of (dis)ability is most apparent in the last paragraph of Rowling's essay, in which she addresses - for the first time - the effect of her thinking on these issues as they relate to the development of the characters Remus Lupin and Alastor "Mad Eye" Moody:

Remus Lupin's affliction was a conscious reference to blood-borne diseases such as the HIV infection, with the attendant stigma. The potion Snape brews him is akin to the antiretroviral that will keep him from developing the 'full-blown' version of his illness. The sense of 'apartness' that the management of a chronic condition can impose on its sufferers was an important part of Lupin's character. Meanwhile, Mad-Eye Moody is the toughest Auror of them all, and a man who was very much more than his significant disabilities. ("Illness and Disability", para 5)

Rowling devotes more time explaining Lupin's lycanthropy as illness, while Moody's "significant disabilities" are only given one sentence, as perhaps Rowling assumes that Moody's physical disabilities are more self-evident to the reader. Accordingly, Moody's disabilities are not named, although admittedly, Rowling does not name Lupin's illness as lycanthropy either. 
But her explanation of Lupin's "illness" reveals several underlying assumptions about disability that can then also be applied to a discussion of Moody's disabled identity.

First, Rowling directly ties lycanthropy to HIV, complete "with the attendant stigma." This assertion makes sense given the comparison that Rowling is putting forth; yet, what Rowling neglects to mention here is the extent to which stigma and fear from the rest of the Wizarding world essentially drives Lupin out of Wizarding society. Relatedly, Rowling places emphasis on Lupin's management of his own disease as the mechanism that creates this "sense of apartness" that Lupin experiences. These two facets of Lupin's disabled identity indicate that Rowling views Lupin's disabled identity as a largely individual, and insular, experience when the reality is that her Wizarding world consistently disables Lupin, and in doing so, forces him to live in poverty and shame. Second, how Rowling talks about the Wolfsbane potion, which is what Lupin takes to "keep him from developing the 'full-blown' version of his illness," plays upon the assumption that a sick and/or disabled person cannot live a fulfilling life ("Illness and Disability", para 5). Curiously, Rowling has a character in the series who does not seek treatment for lycanthropy and even embraces it. Of course, this character, Fenrir Greyback, is presented as evil, but Fenrir lives a life and even participates within a larger social group. These affordances only exist for Lupin under the care of Snape and Dumbledore, within the walls of Hogwarts. Still, even at Hogwarts, Rowling makes it clear to the reader that suffering is the bane of Lupin's existence; it is perhaps worth noting that this is frequently repeated in the entry on "Remus Lupin" on thewizardingworld.com (formerly Pottermore) ("Remus Lupin").

A closer look at these characters shows that Lupin and Moody share some common characteristics. They are both gifted and accomplished wizards who acquired their disabilities/illnesses. They are both also original members of the Order of the Phoenix and serve 
as quasi-father figures to Harry throughout the books, although that honor belongs to Lupin more so than to Moody. Given these similarities, it is odd that Rowling rhetorically connects Moody with achievement while she connects Lupin with suffering. This distinction leads me to argue that Rowling thinks of Moody largely as a "supercrip"." Yet, even this categorization of Moody’s character does not account for how Rowling sees Moody's disabilities fitting into the larger societal framework that she sets up in the books, which "simultaneously [calls] attention to and [ignores] disability through omission and/or exclusion of disability" (Freeman, 10).

While both men's disabilities are a central tenet of their characters and receive much attention in the books, Moody circumvents many, if not all, of the oppressive structures that Rowling erects for other characters in the novels, even beyond Lupin. Although this may be due

${ }^{3}$ Eli Clare writes that "supercrip" stories "focus on disabled people 'overcoming' our disabilities. They reinforce the superiority of the nondisabled body and mind. They turn individual disabled people, who are simply leading their lives, into symbols of inspiration" (2). These stories "rely upon the perception that disability and achievement contradict each other and that any disabled person who overcomes this contradiction is heroic" (8). Sami Schalk expands on this definition, writing that there are three types of supercrip narratives: "the regular supercrip narrative," "the glorified supercrip narrative," and "the superpowered supercrip narrative" (79-81). Moody clearly fits into the definition given by Claire but also "the superpowered supercrip narrative" identified by Schalk: importantly, however, Rowling only recognizes the first definition in her thinking on Moody's status as a disabled person in the Harry Potter universe. 
to Moody's status as an Auror and/or how he acquired his disabilities, the text offers no real solution as to why Moody is afforded this privilege and Lupin is not - other than my suggestion that it is because Rowling attempts to engage in discourses on (dis)ability that imagine illness and disability as not only Other but also as fitting loosely into the binary of "good disability" and "bad disability." This assertion is supported by other characters in the novel, as Alice and Frank Longbottom are institutionalized after being tortured by Bellatrix Lestrange and looked at with pity from Harry and company, while Albus Dumbledore's burnt and blackened hand is of almost no concern in the sixth book (until it must be, for narrative reasons). The former example is one where (dis)ability is explicitly Other as well as "bad," while the latter is associated with Dumbledore's eccentric nature and talent, thus, by association, making (dis)ability appear "good."

This analysis further demonstrates that Rowling conflates not only the terms "illness" and “disability," but moreover, the US and UK (dis)ability discourses as a primary feature of her conceptualizations of both Lupin's and Moody's disabilities. At the core of both characters is a concern with embodiment and Othering (US model). At the same time, it is also clear that Rowling is concerned with the systemic forces that impede the living of a disabled life (UK model). Grue asserts that both can be true, as these models are just that - theories of how disability functions and works in real life (47-50). Yet, it is clear throughout the Harry Potter series that these models are only maintained and/or enforced for certain characters and not others. Lupin and Moody are clearly not the only disabled characters in the series-Harry would qualify under the conditions Rowling sets out in her essay, and fans and scholars alike have taken up the issue of Harry as a disabled character — but still, Lupin and Moody are the ones Rowling specifically classifies as disabled and deems it necessary to explain why and how they 
are disabled. As such, the grounds for Rowling's decision to include illness and disability in the Wizarding world, in the ways that she does, are certainly questionable. After all, Rowling effectively sets up a society that would be free of both "regular" illness and disability; however, she consciously makes the authorial choice to replicate the external forces which create (dis)ability through the rule that (dis)ability and illness can only appear in the Wizarding world due to magical causes ("Illness and Disability," para 2). This point suggests that disability (as impairment) and (dis)ability (as a structural system of oppression) are technically represented in the series, but in ways that imagine the disabled body through a discourse on (dis)ability that is primarily informed by an able-bodied experience of the world, as (dis)ability and disabled identity are afterthoughts of characters and systems in the novels rather than focal points.

Consequently, disabled identity is not an immediate concern of the texts, even though these characters are given considerable weight by the author in the narrative and by fans in connecting with the stories. Rowling's work (canonical and otherwise) erects barriers between real readers who continue to engage with the Wizarding world and their ability to negotiate its portrayal of (dis)ability and disabled identity for themselves because these characters are only allowed to exist within that kind of narrow framework for imagining either (dis)ability or a disabled identity. The roadblocks that Rowling's (dis)ability discourse and imagining of disability identity created (and continues to do so) has become clearer as the series has grown and changed, and our means for interacting with it have done the same, with a constant being that fan discussions of (dis)ability and disabled identity have largely struggled to combat such limited imaginings of characters like Lupin and Moody in online spaces. Thus, the rest of this chapter will focus on analyzing the audience reception on social media to the (dis)ability 
discourse created by Rowling through her commentary and novels, as well as, by extension, how this discourse imagines the disabled identities of both Moody and Lupin.

\section{Harry Potter and the Analysis of Audience Reception to (Dis)ability Discourse}

Before Twitter, Facebook, and Reddit, there were other places on the internet for people to connect like LiveJournal and early blogging sites. Anelli notes in Harry, A History, that these sites were fundamental to the popularity of the books and to the formation of the fandom itself (77-100). John Green has long asserted that "books belong to their readers," (@johngreen) and since the early days of Harry Potter, this idea has been at the forefront of audience reaction to the series, as fanfiction, cosplay, the musical genre "wizard rock," and other reader-generated content sprung up around the novels, primarily proliferated by (and sometimes explicitly created for) the Internet. Fanfiction based on the Harry Potter series has been of particular interest to scholars, as Ernest Bond and Nancy Michelson note in their chapter, “Writing Harry's World: Children Co-Authoring Hogwarts" (Critical Perspectives on Harry Potter, 2009). Bond and Michelson devote attention to the ways that new stories — and importantly, new meaning — has been made through the advent of remediating the Potterverse into multimodal experiences such as Wizard rock, but also, podcasts, and blogs (320-24).

My research into the audience reaction to the novels focuses less on the "participatory authoring of literary worlds" (310) that Bond and Michelson detail at length and more on the ways that audiences have responded to the portrayal of Lupin and Moody as disabled characters by commenting on blogs, forums, and/or through reacting to other content posted by fans about the subject or Rowling herself. With this research, I answer the overarching question of: "To 
what extent do audience members engage with [the (dis)ability] narratives [presented by these texts] outside the story world, especially in online platforms?" I conclude that audience members - fans — not only struggle with engaging with the disability narratives presented by the Harry Potter series and subsequent outside information, but also that they seem ill equipped to recognize those narratives. This difficulty applies especially to Harry Potter, as the series has been fundamental to the development of modern literature for young people and has grown into a multi-media empire. Moreover, the series has an ever-expanding social media footprint which first began with Potter devoted fan-sites.

Many of the specific Harry Potter fan-sites, such as MuggleNet, The Leaky Cauldron, and Pottermore (among others), had robust forum sections during the peak of Harry Pottermania in the mid 2000's; these forums allowed fans to discuss the texts, theory-craft, and build communities. For these reasons, forums on fan-sites have long been an object of scholarly analysis, as Charo Lacalle and Núria Simelio document in their study of television fandom in online spaces (451-53). Yet, Lacalle and Simelio also assert that the study of particular types of platforms - and the users who inhabit them — has also changed to reflect the inclusion of more "spontaneous fans": "These fans, who follow and comment on different types of programs while they are being broadcast, are extremely important in understanding the functioning of audiences and fan communities" (452). Lacalle and Simelio therefore name sites such as Facebook and Twitter as places of interest for analysis alongside more traditional fan-community sites such as MySpace and LiveJournal (any of the Potter-related sites would fit into this category), although they acknowledge that certain types of platforms engage fans at different activity levels and in different ways (452). 
A limitation on my research is that many of the specific Harry Potter fan-sites, such as MuggleNet, The Leaky Cauldron, and Pottermore (among others), no longer exist in their previous forms; entire webpages of these (and other) sites have been archived or "deleted" from the web-most notably, the forum sections. However, following in the footsteps of Lacalle and Simelio's work, I have attempted to capture both the past fan-community discussion of disability in the Harry Potter series on forum and blog posts formerly housed on Potter-specific fan sites as well as the current discussion about disability on non-Potter specific sites such as Twitter and Reddit through purposeful sampling of said reactions. The online responses I've gathered provide a much-needed perspective to the way that the books mediate disabled identity, as they demonstrate the degree to which Rowling's (dis)ability discourse creates a sense of disabled identity that is not quite analogous to the first-hand knowledge of (dis)ability and disabled individuals that fans possess.

The Leaky Cauldron (the-leaky-cauldron.org) was one of the earliest fan-sites devoted to the Harry Potter series, debuting in 2000 "as a badly designed one-page roll of news; it has now turned into a destination for fan entertainment and discussion, and has become the Harry Potter site of record, hosting the oldest and most comprehensive Potter news archive on the Web" (“About The Leaky Cauldron”). The site also touts Rowling’s endorsement among other accolades, scoops, and general celebrity noshing that the staff of The Leaky Cauldron enjoyed during the site's heyday ("About the Leaky Cauldron"). As a long-time fan of the books (since I was 5!), I was a frequent visitor to The Leaky Cauldron and sites like it. A common feature of these sites was their robust forum sections, where fans discussed, debated, and speculated upon the upcoming books as well as dissecting every word that had come to pass. While my memory of these forums revolves mostly around the larger fan debates (Is Snape Good or Evil?; shipping 
wars; etc.), I also recall not seeing much—if any—discussion about the specific natures of either Lupin or Moody within the fan site forums, including on The Leaky Cauldron. The Leaky Cauldron dissolved its forum pages (The Leaky Lounge), but in their place they published a series of essays between 2006-2011 that drew upon the larger discussions that took place in original the forum sections.

During this time frame, over 150 essays were published. It should be noted that none of those listed in the essay archive explicitly analyze Moody's character; additionally, of these essays, just one discusses Remus Lupin in detail, while a few others reference the character in relation to the character development of Harry and/or the overall plot of the books, especially The Prisoner of Azkaban, in which Lupin is a central figure. Canis Sapiens's "Mr. Moony: Lupin's Curse and His Inspiration?” (2007) contains analytical elements, but mostly it lays bare Lupin's character-from his relationships with Sirius, Tonks, Harry, and Dumbledore to Lupin's intelligence, skill, and lycanthropy. Sapiens's main argument is that Lupin's lycanthropy affects his character and vice versa: one cannot be separated from the other. Notably, the essay never outright equates lycanthropy with disability; the closest Sapiens gets is the phrase "ill health" ("Mr. Moony," para 3). This is interesting as it indicates the possibility that some readers, like Sapiens, do not read Lupin's character as disabled. For instance, the "Disability in Kidlit" blog (a blog that specifically details the representations of disability in Middle Grade and Young Adult fiction) argues that "a person being a werewolf" is actually not a true representation of a disability ("Disability in Kidlit"). However, this trope is often used to convey, as David Mitchell and Sharon Snyder state, "the mutable or 'deviant' body as an 'unbearable weight' ...in order to counterbalance the 'meaning-laden' and ethereal projections of the mind" (49). This facet of the werewolf trope is admittedly not the focus of Sapiens's essay, 
yet the argument that it is making would benefit from a longer discussion of how Rowling's views on (dis)ability affect how Lupin's identity is constructed—a task that Sapiens could not have completed or anticipated due to the date in which they published the essay, almost ten years prior to Rowling's writing on the subject.

In fact, much of the academic scholarship about illness and disability in the Harry Potter books also runs into this analytical problem, as Rowling's continuous drip of Wizarding-world details continues to unfurl to this day. For example, Karen Brown's book, Prejudice in Harry Potter's World: A Social Critique of the Series, Using Allport's The Nature of Prejudice has an entire chapter on disability in the Wizarding world. Yet, the book was published in 2009, and as a result, Brown is not able to include Rowling's thoughts on the subject when she does her analysis on squibs (a person born into a magical family that does not have magical powers) and werewolves as her representations of disability in the series. Brown's general framework for the book is examining The Harry Potter series using Allport's The Nature of Prejudice as a guiding theoretical text; ultimately, though, Brown's work is an in-depth study of social hierarchies in the Wizarding World. Thus, the larger (dis)ability discourse that informs the systems of power in the Harry Potter series is, in part, mentioned by Brown in her focus on legislation and social attitudes toward both werewolves and squibs. However, as Therí Pickens notes in her review of the book in the Disability Studies Quarterly, Brown's work does not "examine disability primarily...it leaves the understanding of what constitutes disabled unexamined" (para 6). Pickens attributes this to a lack of integration of other Disability Studies and Critical Race scholars and Brown's confounding choice to term the characters she is discussing as "magically disabled" (para 6). I generally agree with this analysis, but I would like to discuss further the problem that Pickens articulates later in her review: 
It would seem that [the naming of characters as "magically disabled"] should be interrogated in the face of Brown's extensive work on social hierarchies, if only to demonstrate the ways in which Rowling's text relies on some of the social realities it attempts to debunk. Certainly, these magical creatures would be considered disabled in the wizarding world, according to the social model of disability; however, the employ of terms and characters' embodiments of and reactions to these terms deserves to be expanded a la Vivian Sobchack's Carnal Thoughts or Simi Linton's Claiming Disability or Nancy Mairs' Plaintext. (para 6).

I have already mentioned how important I think Rowling's input on (dis)ability has been to the crafting of her texts, and moreover, her disabled characters. Pickens picks up on this idea in noting how Rowling's use of existing "social realities" guides the series' understandings of marginalized characters — especially disabled characters. Pickens suggests — and rightfully sothat naming is one of the main ways by which disability identity can be centered in a text. And crucially, Pickens highlights the importance of "characters' embodiments of and reactions to these terms."

Such analysis uncovers how integrated Rowling's able-bodied (dis)ability discourse is within the texts themselves, as my reading suggests; yet, by focusing on naming and its relationship to disability identity in the texts as the primary method of analysis, it is likewise evident that audience discussions of (dis)ability in the Harry Potter series often neglect to take into account these units of measurement, and instead, they end up ascribing their own notions of (dis)ability and disability identity to the novels' disabled characters. Sometimes, such audience interaction looks like speculating about the ability status of a character, while at other times, this looks like incorporating real-world understandings of disability law to the fictional world of the 
books: still, a common denominator among these discussions is the reluctance to engage with the textual evidence that discusses how these characters feel—or do not—about identifying as disabled. On the Harry Potter subreddit, there are several discussions about (dis)ability in the Wizarding World. Recent ones include: "Squibs and the mentally disabled," "Does Hogwarts not have any disabled students?," and even a discussion on the application of Scottish accessibility law to Hogwarts' architectural features ("rr/HarryPotter"). Older discussions (2 years older or more) discuss how physically disabled people navigate Hogwarts: "Wizards with congenital disabilities," and even a poll asking, "If you have a disability, what House [were] you sorted into?" ( $\mathrm{r} /$ HarryPotter). This is only a snapshot of the topics when one does a search for "disability" in the Harry Potter subreddit. Upon a further investigation of the conversations themselves, there is almost no use of textual evidence to support the claims that users are making about how (dis)ability functions in the series — or for that matter, how the individuals who are being invoked by these discussions embody (dis)ability and react to it as an identity marker. Ignoring, through omission, the ways that characters embody and react to (dis)ability in material ways compounds existing able-bodied discourses of (dis)ability, as characters' agency and power become limited and the context-specific manners in which they embody (dis)ability and disability identity are reduced and re-imagined in ways that are contrary to their experience.

In the Reddit discussion, "Squibs and the mentally disabled," the user who started the discussion makes a connection between squibs—specifically Ariana Dumbledore—and the "real world" treatment of those living with cognitive disabilities and mental illnesses (u/tinyemoheart), a clear indication of how (dis)ability and disability identity are ascribed by users without concrete textual evidence or considering how characters already embody these within the storyworld of the books. This "realization" is not altogether unfounded, but the texts—and subsequent 
writing by Rowling - never confirm that Ariana is a squib. In Harry Potter and the Deathly

Hallows, Ron's Aunt Muriel, in recounting the substance of The Life and Lies of Albus

Dumbledore by Rita Skeeter, puts this argument forward with no real basis in fact. While this assertion is hardly addressed in replies to the initial post, users generally agree with the statement put forth by tinyemoheart; furthermore, they name two additional characters who might fit the definition of a squib: Neville Longbottom and Arabella Figg. The texts outright deny the naming of Neville as a squib, even though as one user points out, his family thought he was for much of his childhood (u/pet_genius). Arabella Figg, however, is a squib.

In Harry Potter and the Order of the Phoenix, Mrs. Figg is identified as part of the wizarding community for the first time. After Harry illegally uses magic to save himself and his non-Wizard cousin, Dudley, from Dementors, Mrs. Figg appears and ushers both of them to safety, revealing to Harry that not only is she a Squib, but that Dumbledore himself had set her the task of keeping an eye on Harry over the summer (24). In this introduction, it is clear that Mrs. Figg has come to terms with her identity as a Squib, as she confidently reminds Harry of the fact that she cannot do magic several times (21-25). Notably, however, Rowling's largest interrogation of this identity through Mrs. Figg comes about a quarter of the way through the novel at Harry's hearing in front of the Minister of Magic and the Ministry's legislating body, the Wizengamot. Harry is on trial for performing magic in front of Dudley, a non-Wizard. Out of nowhere, Dumbledore strides in to defend Harry against his charges — calling Arabella Figg as a witness. The Minister of Magic, Cornelius Fudge, as well as Amelia Bones, the Head of the Department of Magical Law Enforcement, both express doubt at Mrs. Figg's relevance to the trial, much less her ability to give an accurate testimony of what occurred. However, in negotiating the presumptive demeanors of both Fudge and Bones, Mrs. Figg-much like in her 
introductory conversation with Harry in The Order of the Phoenix - reminds her Wizarding peers of her Squib identity, stating quite plainly that, yes, squibs can see, and importantly, feel, Dementors, but also, that the reason why Fudge and Bones do not know she exists is because Mrs. Figg understands that squibs are not registered, and therefore, monitored, by the Ministry of Magic (143).

It is important to understand that there are assumptions made of Mrs. Figg not only during the ceremony, but throughout the book because she is a Squib. Harry's interactions with her have always been influenced by that fact—even though he (and readers) did not know it at the time; and when Harry finally does meet the true version of Mrs. Figg, she proves herself to be capable and prudent, character traits that are again highlighted in the courtroom. Mrs. Figg's testimony is therefore further textual evidence of how she embodies and reacts to the systemic, ableist attitudes and processes that Other her. Throughout the text, and not just in the courtroom, her embodiment of and reaction to being a Squib is conveyed through her actions: she takes care of Harry, she speaks for Harry. Yet, what is missing in all of this is an explication of how she feels about being a Squib, even though her actions speak to those qualities.

This point is crucial to my larger argument about audience reaction to both Remus Lupin and Mad Eye Moody, because within the "Squibs and mentally disabled" Reddit discussion, user hemingways-kitten writes: "I'm not sure how Arabella Figg felt about being called a squib" ("r/HarryPotter"). The above passages reflect a sense of how Arabella Figg felt about being called a squib, yet, to hemingways-kitten's point, there is not much else about how Mrs. Figg negotiates her Squib identity to unpack in the book, let alone the series. This could be one reason that in the discussion thread itself, this point is not expounded upon by any other users. One user writes that they "would have loved to have had a character arc that was more in depth about her" 
("r/HarryPotter).But because the books do not give readers that arc, and Rowling's (dis)ability discourse limits the ways that (dis)ability and disability identity are represented in the series, readers are not as inclined to take up this train of thought. Extrapolating from the work of Linda Alcoff, this type of conversation furthermore calls into question whether these reactions and discussions are speaking with the particular (dis)ability discourses that the characters operate in within the series rather than over them (Alcoff, 5-32). Charlton's concept of "Nothing about us, without us" also applies here, as this type of conversation makes it plain that the discussions about (dis)ability that Harry Potter fans are having seem to exclude the voices of disabled readers, and in doing so, ignore the (dis)ability discourses that they bring to discussions of the texts and characters. Thus, fans — much like Rowling — continue to speak about (dis)ability and disability identity or without the input and experiences of disabled readers.

This is best expressed by the Reddit discussions that mention Lupin and Moody. Moody is often cited in these threads as an example of someone in the Wizarding world who is physically disabled, with one user, hockeypuckbt15p writing, "Mad Eye has a peg leg, does that count?" ("r/HarryPotter"). To be fair, Moody's leg may be the most prominent signifier of disability that he exhibits, as Moody is introduced in The Goblet of Fire entering the Great Hall "limping" towards Dumbledore. This description is almost always used to denote Moody walking throughout that novel. But textual evidence also points to at least two other important signifiers of disability that Moody possesses:

[His face] looked as though it had been carved out of weathered wood by someone who had only the vaguest idea of what human faces are supposed to look like, and was none too skilled with a chisel. Every inch of skin seemed to be scarred.... But it was the man's eyes that made him frightening. One of them was small, dark, and beady. The other was 
large, round as a coin, and a vivid, electric blue. The blue eye was moving ceaselessly, without blinking, and was rolling up, down, and from side to side, quite independently of the normal eye - and then it rolled right over, pointing into the back of the man's head, so that all they could see was whiteness....He stretched out a hand that was as badly scarred as his face, and Dumbledore shook it, muttering words Harry couldn't hear.... (121) The text clearly identifies Moody's bodily difference through the pointed references to Moody's scarring and missing eye. These signifiers of bodily difference clearly code Mad Eye as a disabled person. However, as Leigh Neighhardt astutely argues in "Splinched: The Problem of Disability in Harry Potter" in Critical Insights: The Harry Potter Series (2015), Rowling takes careful steps in the series to separate Moody's disabilities from his character by employing several different strategies. Prior to Moody's entrance in the Great Hall, Neighhardt notes that Mad Eye is first mentioned by the Weasley family in reverent tones (284). She goes on to articulate how this reverence, combined with an incessant lauding of Moody's talents, and allyship with Dumbledore, rhetorically positions Moody as a different type of disabled person (284-86).

Interestingly, Neighardt does not label Moody as a supercrip, but her analysis provides some insight into the audience reactions, namely the idea of how (dis)ability is conceptualized by readers and ascribed to characters like Moody, especially in the absence of additional information on how that character deals with, as Pickens notes, "embodiments of and reactions to [being named as disabled/Other]" (para 6). After all, there is little indication in any of the books in which Moody appears that he feels a particular way about his disabilities. The closest Rowling comes to suggesting this may be when Mad Eye makes a remark about his magical eye "sticking" and not working properly "ever since that scum wore it" (Order of The Phoenix, 50). 
Thus, in the absence of textual evidence that demonstrates the character's negotiation of (dis)ability, audiences are left to imagine disabled bodies as fitting into (dis)ability discourses that they are already engaged in and/or familiar with.

The implications of this notion are easy to see in an analysis of audience reaction to Lupin's embodiment of and reaction to his disability. Using the "advanced search" function on Twitter, I looked for tweets that explicitly referenced "Remus Lupin" in conjunction with “disability". Users have been tweeting about Lupin as a disabled character since 2011. However, especially in the earlier tweets, many users were only conveying what Rowling had publicly said about Lupin in interviews, which is that Lupin's lycanthropy was a metaphor for disability and illness. This crowd-sourced type of reporting about Lupin is a feature rather than a bug of the Harry Potter fandom, on many different topics. But these specific social media relays of Potter related information were confirmed by Rowling herself in tweets posted in 2016: "The so-called 'revelation' now circulating is recycled from interviews given 17 years ago in which I was asked whether Lupin's treatment by others could be seen as a metaphor for (then) stigmatized conditions. I agreed that it could”(@jk_rowling). The context of her tweets relates to a "revelation" made in a Potterverse affiliated e-book series that was published in 2016, namely the idea that 'the werewolf 'illness' belonging to Remus Lupin - the professor played by David Thewlis in the film franchise - is a metaphor for 'illnesses that carry a stigma, like HIV and AIDs"” (The Independent).

It is worth noting that Rowling does not dispute the substance of this fandom/media reaction to her supplemental writing. However, Rowling's suggestion of "recycled" fan/media narratives about the series—and their impact—requires further unpacking. Part of Rowling's exasperation with the situation is her own making, as she has routinely taken to social media in 
the years since the last Harry Potter book was published to tell fans more about the fictional world she created. On the other hand, however, Rowling's overarching sentiment is that these details should not be news, especially to readers and fans of the books. Still, this exchange about Lupin's disability, especially its sudden prominence in the media and internet fandom upon the release of the Harry Potter adjacent e-books, moves to convey the power of (dis)ability discourses that are rooted in able-bodied ideas of (dis)ability. After all, what is disability when it is reduced to metaphors? We can look to Mitchell and Snyder's concept of narrative prothesis to answer that question ${ }^{4}$, but what I am arguing now actually goes beyond that claim: imagining disability identity should be more complex than metaphors and literary devices. And it can be more complex when we consider how the author-text-audience relationship has radically changed due to social media, and likewise, when we acknowledge that these changes have resulted in a turnover of power to fans and audiences; they not only have the power to change and combat existing discourses, but create entirely new ones to more aptly capture embodied realities that affect the way readers experience texts.

\section{Doing Disability Identity Differently}

Later tweets about Lupin and disability show an effort to move away from strictly quoting Rowling on what she says about the series, or about disability specifically. Interestingly, these tweets (post 2011) all seem to agree that Lupin is disabled, with some explicitly mentioning his lycanthropy as a disability and not just as a metaphor for disability (although there are tweets that point this out too). Twitter users seem to extrapolate real world systems of

\footnotetext{
${ }^{4}$ In previous work, I have argued that Rowling's Potter books serve as a great example of narrative prosthesis and go so far as to "perform ableism" through its reproduction of ableist systems and attitudes.
} 
the governance of disability in their commentary on Lupin: "The way Remus Lupin is treated in \#HarryPotter is very similar to how those with chronic illness or disability are treated in the workforce. Unwell, discriminated against for something they can't control, struggling to find \& maintain employment” (@harrypotteran13). And: “Sometimes I wonder if Remus Lupin could have gotten get disability for chronic illness/pain. Fibromyalgia feels like turning into a werewolf but it happens more often then not and there's nothing good that comes with it”(@Avivafae). These tweets demonstrate fan attempts to place Lupin's disability identity into existing discourses on (dis)ability that frame their understanding of how (dis)ability functions in "real life"; in doing this work, fan audiences change the relationship between themselves and the texts by imagining not only (dis)ability more complexly, but also disabled bodies, and therefore, disabled identity too. While these tweets — and a few others that make similar claims - do not overtly incorporate Lupin's feelings about his condition, the overarching thread between them is that they are at once affirming Lupin's status as disabled while simultaneously shifting the discourse in which it is discussed to more radically center (dis)abled experiences of the systems that Lupin faces in the Wizarding World and could hypothetically navigate if he existed in real life.

With this in mind, perhaps the largest form of audience reaction to Harry Potter that has been proliferated by the Internet is fan fiction. Entire books have been written on the phenomena that is fan fiction, including tomes that precisely examine the ever-evolving state of Harry Potter fan fiction. Still, I resist discussing fan fiction in part due to the lax relationship to the texts that fanfic authors often take in their writing as a means of establishing their remediation of the original works. For these reasons, I am more interested in how audiences have reacted to the original texts and the canon-shaping words of Rowling, as well as how they continue to do so. 
However, I recognize that fanfiction is one of the most effective ways that the power of dominant discourses can be changed, as fans remediate canon and question and, most importantly, reimagine the identities of the characters within.

Fan fiction can take many forms, and it can be found in many places on the Internet. A common practice of readers of fan fiction is also to cross-post favorite fics (shorthand for a piece of fanfiction) on other platforms, to increase the fic's popularity. @DreaDreamings, in a tweet about Remus Lupin post-2011, performed this kind of cross-posting by simply sending out a link to a Tumblr page. The Tumblr users ladyolivers and transremus had posted a headcanon in 2013 (a fan interpretation of canon) that completely reimagines Lupin's lycanthropy:

[TR] [A]hh but Remus Lupin with a disability that affects his mobility and back and makes it hard for him to bend down for things and pick them up or anything and he uses a cane most of the time to get around anyway so he doesn't have a lot of room to carry things around, especially if he's trying to use his wand and walk at the same time [A]nd when he's at Hogwarts or among other magical folk, he can just use a spell to levitate his stuff and move it along with him without carrying it...[W]hen he goes out among muggles, though, he has to carry things himself and he's always carrying too many books along with his bag or whatever and it'd all be very hard to manage if he didn't have a giant black service dog who's exceptionally clever and willing to pick things up for him so that he can rearrange everything in his arms and carry on.

[LO] Yes, this, I love this headcanon. And what if he really hates the moving staircases, because the moving staircases are sooo great and accessible? And what if when random people ask him rude questions like "what's wrong with you?" James and Sirius start 
making up wild stories like how he fought a Hungarian Horntail or he wrestled the Giant Squid.

[TR] Yes ahh! and the Marauders find little hidden pathways and ramps through the school that have been kinda forgotten by now but make it easier for him to get around and they include those on the Marauder's Map

[LO] YES! What if that's the entire reason why they made the Marauder's Map in the first place? (Tumblr, via innkstainedchocolateeyes)

This headcanon radically reimagines Lupin's disability identity in ways that Rowling's essay on disability and illness fails to do. First, the users - like the tweets above-integrate their knowledge of preexisting systems and discourses of (dis)ability into their headcanon. While Rowling also does similar work to incorporate preexisting systems and discourse of (dis)ability in her essay, the ideas that govern illness and disability in the Wizarding World are decidedly informed by able-bodied discourses of (dis)ability. Conversely, this headcanon operates in the vein of the British social model of disability by recognizing the systemic barriers to Lupin's life as a disabled character; moreover, ladyoliviers and transremus focus on the specific ways in which Lupin might embody disability and by extension, require other forms of support to live. At some level, Lupin's accessibility needs are addressed by Rowling through her use of the Wolfsbane Potion in the books; but again, Rowling's inclusion of this accommodation is used to highlight Lupin's suffering. In fact, suffering is such an important part of Lupin's character that at one point in The Deathly Hallows, Lupin tells Harry "You don't know how the rest of the Wizarding world sees creatures like me! When they know of my affliction, they can barely talk to me!" (213). Lupin goes on to call his unborn child "a monster" (213). These lines explicitly 
emphasize Lupin's suffering rather than his agency by highlighting the systemic ableism of the Wizarding world. In the headcanon above, however, the reimagining of Lupin's embodiment of disability emphasizes Lupin's agency and power as a disabled person in spite of the systemic barriers he faces — such as ableist attitudes and inaccessible architecture — in living his life.

This shift in discourse renders a distillation of disabled identity that speaks to the central question I posed at the beginning of this chapter, which is "How do disabled people continue to engage in a fandom that does not privilege disabled bodies?" One of the answers, as shown above, has been for fans to directly respond via social media to the portrayals of disability identity in the Harry Potter series. Another answer, that is more radical in its approach to imagining disability identity, lies in fans' consistent remediation of the canon to make it not only more inclusive, but also reflective of the embodied experiences of living with a disability in an ableist society. But as this chapter also suggests, authors like Rowling play an important role in how disabled identity is mediated to readers, as Harry - the adolescent protagonist at the heart of the series - is never considered as disabled by Rowling herself, but is sometimes considered as such by fans and scholars. This disconnect points to the larger concern of this project, which is that the able-bodied assumptions made by authors, creators, and producers about disabled teen bodies often lead audiences to identify with disability representation that is "Other," but not too Other so as to alienate the reader or viewer. In doing so, it reifies the dominant and oppressive ways in which we think, talk, and write about disabled adolescents and their identities to the detriment of fans and readers who need this representation the most.

To this end, disabled fans' participation in fandom is extremely complicated, for they have to navigate the text's and author's views on (dis)ability, as well as the ways that the discussion is set up by fans who may not have a personal stake in the issue and therefore engage 
in the (dis)ability discourses modeled to them by texts and authors. Because, to some extent, discussion about (dis)ability is already set up in these highly contextualized ways, changing that conversation becomes difficult, especially when disabled voices are not included in the process. However, even while social media has allowed for this change to occur, doing the work to make those changes can be a burden, even as it can be liberating; moreover, no roadmap exists for disabled readers to assert such changes to (dis)ability discourse, leaving disabled readers to find new spaces in which they can better speak to the ways that we think, talk, and write about disabled adolescents and their identities. Wheeler discusses this issue and Harry as disabled, in her analysis of "Harry Potter's Disability fandom," or fan responses to the portrayals of depression, mental illness, and other invisible disabilities in Harry Potter, in addition to the matter of whether (dis)ability is imagined as complexly as other identities in the series. In fact, one of the arguments that Wheeler tacitly puts forth is that such fan engagement with (dis)ability in the books seems to ignore the larger, able-bodied (dis)ability discourses that frame the governing of disability in the Wizarding world in favor of actively seeking its inclusive components (Kindle Location 174-178). As Wheeler writes, “Harry Potter satisfies the longing to find a better fit between self and world" (Kindle Location 177).

Still, while Wheeler's work demonstrates that disabled identity in the Potter series resonates with some disabled readers, I wonder whether her argument — that these readers have to actively choose the inclusive components of the book in order to find that "better fit between self and world"-is a compelling case for how Rowling and her work mediate disabled identity. I take issue with this component of Wheeler's work because Wheeler does not hold Rowling accountable for the larger impact of her external writings on disability and illness in the series. Thus, her point about readers' kinship with the series seems to be half-baked, at best, for it 
assumes that disabled readers are supposed to engage in a discourse on (dis)ability in Harry Potter in a specific manner, even though its discourse is primarily informed by ableism. Holding authors accountable for their work is an idea that has gained prominence, especially in the past few years, as some YA authors have been forced to actually pull their upcoming novels over concerns about different types of representation espoused in them after other authors and readers voiced their outrage, disappointment, and yearning for accountability on Twitter 5 . Rowling did not have to deal with YA Twitter as she wrote the Potter books, but she has had to deal with it since the last book and film were both put into the world. And as she has continued to produce content related to the Wizarding world, she has experienced an increase in calls to be held accountable for the discourses she engages in, such as when she appropriated Native American culture for new information about magic in the United States within the Wizarding world 6 .

The proliferation of social media has allowed fans unprecedented power in their relationship with authors as well as with texts themselves. Yet, fans still seem to operate in one space and authors in another, as whatever disruptions to oppressive systems and worldviews that

${ }^{5}$ See "How YA Twitter Is Trying To Dismantle White Supremacy, One Book At A Time" by Sona Charaipotra and Zoraida Córdova (2017); "The Toxic Drama on YA Twitter" and "The Latest YA Twitter Pile On Forces a Rising Star to Self-Cancel” by Kat Rosenfield (2017; 2019); and "YA Twitter Can Be Toxic, But It Also Points Out Real Problem" by Molly Templeton (2019)

${ }^{6}$ See "JK Rowling under fire for writing about 'Native American wizards"' by Alison Flood (2016) (among other articles on the topic). 
fans create through avenues such as fan fiction are largely not considered by authors: A Very Potter Musical (2009), and its sequels, created by students at the University of Michigan, are premier cases of this idea, as the theatrical remediation of the Potter books never has been blessed by Rowling, perhaps for its liberties with the series' plot and characters . This chapter demonstrates that this separation extends even to the ways that Rowling and fans talk about (dis)ability and disability identity. However, what I am arguing here goes beyond this idea to articulate the notion that disability and childhood/adolescence are identities that are often imagined in specific discursive contexts by systems and actors that are not a part of these identity groups. Of course, it can be difficult to tell whether authors, especially anonymous ones, identify as disabled: but this is also true when it comes to childhood/adolescence. Still, the overarching discourses that are still used to talk about both sets of identities is mired in ways of thinking about them as Other - and if not as Other, as suitable to the able-bodied and/or adult audiences. Thus, these systems and actors often fail to fully comprehend the unique set of problems that either of these identities face separately, much less when they are thrust together.

Therefore, in my analysis of Harry Potter, I have demonstrated that fans and Rowling utilize slightly different discourses to imagine (dis)ability and disabled identity. But challenges remain for the full participation of disabled fans in either discourse, especially as long as ablebodied fans continue to follow able-bodied discourses of (dis)ability, and disabled people (in general) continue to be barred from participation in these discourses due to the lack of access to technology, money, or other types of capital. This point may explain why many of the online fan responses I found seemed to fit into the able-bodied discourse of (dis)ability that Rowling set forth in the books. Taking this idea further, while Rowling has demonstrated that the ethical responsibilities of authors are changing because of social media, so too are the responsibilities 
and expectations of readers, as they seek to better understand, anticipate, and then react to interpretations of and challenges to authors' decisions.

We must consider all these avenues in further examining how adolescent disabled identity is mediated to readers and viewers of these texts, especially when they are placed at the forefront of their works by readers and authors alike. In my next chapter, I consider how Turtles All the Way Down (2017) by John Green, whose understanding and lived experience of (dis)ability identity is vastly different from Rowling's, more complexly imagines disabled bodies and disability identity through its innovative use of narrative voice and character to capture its disabled adolescent protagonist, Aza Holmes. Likewise, I consider how Green invites readers and fans to actively participate in the discourse around (dis)ability (in addition to other issues) that his work inspires, and how they take this up as a group in their shared online spaces. 


\section{CHAPTER III: HOW CRIPPED NARRATOLOGY INFORMS DISABILITY IDENTITY}

DISCOURSE IN TURTLES ALL THE WAY DOWN \& THE BROADER

\section{NERDFIGHTERIA COMMUNITY}

In the previous chapter, I detailed JK Rowling's able-bodied (dis)ability discourse that informs the way that disabled bodies show up and participate in the Wizarding world. This discourse exists within the texts, but also, it exists outside of them as well, for Rowling's external comments about (dis)ability and disability identity, both on social media and on more formal platforms like thewizardingworld.com (formerly Pottermore), have significantly influenced how fans imagine the identities and bodies of the disabled characters (Moody and Lupin) she describes. Rowling's imagining of (dis)ability has historically been rigid; to some extent, this sentiment was echoed in fans' uptake of (dis)ability discourse in fan forums and social media. This chapter examines Turtles All the Way Down (2017) by John Green, whose understanding and lived experience of (dis)ability identity is vastly different from Rowling's, and moreover, who invites readers and fans to actively participate in the discourse around (dis)ability (in addition to other issues) that his work inspires. This collective effort between text, author, and audience suggests new insights into childhood studies, and the imagining of bodiesand minds - that we deem Other; through narrative theory, rhetorical analysis, and audience commentary, I demonstrate how John Green, his book Turtles All the Way Down, and Green's fan community, Nerdfighteria, come together to assert a disabled discourse of (dis)ability that demonstrates how collective efforts to change the ways in which we talk, write, and think about disabled adolescent bodies - from authors to fans, as well as from fan-to-fan — are changing the 
relationship between texts, authors, and audiences, but also, the kinds of discourses that are created about (dis)ability, adolescence, and identity.

In the landscape of Young Adult (YA) literature, few names loom as large as John Green. Author of the Printz award-winning Looking for Alaska and the pop-culture influencer The Fault in Our Stars (among others), Green reaches millions of readers with his literary work. His latest work, Turtles All the Way Down (2017), follows "[s]ixteen-year-old Aza [as she] pursues the mystery of fugitive billionaire Russell Pickett [alongside] her Best and Most Fearless Friend, Daisy, [who] is eager to investigate. [T] ogether, they navigate the short distance and broad divides that separate them from Russell Pickett's son, Davis. Aza ...is trying to be a good daughter, a good friend, a good student, and maybe even a good detective, while also living within the ever-tightening spiral of her own thoughts." (John Green's website). This summary of the novel emphasizes its key features, according to Green himself, which are that it is ultimately a story about a teenager with OCD who must navigate people, and systems, that do not understand her while at the same time, she does not even fully understand herself, either. Turtles is markedly different from his previous endeavors, although hallmarks of Green's style--witty, existentially concerned teenagers and the use of grand metaphors - remain. The most important difference of this work from Green's previous novels is this: the locus of the protagonist's problems, and growth, is turned inward, as Aza Holmes comes to terms with intrusive thought patterns caused by Obsessive Compulsive Disorder (OCD).

According to the American Family Physician Organization, "Obsessive-compulsive disorder (OCD) is a neuropsychiatric disorder characterized by recurrent distressing thoughts and repetitive behaviors or mental rituals performed to reduce anxiety" (“Obsessive-Compulsive Disorder.") The AFPO notes that these distressing thoughts are "unwanted and inconsistent with 
the individual's sense of self (egodystonic), and great effort is made to resist or suppress them. They can involve contamination; repeated doubts; or taboo thoughts of a sexual, religious, or aggressive nature" (“Obsessive-Compulsive Disorder”). For these reasons, they are commonly referred to as "intrusive thoughts" (“Obsessive-Compulsive Disorder”). Green has been extremely transparent with his fans and the media about his experiences with OCD, especially his patterns of intrusive thoughts. In an interview with Terry Gross on NPR, Green said, "I have OCD and it is a really important part of my life, and at times it is a disabling part of my life. But I also have a really wonderful, fulfilling life" (NPR). In the same interview, Green cites these experiences as the catalyst for Turtles, stating “I couldn't write about anything else” (NPR). It should be noted that in recent years, especially around the time that Turtles was published in 2017, Green's willingness to fully disclose and discuss his mental illness has created a discourse on mental illness and (dis)ability that spans multiple platforms. Moreover, this discourse centers ideas about disability that are primarily informed by embodied experiences of (dis)ability; this framework therefore operates in opposition to Rowling's discourse on (dis)ability in the Harry Potter books and other Potter-related materials.

Green mediates this discourse on (dis)ability, and significantly, his own identity as a mentally ill person primarily though his YouTube channel, vlogbrothers, which he runs with his younger brother Hank Green. A Google search of "John Green OCD” reveals at least three videos on his channel that explicitly deal with this topic dating back to 2015; there are countless other videos - primarily interviews with other media outlets such as NPR, The New York Times, and the television program 60 Minutes - that also detail Green's embodiment of OCD. It should be noted that part of Green's appeal to his fanbase, which is called Nerdfighteria (a fan being a Nerdfighter), is his ability to philosophize. To be clear, I am not referring to another YouTube 
channel that he and his brother run, Crash Course, in which he teaches academic material via YouTube. I am explicitly referring to his penchant for turning four and five-minute YouTube videos into ruminations on existence, human connection, and other topics. I would also argue he is quite good at this, and therein lies an important facet of how Green's ideas about (dis)ability and disability identity are mediated to fans.

The element of philosophy, combined with Green's conversational style and tone, as well as the fact that John and Hank will sometimes use YouTube to directly communicate ideas about certain subjects with one another, all contribute to how Nerdfighteria, as a discourse community, takes up discourses of (dis)ability. John Swales identified six primary characteristics of discourse communities (common public goals, mechanisms of intercommunication, mechanisms which primarily to provide information and feedback, utilization and possession of one or more genres to communicate its aims, has some special lexis, community members have relevant content and discoursal expertise) and Green's YouTube channel and affiliated fan communityNerdfighteria — demonstrably meets these criteria: just ask a Nerdfighter what "French the Llama" means, or ask them why The Project for Awesome is so important to the community's values. However, the purpose of this chapter is not to investigate how Nerdfighteria functions as a discourse community, but rather, how Nerdfighteria has created its own discourses of (dis)ability, particularly in response to Turtles All the Way Down, across social media. Moreover, I am concerned with how Nerdfighteria's discourses of (dis)ability create counter-narratives to ableist discourses of (dis)ability, and in doing so, create new ways of imagining childhood and adolescence that reify the lived experiences of disabled youth, promoting a path forward for disability representation in literature and media that authentically and ethically envisions 
disability in opposition to the normative paradigms that currently govern the author/creatorreader/viewer relationship.

Keeping these aims in mind, it is first necessary to explore how Green intentionally breaks rules of narratology to characterize Aza and construct the narrative voice of the novel, thus expanding the possibilities for the way we imagine characters/protagonists/narrators with disabilities. Traditional narratological analysis has historically and culturally developed distinct discourses about disabled people, as Susan Lanser suggests (see Fictions of Authority: Women Writers and Narrative Voice); furthermore, these discourses have also developed into specific types of narratives, and importantly, specific ways of imagining disability identity. My analysis of Green's work complicates existing theories of narratology and narrative voice to show how disability can alter readers' perception of who is speaking, to whom they are speaking, and how they are accomplishing such interactions. Moreover, part of my argument also rests on the assumption that conventional narratological theory fails to account for bodyminds that experience the world differently. Sami Schalk, paraphrasing from the work of Margaret Price, notes "[t]he term bodymind insists on the inextricability of mind and body and highlights how processes within our being impact one another in such a way that the notion of a physical versus mental process is difficult, if not impossible to clearly discern in most cases (269)" (Bodyminds Reimagined, Kindle Edition Location 174-180). In Turtles, (dis)ability—at multiple levels, including disability just as impairment—disrupts conventional storytelling mechanisms, and in doing so, forces those who interact with the text to (re)negotiate their relationship to disability identity in sometimes confusing, if not altogether new ways. Thus, the negotiation of (dis)ability discourse which occurs in young adult literature and other media influences the discourses on (dis)ability that are conveyed to and engaged with by the audience - in this case, Nerdfighters. 


\section{Initial Narratological Concerns: Narrative Voice and Character}

Green's blurring of several levels of narrative voice and character, in combination with the idea that the text itself evolves from a discourse that values and understands (dis)abled experiences, is integral to the overarching discourse on (dis)ability that Nerdfighters have participated in on social media. Mike Cadden states that '“voice' as a narrative metaphor is arguably the defining quality of literature for children and adolescents, and the notion of 'double speech' marks the inherent tension in determining whether a book is a 'children's book.' The issue of voice is, then, the critical issue of how, between who, and to whom" (225, emphasis author's own). Barbara Wall identifies voice in a similar manner, writing, "It is not what is said, but the way it is said and to whom it is said, which makes a book for children" (The Narrator's Voice, Kindle Location 96). The issue of whether Turtles is a children's book or not is outside the scope of this paper; however, Wall's claims and Cadden's both apply to an analysis of audience reaction to Turtles, as their encompassing views of what constitutes a "children's book" would apply to YA as a genre. Moreover, an additional application of both Wall's and Cadden's claims is that children's and YA audiences are capacious, and therefore, YA texts talk differently to different audiences of readers, even if they mostly consist of young people. However, Schalk's bodyminds approach suggests that the number of types of audiences may be more capacious than differently aged populations, as different positionalities, subjectivities, and experiences form different combinations of bodyminds that the text is interacting with (Kindle Location 167-317).

Extending Cadden's, Wall's, and Schalk's concepts, Turtles, as a text featuring a disabled narrator, speaks better to the embodied realities of its audience — and their individual acts of 
reading - by blurring Aza's narrative voice and character together. Green creates a relationship between Aza's voice and character - and the voice and character of her OCD — that renders the distinction between them to become, at times, unclear; yet, this lack of clarity is by design and moves to more fully convey Aza's bodymind as a person with OCD to the reader through the breaking of conventional definitions and understandings of narratology and storytelling. That said, the questions of "between who" and "to whom" are particularly interesting and pertinent to consider for analyzing Turtles because of what intrusive thoughts are and how, as a biological component of the individual that cannot truly be separated from one's actions and experiences, they influence the communication of a text's narrative voice and character. Aza's intrusive thoughts almost exclusively center on her fear of contamination, and when they appear, they usually do so in italics to inform the reader that another voice is speaking; however, Aza's intrusive thoughts are not always communicated to the reader in this way. But is this another narrative and/or character's voice?

To consider Aza's OCD as another voice raises a few concerns. In this context, I am directly relating this idea to the "between who" and "to whom" questions that Cadden raises in his article on voice, as Aza is essentially speaking between and to herself in many of the moments in which her intrusive thoughts make an appearance in the novel: they read as a distinctly different voice, and Daisy goes as far as to anthropomorphize Aza's OCD and even separate it entirely from Aza's person in a few key moments in the novel. Therefore, I will argue that the nexus of (dis)ability and narratology in the novel brings up not only a problem of narrative voice, but rather a problem of character, and importantly, how character is communicated to readers. Suzanne Keen posits that characters are essential to the overall successful functioning of a story, as plots would not unfold without them: "How can we think 
about characters without discussing their actions? (We can't!) How can we judge a set of actions in a plot without referring to the agents we come to know through those actions? (We shouldn't!)" (55). This observation suggests that not only are plot and character "most securely bound to one another" (55) but also, that to ignore or discount a character's set of subjectivities is also to fundamentally misunderstand the functioning of the plot, if not the entire narrative altogether.

Literary and disability studies theorists have moved to convey the complexities of the relationship between disability and narrative, including disability's influence on plot, character, and other features of the novel since at least the late 1990's. In their seminal work, Narrative Prothesis: Disability and the Dependencies of Discourse, Mitchell and Snyder demonstrate that "disability pervades literary narrative, first, as a stock feature of characterization and, second, as an opportunistic metaphorical device" (47). Mitchell and Snyder clarify what they mean here by writing "We term this perpetual discursive dependency upon disability narrative prosthesis. Disability lends a distinctive idiosyncrasy to any character that differentiates the character from the anonymous background of the "norm"” and that "Physical and cognitive anomalies promise to lend a 'tangible' body to textual abstraction; we term this metaphorical use of disability the materiality of metaphor..." (47-8, emphasis in original). In The Secret Life of Stories, Bérubé analyzes Maxine Hong Kingston's The Woman Warrior and J. M. Coetzee's Life \& Times of Michael $\mathrm{K}$. to reveal "intellectual disability as motive, a rendering of intellectual disability as the condition of possibility for the text and its apprehension by readers" (Kindle Edition. Location 1116). In keeping with these thoughts, it is therefore important that we also consider Green's musings on Aza in Turtles: 
I... wanted Aza to struggle with her ability to observe the world outside of herself because I think that is true to my experience, and it is not true to the kind of narrative of the obsessive detective that we have in the popular imagination. Obsessiveness is often linked to this, like, genius of observation that just is not my experience at all. Like, I find that my OCD makes me a terrible detective.... I can't notice the world outside of myself in the way that I want to because I'm so deeply and irrationally focused on stuff that's happening kind of within me. (NPR)

What Green is essentially admitting to here is that he wrote a detective novel predicated on the idea that Aza's OCD would make her not good at it. This admission highlights Bérubé's point, as Green's goal was to write a detective novel with a compromised detective; Green's goal uses disability to upend the detective genre by making readers primarily question the effect of Aza's OCD on her most immediate relationships (with Davis, Daisy, and her mom), as well as herself, rather than the mystery of Russell Pickett's disappearance. (Dis)ability therefore serves a genesis for the plot to unfold, but in a rather incidental way, as Green's real focus in the narrative is on character rather than mystery. The focus on character is so much at the fore of Turtles, that even when Pickett's disappearance is resolved, it is done almost in passing: "I told her about the jogger's mouth, about thinking Pickett was maybe down there, about the stench" (268). The afterthought that is the mystery-being-solved reframes the type of detective novel Turtles sets out to be, as Green's goal for the novel and use of (dis)ability within it reveals the mystery of the book to be about Aza herself, and specifically, the mystery of how someone with a (dis)ability learns to manage it. Mitchell and Snyder write that "difference demands display. Display demands difference" (Mitchell and Snyder 55). Green utilizes displays of Aza's difference to assert (dis)ability as a subjectivity of Aza's character that governs her actions, thoughts, and 
relationships with others as well as the plot of the story, with an emphasis on the former categories.

The emphasis that Green places upon Aza's OCD as an indicator of how she experiences the world and interacts with it - including the people in it—suggests that Aza's unique narrative voice cannot, and should not, be separated from the bodymind that her character inhabits. While the urge to label Aza's OCD as another character is one that could be supported by the text, I would argue that such readings are ableist and reductive. Such readings are ableist because they work to separate the bodymind of the disabled individual and perhaps unintentionally perform narrative prosthesis by anthropomorphizing OCD, and thus, treating it as "an opportunistic metaphorical device” for Aza’s development as a character (Mitchell and Snyder, 47-48); likewise, such readings are reductive because if the consideration of disability here only extends to being able to imagine it as an abstraction of human condition, then the argument shifts from being about what disability is doing in the text in regard to character and narrative voice (e.g. narrative prothesis) to about how real readers are applying their own schemas of disability to character and narrative voice. To this end, Suzanne Keen writes, "readers create fictional characters in their minds by assembling the textual details relayed by the narrator into patterns that seem like people. Thus, fictional characters...invite comparison with the real people of a reader's experience" (57). Even though she was writing about narratology, Keen's words lend credence to the aim of this chapter, and the overarching goal of this project, which is to show how real readers actively participate in the discourses about (dis)ability and disabled identity that are mediated to them by authors and texts: their first available tool for doing this work is likely to be, as Keen suggests, a reading of what Hilary Janks calls "both the word—and the world" according to their preexisting knowledge of, and literacy with, (dis)ability as a system of 
oppression, and disability identity as an embodied reality (227). To wit, first-hand experience with (dis)ability as a system of oppression and/or disability identity as an embodied reality, is far more likely to construct a kind of fictional disabled character that combats the pervasive ableist worldviews that exist in our day-to-day life, but also, in fiction.

Yet, my concern lies with readers who, in their individual acts of reading, engender the pervasive qualities of (dis)ability stereotypes and narratives in real life that advance and adhere to a worldview of disability as Other. This question reframes Gérard Genette's distinction between voice and mode, where "voice is concerned with 'Who speaks?' (the narrator? a character?) and mode with 'Who sees?' (or the perspective from which the story is presented) (Fludernik, 98). It puts forth the notion that if real readers are creating fictional disabled characters with a worldview of disability as Other in mind, they are ultimately asking significantly different questions about who is speaking and seeing in these kinds of texts and imagining the answers to those questions differently. In the last chapter, I demonstrated the opposite reaction occurring regarding Rowling and fans' uptake of (dis)ability discourse in the Harry Potter novels. However, here, my meaning has direct implications for a text like Turtlesa text that makes it abundantly clear, from the author's lived experiences and surrounding (dis)ability discourse to the way that narratological components are employed for specific effect, that the reader is also supposed to imagine Aza's narrative voice and character in highly contextual ways that affirm Aza's disability identity rather than deny it. Thus, a path forward for thinking about the problem of narrative voice in this text is to consider how (dis)ability informs character, and in doing so, also informs the various definitions of voice expressed in this paper, as well as the overlap between the two categories. Through the following analysis, I highlight the need for a departure from these conventional definitions of narrative voice and character in order 
to better speak to the failings of novels' verbal mediums to get at a set of experiences that are almost impossible to categorize.

\section{Focalization as Indicator of OCD}

To explicate the need for more encompassing definitions, we can turn to the text of Turtles to examine how Green blurs levels of character and narrative voice, specifically through a constant switching of focalization, and its effect on the reader's sense of Aza's disabled identity. 'In Genette's model, focalization is concerned with 'Who sees?' However, issues of visual representation (for example, the description of various scenarios) are often mixed up with the question of access to characters' minds" (Fludernik, 153). Genette identified three types of focalization: internal, external, and zero focalization (Fludernik, 153). Turtles almost exclusively operates using internal focalization, which "represents a view of the fictional world through the eyes of a character, in other words, a view from within" (Fludernik, 153). That view is given to readers through first-person narration; and as such, this narrative can be considered as autodiegetic, since "the narrator and the hero/heroine are identical...according to Genette: the main protagonist tells his/her own story" (Fludernik, 152). While these traits are almost constantly maintained throughout the novel, Turtles departs from these conventions because of how OCD forces changes in Aza's narration to communicate the state of her mental consciousness to the reader.

A good example of Green demonstrating how OCD forces changes in Aza's narration to communicate the state of her mental consciousness to the reader occurs roughly halfway through the novel, as Daisy and Aza drive to the bank: 
I felt like a perfectly normal person, who was not cohabitating with a demon that forced me to think thoughts I hated thinking, and I was just feeling, like, I've been better this week. Maybe the medicine is working, when from nowhere the thought appeared: The medicine has made you complacent, and you forgot to change the Band-Aid this morning.

I was pretty sure I had actually changed the Band-Aid right after waking up, just before I brushed my teeth, but the thought was insistent. I don't think you changed it. I think this is last night's Band-Aid. Well, it's not last night's Band-Aid because I definitely changed it at lunch. Did you, though? I think so. You THINK so? I'm pretty sure. And the wound is open. Which was true. It had not yet scabbed over. And you left the same Band-Aid on for--God--probably thirty-seven hours by now, just letting it fester inside that warm, moist old Band-Aid. I glanced down at the Band-Aid. It looked new. You didn't. I think I did. Are you sure? No, but that's actually progress if I'm not checking it every five minutes. Yeah, progress toward an infection. I'll do it at the bank. It's probably already too late. That's ridiculous. Once the infection is in your bloodstream--Stop that makes no sense it's not even red or swollen. You know it doesn't have to be--Please just stop I will change it at the bank--YOU KNOW I'M RIGHT (128). Notable features of this passage include Aza's personification of her intrusive thoughts and the use of italics throughout to sometimes, but not always, indicate that they are occurring. This passage also utilizes a switching of focalization ("I" and "you") to distinguish Aza and intrusive thoughts, or who is speaking. But because this is all happening inside Aza's head, the narration is focalized through her, even though the italicized voice uses "you", but the standard print does not—also, both voices use "I". Therefore, standard definitions of focalization do not adequately capture the complexity of these meta-interruptions to Aza's narration. This kind of narration 
"warps the very fabric of the text itself, producing 'disabling' effects in readers' comprehension of narrative" (Bérubé, Kindle Location 594), as well as readers' ability to tell who is speaking and to whom they are doing so (Cadden, 225).

\section{Cripped Narratology}

In my research for this chapter, I did not come across a disability-studies-informed narratological definition of what I see occurring in Turtles, as the major theorists that I have drawn on for this work—Bérubé, Keen, Fludernik, and Mitchell and Snyder—do not primarily concern themselves with interrogating the interplay between narratology and disability. Dorrit Cohn's definition of psycho-narration, “the narrator's discourse about a character's consciousness" (14) is perhaps the closest narratology comes at defining such a text. But what Cohn's definition of psycho-narration fails to account for is the concept of the bodymind. Again, "[t]he term bodymind insists on the inextricability of mind and body and highlights how processes within our being impact one another in such a way that the notion of a physical versus mental process is difficult, if not impossible to clearly discern in most cases (269)" (Schalk, Bodyminds Reimagined, Kindle Edition Location 174-180). Bodymind theory alludes to the idea that disabled bodies are points of entry to exploring the ways that these processes challenge our established ideas about normalcy—including what we deem normal about narrative—and what alternatives they may provide for doing otherwise.

My focus on character and narrative voice in this chapter has thus far demonstrated how disabled bodyminds uproot conventional understandings of the novel and narrative and demand new understandings to emerge. Lennard Davis, in Ideology and the Novel (1987), put forth a new 
understanding of the novel "as a mediator between the self and the world" (Kindle Edition 4). This mediation takes place largely between readers and the characters and story-world that authors design: "novelists do not create characters but only provide instructions to readers who, in turn, must create a character in their minds," (Kindle Edition 114). This argument is similar to what Keen notes in her work on character and narratology in Narrative Form, and it is important for (dis)ability and disability identity mediation in literature because of how different authors create disabled characters and (dis)ability systems in their works. However, Davis importantly also sees that a central function of novels - and one of the primary reasons that authors write them - is to invite readers to identify with the protagonist of the book (Kindle Edition 21). Of course, Davis also argues that novels are ideologically predicated upon instigating this process, as are our individual acts of reading (Kindle Edition 103, 126). As such, "characters therefore need to be organized in ways in which their developments and changes make sense" (Kindle Edition 118) in order for the identification process to fully transfer. My analysis shows how (dis)ability and disability identity can intervene in the process of character development, and conventional storytelling mechanisms and logic, to articulate an embodied reality that is difficult to verbally describe but is largely understood by readers.

Disability rhetoricians Jay Dolmage, Melanie Yergeau, and Julia Rodas communicate similar ideas about disability's embodied reality that make it difficult to qualify. But they also suggest new ways of looking at how disability—and the disabled body—has been positioned by able-bodied systems and thinking. Dolmage, in Disability Rhetoric (2014), traces a history of rhetoric that notably centers non-normative bodies. In the first chapter, Dolmage extrapolates Davis' work on normalcy to claim that rhetoric — and the history of it, especially in the West— has been hyper focused on normalcy, much to the detriment of disabled people, as the idea of 
what is normal became used as a tool to not only Other them, but to oppress them (9-10).

Dolmage writes that "one must face the dismissive conclusions of other rhetorical historians: the idea that disability precludes rhetoricity. The historical record seems to reinscribe this dismissal - and we have few stories of orators or rhetors with disabilities" (149). However, throughout Disability Rhetoric, Dolmage proposes that "practicing an embodied rhetoric, [changes] the world as we move through it," and furthermore, that disabled bodies offer new ways of doing rhetoric (149).

In Authoring Autism, Melanie Yergeau similarly takes up the issue of the disabled body as "precluding rhetoricity," writing that "My dual positionality is no small irony because I have, at many junctures, been told that autism precludes me from being rhetorical, much less a rhetorician" (Kindle Edition 5). Yet, Yergeau rebels against this positioning through the narrativizing of her scholarship; and in doing so, Yergeau demonstrates how the "storying" of autistic individuals, often based on their symptoms and the attendant able-bodied discourses and narratives about autism and normalcy, has been so misinterpreted and misrepresented rhetorically (Kindle Edition 20). For Yergeau, storying is at the heart of the autistic experience: "stories about embodiment and intention, stories about humanity and hierarchy, stories about diagnosis and detection and prevention (Kindle Edition 20). However, Yergeau also acknowledges the risks to this approach:

But what's at risk here is who tells my story and, more broadly, who tells the story of my people. What's of concern is who gets to author our individual and collective identities, who gets to determine whether we are, in fact, narrative creatures, whether we are living beings in rhetorical bodies, whether we are even allowed to call ourselves human (Kindle Edition 21). 
My analysis in my first chapter, as well as in this chapter, has concerned itself exactly with what Yergeau describes, the question of who is telling stories about disabled people. Yergeau and I also question how stories are being told about disabled people, especially by the people who create them — or have the power to do so. My analysis extrapolates from Yergeau's writings on autism and rhetoric, to furthermore claim that we should also concern ourselves with the notion that the "how" of storytelling, due to an embodied experience of disability, necessitates broader understandings of the ways in which we communicate stories - especially in literature and other mass media — as a disabled bodymind may require alternative ways of being in and experiencing the world (a point Yergeau mentions throughout Authoring Autism).

Julia Rodas, in Autistic Disturbances, builds upon Yergeau's work on the intersection between autism and rhetoric. Her analysis highlights how autistic language "is not ordinary language" (Kindle Edition 2); rather, she argues that autistic language "is language that is unexpected, outspoken, rich, florid, nondialogic. Queer language. Both unruly and prescriptive" (Kindle Edition 2). Rodas demonstrates "the power of autistic language to disturb, disrupt, and undo" (Kindle Edition 3) and furthermore notes how autistic authors leverage autistic language to articulate their sense of an embodied, autistic reality through a linguistic analysis of common ways that they describe autism (Kindle Edition 4). But Rodas makes it clear that even though many commonalities exist among autistics as a group for describing their experience, autismand the ways that autism is communicated to others-remains a highly individualized experience (Kindle Edition 5-6). Yet, Rodas' analysis of texts as mediators of autistic experience, especially her work on Villette (Chapter 5), Frankenstein (Chapter 6), and Robinson Crusoe (Chapter 7) advocates that autistic language renders changes in the ways novels and narratives work-down to their syntax. This chapter and "cripped narratology" more broadly, argues something similar, 
which is that the disabled bodymind disrupts conventional uses of language and even ways of acting/ being in the world within the context of a novel or fictional narrative to better attend to the embodied reality of living with a disability and communicating it to readers.

Thus, in coming up with a formal definition of "cripped narratology," I drew heavily upon Schalk's definition of the bodymind, and the work of Dolmage, Yergeau, and Rodas. However, equally influential to the development of cripped narratology was Alison Kafer's extended definition of crip theory ${ }^{7}$ and Ato Quayson's theory of aesthetic nervousness, especially his category of "disability as hermeneutical impasse"8. Both Kafer and Quayson's work challenged me to more critically consider how disabled characters appear in texts and to what degree they are revealed to embody disability, but also, how disability challenges readers to engage with these characters and their story-worlds . Cripped narratology cannot account for every combination of bodymind that a character may be embodying and its subsequent effect on the narrative mechanisms that authors employ to convey those embodied experiences, but this

${ }^{7}$ According to Kafer, crip theory “[includes] disability communities who lack a 'proper' (read: medically acceptable, doctor-provided, and insurer-approved) diagnosis for their symptoms," and also, "departing from the social model's assumption that 'disabled' and 'nondisabled' are discrete, self-evident categories, choosing instead to explore the creation of such categories and the moments in which they fail to hold" (Feminist, Queer, Crip 36, 18).

${ }^{8}$ Quayson never actually defines "hermeneutical impasse" in his book. However, Berube writes that "a 'hermeneutic impasse' [can occur] within the text (with regard to content) but also sets the terms for readers' engagement with the text (with regard to form)" (Kindle Location 594). 
term moves to convey the idea that disabled bodies experience reality in vastly different material ways. And as such, characters who are disabled may tell stories to us (readers) in ways that best encapsulate their embodied realities using different forms of language, narration, and pursuing actions that disrupt and break typical storytelling conventions of the form of the novel.

Therefore, in Turtles, Green employs a cripped narratological framework through the breaking of conventional rules about narrative voice and character, especially when it comes to focalization. Green demonstrates this framework by highlighting Aza's discourse about her own consciousness using italics and what appear to be changes in focalization but are actually the language by which Aza best knows how to describe, and communicate, what an intrusive thought feels like. However, this communication is not just about Aza's feelings in that moment but also about how her character embodies them and manages them in her interactions with others. Thus, it makes sense that the italicized voice uses "you", but the standard print does not, while both voices use "I" in the above passage. Green consistently breaks the rule that italics indicate an intrusive thought to demonstrate the degree to which Aza's OCD impacts her ability to communicate to others who are ill equipped to understand her negotiation of the world around her. A good example of this rule-breaking occurs in the first paragraph of the Band-aid passage, as the lines, "I've been better this week. Maybe the medicine is working" are presented as Aza's internal commentary on her mental health state in italics, but in the next phrase in the passage"when from nowhere the thought appeared"-Green neglects to continue them (128). This particular use of italics is a trick move by Green, as the context surrounding the phrase in the italics makes it clear that Green is denoting a thought that Aza was consciously bringing into being. Only after the phrase "when from nowhere the thought appeared" are italics used primarily in conjunction with second-person narration to more clearly point to the flurry of 
intrusive thoughts that Aza is experiencing. From that point on in the passage, the focalization continuously shifts to convey the exchange of emotions and state of Aza's consciousness as she wars with herself over whether she changed the band-aid in question.

Suzanne Keen writes that "second-person narration refers to a protagonist as 'you.' This conflates the protagonist called 'you' with the narratee, or even with the real reader...Most commentators on second-person narration emphasize the blurring of boundaries between protagonist and reader by the use of 'you."' (46) In this passage, and others in which Green utilizes this framework, it is clear that "you" refers not to the real reader, but to Aza. Keen acknowledges this phenomenon by stating "second person narrative can be external or internal, authorial or figural. It can [also include] extended interior monologue of a first person-character addressing himself or herself as "you"' (46). This is the primary method of address that Green uses to characterize Aza's OCD in the novel, even when not in italics, such as in this passage from early in the novel when Aza has just returned from canoeing down the river to Davis's house:

Now you're nervous, because you've previously attended this exact rodeo on thousands of occasions, and also because you want to choose the thoughts that are called yours. The river was filthy, after all. Had you gotten some river water on your hand? It wouldn't take much. (46).

However, this passage demonstrates the degree to which Aza's bodymind as a person with OCD necessitates a widening of narratological definitions to include moments in which the narrator's subjectivities upend the ways in which one might usually communicate events or thoughts. The passage directly conveys Aza's affective response to her intrusive thoughts, as she questions how they are different from "the thoughts that are called yours": the choice to forgo the usual 
mechanism of italics as denoting Aza's intrusive thoughts underscores Aza's bodymind, her embodiment of OCD, and importantly, how she is "allowed" to mediate her reality to readers . In the sentences that follow this passage, Aza's actual intrusive thoughts— “Time to unwrap the Band-Aid," "But what if you touched something that touched the water," "You need to check for infection; just check it so we can clam down"-are interspersed with Aza's continued description of how her thoughts are making her feel, resulting in Aza's interrupting, obtrusive thought patterns becoming almost indistinguishable from the non-italicized, but equally obsessive thoughts on the state of her possible contamination.

Green's breaking and blurring of narratological conventions to capture Aza's affective responses to OCD most prominently appear in a passage that takes place near the end of the novel, as Aza recovers from a car accident in the hospital and contemplates drinking hand sanitizer to cure her "infection." This passage contains almost four pages of narration that trace Aza's intrusive thoughts, which range from Aza's preoccupation with “c. diff” to Aza questioning how she could attend school far away from home; ever kiss someone; be a "functioning grownup"; and more (227). However, there is one sixteen-line-long sentence, with only commas for punctuation, that encapsulates the issue at hand precisely:

It's the only way that's stupid if it worked alcoholics would be the healthiest people in the world you're just going to sanitize your hands and your mouth please fucking think about something else stand up I HATE BEING STUCK INSIDE YOU you are me I am not you are we I am not you want to feel better you know how to feel better it'll just make me barf you'll be clean you can be sure I can never be sure stand up not even a person just a deeply flawed line of reasoning you want to stand up the doctor said stay in bed and the last thing needed is a surgery you will get up and wheel your IV cart let me up out of this 
wheel your IV cart to the front of the room please and you will pump the hand sanitizer foam into your hands, clean them carefully, and then you will pump more foam into your hands, and you will put the foam in your mouth, swish it around your filthy teeth and gums (227-8).

In this sentence, as appears elsewhere in the novel, Aza's intrusive thoughts appear in italics; Aza's agential thoughts are set in regular type. The intrusive thoughts dominate the landscape of the sentence--what conscious thoughts are left form incoherent phrases such as "it'll just make me barf", "not even a person just a deeply flawed line of reasoning", and "let me up out of this" (227). Yet, the difference in this passage from the canoe ride passage is that Green more fully centers Aza's bodymind, even on the level of syntax, in the choice to write this as one run-on sentence. This decision allows for Aza's intrusive thoughts to act as the narratee at certain points in the text, and at others, the narratee is the Aza that appears through most of the novel. To be clear on the latter issue, I mean that the narratee is Aza sans-intrusive thoughts; but, of course, Aza is never truly without them, which is why I am arguing that this novel blur and bucks traditional narratological conventions. Even the lines between character and voice are blurred here, as evidenced by the lines, "you are me I am not you are we I am not" (228).

This is the most explicit reference in the novel to Green acknowledging Aza's bodymind as a complete entity and, furthermore, to Green creating a (dis)ability discourse that recognizes how one's affective responses to their bodymind — and how people react to it—affect one's sense of identity. Of course, Green tries to make sure that readers are consistently aware throughout the novel that certain behaviors, dialogue, and events may be direct results of OCD, even when the explicit textual evidence for these occurrences is not present. For instance, when Aza, Davis, Daisy, and Mychal go out to dinner together on a double date, there is no explicit mention of Aza 
having intrusive thoughts; rather, Aza narrates that "it felt like I was watching the whole thing from somewhere else, like I was watching a movie about my life instead of living it” (97). But the reader can infer from textual clues in the chapter-as well as the action of the previous one, in which Aza attends therapy and starts to spiral about having an infection-that Aza's OCD is influencing this event, even though Green offers no explicit mentions of it occurring.

Therefore, the conventions that this novel does meet in these moments are complicated by the biological fact that intrusive thoughts, by their nature, "are unwanted...and great effort is made to resist or suppress them" (“Obsessive Compulsive Disorder”). Moreover, not only are these thoughts unwanted, but their repetition and relentlessness transform a reader's relationship with the novel, as readers are presented with a raw look at how (dis)ability as a system, and disability as impairment, forces disabled adolescents to perform their identities and develop relationships with others in different ways than their able-bodied peers. Green makes this point rather clear in Turtles, as Daisy and Aza's character arcs revolve around each of them learning to understand the other better, and for them to learn how to negotiate Aza's accessibility needs together. Likewise, Aza ends the novel with commentary on how she "know[s] [she] would go on, that she would grow up, have children and love them, that despite loving them she would get too sick to care for them, be hospitalized, get better, and then get sick again” (285).

This type of character development demonstrates to the reader that a disabled life is not a tragedy: it fully imagines Aza as a disabled adolescent who must constantly negotiate the systems and people that bar her from participating in life in the ways that she wishes_-including herself. In some ways, Green wrote Turtles to explain to the world this exact fact, only about him instead of Aza. But in doing so, Green made clear that his disease, and Aza's, cannot truly be separated from their person, and how, in turn, it affects the way that they communicate their 
embodied realities as disabled people. Of course, for Aza, as a fictional person, this comes through her narrative voice and character, especially when Green gives readers a glimpse into her mind. Still, Green couples narrative voice, character, and disability together in ways that real readers might understand and connect with, while similarly presenting a representation of disability that is unflinching in its portrayal of the processes that influence disabled bodyminds.

\section{Nerdfighteria and (Dis)ability Discourse}

Green's openness about his OCD, and its connection to Turtles, has served as a catalyst for how fans have engaged in talking about (dis)ability and disability identity. Similarly, fans have directly engaged in talking about (dis)ability and disability identity in part because of the attention paid to the material qualities about living with a disability that Green evokes through Aza's narrative voice and character. To this end, Green's employment of a cripped narratology critically engages readers in (dis)ability discourse as it conveys how someone like Aza may tell stories to readers in ways that best encapsulate their embodied realities using different forms of language and narration, as well as pursuing actions that disrupt and break typical storytelling conventions of the form of the novel. Thus, the immediate connection that many Nerdfighters make to the novel—across several different social media platforms—is one of personal connection to Aza. That is, readers, especially those who are themselves disabled (by mental illness or other disabilities), identify with Aza and not only become engaged in the conversations about disability and mental illness that the story evokes, but also become vocal about it in specific discursive contexts. 
One of the most unique things about Nerdfighteria is that it is a primarily "online" community: while several "IRL" (in real life) Nerdfighter groups exist, the vast majority of community members connect on Twitter, Reddit, Facebook, and elsewhere, such as the previously mentioned Crash Course (YouTube) and platforms like Discord and Tumblr ("Online Nerdfighter Communities"). For this chapter, I am mostly concentrating on fan engagement with the (dis)ability discourse put forth by Green in Turtles and his external writings and interviews about OCD on YouTube, as most of Green's content is located there. Green utilizes this platform much more than other social media; he has publicly taken an indefinite leave of absence from all other social media besides running the vlogbrothers channel on YouTube. While the fan responses to Green's YouTube videos about OCD and Turtles will form the bulk of my analysis, I want to also include Green's responses to fan comments as another level of analysis. Like Rowling, Green participates in the creation of (dis)ability discourse, but in a way that directly engages with fans in a timelier fashion, as well as in a way that allows for both parties to cocreate meaning together. Yet, my analysis of Nerdfighteria related content about (dis)ability, disability identity, will also focus on the (dis)ability discourses that fans engage in on a peer-topeer basis.

Green has posted numerous videos that discuss his mental health on vlogbrothers; his brother Hank has additionally posted a few (dis)ability related videos about his own experiences with ulcerative colitis, in addition to more general content that deals with living as a disabled and/or chronically ill person: this type of content development and sharing demonstrates to fans of the Green brothers - who call themselves Nerdfighters - that discussion of these topics is not taboo, but rather, encouraged. And not only is this kind of dialogue about (dis)ability and illness encouraged to take place with and among fans, but each brother also contributes to the discourse 
that occurs within each video's comment section from time to time, therefore bringing the author-text-audience relationship into new territory. My analysis of John's videos about his OCD and his videos on writing Turtles suggests that not only do Green and his fans co-create (dis)ability discourse together, but they also co-create new meanings of what it means to identify as disabled and/or mentally ill.

Green's videos about his OCD and his videos on writing Turtles only make up a small subsection of the hundreds of videos that exist on vlogbrothers; however, these present to fans introspective takes on how Green functions as a person, and therefore, how that affects his writing. A video that exemplifies this sentiment is "Why I Haven't Written a New Book," published Jun 11, 2019 - almost two years after the publication of Turtles. In the video, Green addresses the precise reasons why he has not come out with another novel. One of those reasons, he says, is this: "Writing has always been, like, a way out of myself — trying to inhabit other people's consciousnesses can give me a break from having to inhabit my own" ("Why I Haven't Written a New Book"). An important point that Green couples with this notion is the hope that "[his] stories will be useful or important to those who read them" ("Why I Haven't Written a New Book"). There are numerous comments on this video espousing that Green's books have been "useful or important" to readers, such as this one from Noelle H.: "I know this wasn't the point of the video, but I've got to say that Turtles absolutely was a good and useful thing to put into the world. My world, anyway. And I thank you for that.” However, many more fans were concerned with the well-being of Green himself: "I hope you realize a large community of us care more about your mental health than your book. Take care of yourself John. Explore all you need" (u/Kelley Crawley); "Take your time John, the wait between your novels are hard but it's always worth it every time. I love listening to your podcast $<3$ ” (u/ yOu_kNoW_wHo). 
There is no way to know if these responses would be less positive about Green's novel hiatus if he had not been openly talking about his mental health for years. Yet, the above responses demonstrate that Nerdfighters consider Green's bodymind as a mentally ill person and its effect on his writing process, productivity, and more. As such, Nerdfighters' awareness of the capaciousness of disability identity, and its impact on reality—including yet unborn fictional realities - serves as a profoundly distinctive characteristic of the fandom. This characteristic was not as holistically evident in the Harry Potter fandom, and therefore, says a lot about how Nerdfighteria may engage in (dis)ability discourse to more inclusive ends. Nerdfighteria's more inclusive, complex imagining of disabled identity is most apparent in responses to Green's video, "What OCD is Like (For Me)," published July $25^{\text {th }}$, 2017, in which Green discusses how OCD informed the writing of Turtles.

"What OCD is Like (For Me)" covers the larger, cultural stigma of mental illness in addition to describing the specific behaviors and thought processes that Green experiences living with OCD, which ultimately inspired him to write Turtles ("What OCD is Like (For Me)"). He says: "When I'm stuck inside a thought spiral, I find it very difficult to observe, like, anything outside of myself. I become a terrible detective. So, when I started [to write] Turtles All the Way Down, I wanted to try to find form and expression for this way down non-sensorial experience of living inside of thought spirals" ("What OCD is Like (For Me)"). He ends the video by saying: "The vast majority of mental illness is treatable and lots of people with chronic mental health problems have fulfilling and vibrant lives" ("What OCD is Like (For Me)"). This narrative that Green ends his video with is important to consider as to how it positions fans' (dis)ability discourse within a framework that acknowledges the challenges of embodied identity, but also combats ableist ideas about disabled identities, particularly the notion that being disabled, sick, 
etc. makes one unable to lead a "worthwhile" life, as Beth Haller documents in Representing Disability in an Ableist World: Essays on Mass Media (2010). While this positioning is, on the level of diction, not so different from Rowling's comments about Moody being "more than his disabilities" ("Illness and Disability”), it operates from a discourse informed by disabled experiences, and combats the dominant (dis)ability discourse that exists in the US, which is, according to Jan Grue, "disability theorized partly as a form of cultural otherness" (37).

Therefore, Green invites Nerdfighters to openly discuss disabled identity, and fan reactions show an urgent desire to do so.

This video has over 2,000 comments. However, the bulk of them are like this one: "My OCD takes a very similar form. Thank you for sharing. It always helps to be reminded that we're not alone" (u/Cassieosaurus_). Wheeler's chapter on Harry Potter and disability fandom highlighted how representation - even if it is on the periphery of a text - matters to fans, reifying the importance of seeing one's identity validated: this is an unmistakably recurring theme in Nerdfighteria's responses to this video. But fans' responses go deeper than expressing the fact that they feel seen or represented by Green's novel, or more likely, the story of how his novel came to be. A good example of this is lies in the replies to this comment on the video: "It disgusts me when people say they have OCD just to be edgy. Or any other mental issues like being bipolar for example. Idiots. Mental illnesses are not to be glorified and are serious disability's that some unfortunate people have to experience. I wish you the best with your OCD” ( $\mathrm{u} /$ Marc Cercone). The reply thread consists of nine comments, and while many agree that OCD (or any disability for that matter) should not be used to make someone appear "edgy", at least three make the following point expressed by GlintTheStrong: "Conversly, OCD is a spectrum, and there are indeed minor states of OCD. I have diagnosed OCD, but it is very minor and I just 
want things to be 'even', and if things aren't even, it bothers me. But that is mostly the extend [sic] of it." The idea of (dis)ability as a spectrum is one that has been long embraced by disability studies scholars - but to see it being taken up by fans, in response to a video on an author's explication of how identifying as a mentally ill person affects his work, including on the levels expressed earlier in this chapter, is evidence of how Nerdfighters' imagining of disabled bodies is more complex and informed by disabled (dis)ability discourses. A similar exchange takes place in the responses to BALENCIAGA's comment, “ "People with mental illnesses can still get treated and live full and vibrant lives' Can someone please help me believe that?" Fans directly respond to the initial post by giving personal, anecdotal evidence that, yes, things do get better, even though illness never goes away. At the heart of these responses is the notion of the bodymind, and how to live in a bodymind that experiences the world differently from othersincluding the negotiation of disabled folks' interactions with able-bodied individuals. This interaction amongst Nerdfighters also suggests that this stigma is an overarching concern of readers, which is furthermore supported by several comments elsewhere in the Comment Section that speak directly to the stigma of mental illness itself.

Missing, however, in the (dis)ability discourse from the "Why I Haven't Written a New Book" and "What OCD is Like (For Me)" comment sections are mentions of Turtles, and specifically, discussion of Aza herself. I ended up finding mentions of Aza located within the comment section in a video titled, "John Reads the First Chapter of Turtles All the Way Down," published on September $5^{\text {th }}, 2017$. Many viewers simply were reacting to the new-ness of another John Green novel, stating their excitement for the then-forthcoming book. But others, like Jinxx, noted how much they seemed to connect with Aza after only hearing one chapter of the story being read: "I connect with Aza on [an] emotional level. Always being in my thoughts 
even when I really don't want to. I was just crying last night feeling trapped in my own thoughts." Again, the theme of connecting to Aza's identity, and its "usefulness" to readers' own formulations of themselves, comes to the fore. Jasmine Daniels articulates this theme well in her comment:

This story really helped me.... You know how in many coming of age movies the students are reading books that somehow perfectly relates to what the main character is going through? Well, somehow, for some reason, that is exactly how [your] book [is] in my life. I've been struggling with some depression and anxiety (not nearly as severe as Aza's) and it has been really scary for me because I have never had to deal with my mental health before. I have also been dealing with a lot of missing. Missing people, things, parts of my life that I have left. TATWD has really helped me solidify the depths of my feelings.

The last few sentences of Daniels' comment are particularly generative for thinking about the ways that Green's novel plays into (dis)ability discourses that more complexly imagine disabled identity, as Daniels alludes to not only the power of representation (as has been previously mentioned), but also how Aza's character in particular models a way forward for her in negotiating life as someone with depression and anxiety. Daniels does not explicitly name what that "path forward" might look like, but by actively naming the disabilities that make up their identity in direct comparison to Aza's, Daniels is likewise identifying how Aza's character negotiates her life in a way that actively combats ableism through the act of naming her illness to others. And in this act of reclaiming her illness, Aza is also reclaiming what OCD means to those who interact with her, educating them on what needs to change for — to use Daniels' wordstheir relationships with others to not go "missing." To that end, other posts indicate the books' 
usefulness in educating readers who may be unfamiliar with OCD: "I can already tell it is a beautiful book that will hopefully build a foundation for a little more empathy and kindness towards people who struggle with this stuff"' (u/Porkchop).

While this comment was made by someone who experiences symptoms similar to Aza, it does bring up the important issue of how able-bodied readers are supposed to engage in the (dis)ability discourse that Turtles (and Green) sets up. To this end, Hallie Ramos writes:

I love this, John. Not just because you write in such a beautiful, yet relatable manner. Or even because the way you wrote highlights the reality of mental disorders, and you did not try to play it down. I love this because I can feel it. I do not struggle with the mental things you or Aza do, but this made me feel it. I feel like I understand people who struggle deeply with mental disorders more than I ever have. Art is self-expression, and I feel like this is your greatest self-expression yet. Thank you, John.

Ramos admits to "not [struggling] with the mental things" that Turtles and Green both showcase in their respective ways; but what is more striking here is the repetition of the phrase (in some variation or another) "I feel it." Julie-Passante Elman writes that, "The cultural value of literary realism has something to do with 'how we feel' and how we believe others should feel" (Chronic Youth: Disability, Sexuality, and U.S. Media Cultures of Rehabilitation, 121). Elman also implicitly puts forth the related idea that "able-bodied audiences want to feel pain, but not experience it for themselves" (Freeman, 5). Ramos' comment underscores both of Elman's points, as Ramos insinuates that Turtles can do the work of educating able-bodied individuals on the issues that the text addresses, and thus, able-bodied readers will be better equipped to engage in (dis)ability discourse and more complexly imagine disabled identity. But this way of "feeling" is still predicated on able-bodied understandings of (dis)ability. In a sense, what Ramos is 
indicating in their response is what I have talked about as "reading for catharsis," which is a kind of reading that I think fails to account for a complex imagining of disabled identity by not seriously considering the experiences of disabled characters, and moreover, valuing the role of disability in the character's experiences. It is therefore not only a failure in identification with disability, but also a distancing from it. But this point brings me back Green and his role in all of this.

Green has long stated that "books belong to their readers" (@johngreen) and has been a vocal supporter of the ways that fans take up texts in new ways. In fact, he and his brother Hank did (and sometimes continue to do) this exact type of work in the Harry Potter fandom (although Hank more than John). So, in that vein, I think he might argue that Turtles can belong to Hallie Ramos in whatever way they want it to belong to them. Still, Green continues to shape these kinds of decisions for readers, whether through the creation of new YouTube videos on these issues or making comments on old ones. Two of Green's comments from "What OCD Looks Like (For Me)" exemplify this idea, on two different levels. The first comment is in response to a Nerdfighter who thanked Green for saying in the video how to pronounce "Aza": Well, that's how I pronounce Aza, but authors' intentions are not always the results. So, if everyone else pronounces her name differently, that's okay! -John" (emphasis Green's own). This quote, on a

${ }^{9}$ While the common definition of catharsis is applicable here, I envision the term as indicating a far more specific idea: the process of able-bodied readers consuming stories about disabled characters in order to "feel something" about themselves. This line of reasoning is based on Julie Passante Elman's work on sick-lit in Chronic Youth (Elman 121), and was presented at MMLA in 2018 . 
small scale, is indicative of how firmly Green believes in the "books belong to their readers" doctrine. Yet, it is also important because it directly acknowledges the gap between the implied reader and the real reader, as Green says that "authors' intentions are not always the results." The recognition of the differences between the implied reader and the reader by Green in this quote make me think about the underlying notion that the book's portrayal of disability identity was risky, particularly as it applied to what would most likely be a majority able-bodied audience. Due to this fact, it is interesting seeing Green interact with fans who are already aware of —if not a part of - the disability community. Green's feelings about how readers are able to respond show that even though he's modeling this discourse, he cannot control how people respond. Nevertheless, he is still pointing people to respond in a certain way.

The pinned comment of "What OCD Looks Like (For Me)" (meaning the comment that Green chooses to be displayed at the top of the comment section) is a fan endorsing a certain type of therapy for OCD, exposure and response prevention therapy (ERP), in addition to the International OCD Foundation, as well as generally expressing the wish that this treatment was more widely known (u/Morgan Rondinelli). Green's response to this comment, “Comment pinned! (I've been through ERP. Doesn't help everyone with OCD--there's no one magic bullet for every case--but definitely helpful for me.) -John" is on a separate level from the other comment, as it more directly deals with (dis)ability discourse and how fans take it up. Green's pinning of Rondinelli's comment is a rhetorical choice that has implications for the fans who read it, as it upholds that information as being important for Nerdfighters to consider. Conversely, the substance of Green's comment equally places importance on the idea that no one treatment can help everyone. And it is this idea that took hold in the replies to Green's response, with Green's original comment being upvoted, agreed with, and even debated, as fans swapped 
experiences using different therapies to manage their various illnesses. This interaction shows how Green simultaneously contextualizes (dis)ability discourse within his own experiences, while furthermore making it a point to extend those arguments outward, so that they may be beneficial to others. The need for authors to contextualize and extend their ideas about their texts, and then, for fans to directly engage with those ideas, is perhaps the unnamable quality that is at the heart of the constantly changing connections between authors, readers, their identities, and the characters in novels, and reveals something about these connections in relation to (dis)ability discourse and how we write, talk about, and imagine disabled adolescents. Namely, it reveals how audiences are equipped to engage in disabled (dis)ability discourse when it is modeled for them, and as a result, do the same when it comes to complexly imagining the life of a disabled adolescent. Importantly, it also reveals how fans take up what has been modeled for them in online spaces.

In my next chapter, I will consider what happens when a text engages in able-bodied and disabled (dis)ability discourses and imaginings of disabled adolescents at the same time, and how fans take up this type of mixed (dis)ability discourse in online spaces. While the TV show Speechless starred a disabled actor (Micah Fowler) playing a disabled adolescent (JJ Dimeo), and the show was created by an individual whose brother has Cerebral Palsy, the show is ultimately more about the Dimeo family. As such, the show spent much of its three seasons (2016-2019) juggling narratives that focused on how the rest of the Dimeos negotiated JJ's identity, usually in able-bodied ways, with narratives that focused on how JJ negotiated his identity in relation to others. In this chapter, I demonstrate how Speechless, by engaging in multiple types of (dis)ability discourses and imaginings of disability identity, presents a more complex view of how fans are expected to engage with such texts. 


\section{CHAPTER IV: SPEECHLESS AND (DIS)ABILITY DISCOURSE: TOWARD NEW UNDERSTANDINGS OF DISABILITY IDENTITY}

Nearly 1 in 4 people live with a disability in the United States alone ("CDC"). While television and movie consumers have increasingly held the view that disability representation in these media should be higher than it is, and importantly, much more accurate ("Disability Inclusion in Movies and Television: Market Research"), disabled actors often face numerous obstacles getting cast in television shows and movies in the first place ("The Challenge to Create More Authentic Disability Casting and Representation on TV"). As a life-long media consumer who is disabled, I have struggled to find media that reflects my lived experiences-especially as an adolescent. These struggles, on an individual level, were part of the reason for this project. And in reflecting on the two texts I have so far covered-the Harry Potter series and Turtles All the Way Down - I am more aware of how my relationship to each of them has changed as I have grown from being a disabled adolescent to a disabled adult. As time has passed, I have grown more cognizant of how my adolescence as a disabled person was complicated by (dis)ability, as I had to negotiate the power dynamics of adulthood versus childhood, but also, the dynamics of being able-bodied versus being disabled. I have demonstrated in the previous chapters that the Harry Potter series does not plumb these distinctions with respect to its adolescent protagonist, Harry, much to the detriment of its disabled fans. And while Turtles highlights how the negotiation of norms and normativity (as Nikolajeva says) are immensely less straightforward for disabled characters, Nerdfighters still struggled, to some degree, to participate in (dis)ability discourse that was not predicated on able-bodied ideas about disabled identity. Because of these findings, and my own lived experience, I wondered what might occur if media blended the 
approaches of Rowling and Green to create a mixed (dis)ability discourse that appealed to the sensibilities of able-bodied audiences, while also centering disabled voices and disabled identity in authentic ways: my curiosity was met with the television show, Speechless.

Speechless features a disabled adolescent protagonist, JJ Dimeo, played by a real-life disabled actor, Micah Fowler. Scott Silveri, the creator and executive producer of the show (as well as a writer for it), used his first-hand knowledge of having a family member with cerebral palsy (CP) to tell the Dimeo family's story (“Interview with Easterseals"). (Dis)ability, therefore, is showcased in multiple ways within the series: JJ navigates his disabled identity throughout the show, while his family and friends similarly grapple with their identities as able-bodied individuals caring for someone with a disability. This chapter explores the ways in which Speechless engages in a mixed (dis)ability discourse to show audiences how the various ways in which we think, talk, and write about disabled adolescents and their identities promote specific understandings of (dis)ability and disabled bodies, especially as these concepts relate to notions of childhood, independence, and normalcy. Through a rhetorical analysis of a core set of the show's episodes, and an examination of audience members' online reactions to the series on Facebook, Twitter, and YouTube, this chapter demonstrates how audiences engage with the mixed (dis)ability discourse approach that Speechless takes to discussing (dis)ability and disability identity in online spaces.

My analysis reveals Speechless as being the "right type" of inclusive for able-bodied audiences, as disability is Othered, but not so Othered as to completely alienate them. While the show clearly caters to able-bodied audiences and their ideas about (dis)ability and disability identity, disabled audiences are given multiple moments for identifying with $\mathrm{JJ}$ and the issues he faces, especially in episodes that highlight his yearnings for independence and normalcy. In turn, 
the audience analysis undertaken in this chapter highlights how the show's mixed (dis)ability discourse approach contributes to differences in how able-bodied and disabled audiences connect their identities and lived experiences to the show's portrayal of the "real life" systematic effects that (dis)ability has on individuals and the family. These differences appear in all three categories of online responses_ " "celebration of the show's inclusivity," "seeing themselves or someone they know represented in the show," and "(dis)ability discourse awareness" - and across/within a variety of social media platforms, further demonstrating that the audience reaction to Speechless, and the show's implications for (dis)ability discourse and mediations of disabled identity, are complex and important to understand.

Speechless, as a fictional representation of "real-life" discourses on (dis)ability, presents itself as a particular type of show about the subject; that is, at its core, Speechless is about how a family deals with (dis)ability. However, Speechless also makes it clear that it is not a reality television show, nor is it fixated on the disabled body as supercrip or as inspiration porn ("I'm Not Your Inspiration, Thank You Very Much"). Having aired on ABC for three seasons (20162019), the show is geared toward families with middle-grade to young adult children due to its themes, but also due to its advertising as a family-oriented program on a network owned by the Walt Disney corporation. The episodes that I will be analyzing here ("P-P-Pilot," from Season One; "S-S-Silent Night," from Season 2; and "N-N-new JJ," from Season 3) create (dis)ability discourse that can be roughly divided into two categories: able-bodied discourses on disability (the Dimeo family and Kenneth, the school janitor turned personal aide for JJ) and disabled people's discourses on (dis)ability (JJ). The titles' spelling refers to JJ's assistive tech and speech patterns, as he must spell out words individually before someone else can read out the whole word. However, as stated previously, I label Speechless as taking a mixed (dis)ability discourse 
approach because the series employs both types of discourses, sometimes even simultaneously. These episodes demonstrate clear points when these (dis)ability discourses diverge, intersect, and even agree; and while not fully explored in the scope of this chapter due to the show's number of episodes, they are discourses that persist throughout the series. The pervading nature of the (dis)ability discourses that Speechless employs contextualizes and reinforces its viewers' knowledge of (dis)ability in specific ways unique to the story-world of Speechless, as the show creates a sense of what it means for a family—but also, a disabled adolescent—to navigate and negotiate (dis)ability and disability (as impairment). In turn, the (dis)ability discourse that Speechless employs that allows for viewers to reexamine how (dis)ability functions on both individual and systemic levels as well as how (dis)ability informs and influences identity development for both carers/family members and disabled individuals themselves.

\section{Episode Analysis}

Speechless centers on the Dimeos, who are presented to the audience in the pilot episode as a scrappy, hardworking, clearly lower-middle class family consisting of the father, Jimmy; mother, Maya; sons, JJ and Ray; and daughter, Dylan. The show is named for JJ, as his character is non-speaking; however, JJ communicates his thoughts via a laser pointer that is attached to his glasses, which he then points at combinations of letters, numbers, and words on a board to form sentences. Someone - usually his family or Kenneth, who becomes his aide - then reads the sentences aloud for whomever JJ is conversing with. The tension created by the embodiment of disability serves as a theme for the show throughout the series, which is encapsulated within the first three minutes of the episode when Maya describes' JJ's disabilities and narrates JJ's gesture 
("That's the finger") to teenage on-lookers (0:2:04). This moment sets in motion the program's main conflict - JJ attempting to finding his voice and independence in opposition to other members of the family, but especially Maya, who must let him do so on his own terms. This initial introduction to JJ, and the Dimeos, necessitates further analysis if we are to fully understand how Speechless facilitates a mixed (dis)ability discourse. In the previous chapter, I put forth cripped narratology as a way of describing the idea that disabled bodies experience reality in vastly different material ways, and as such, characters who are disabled may tell stories to us (readers) in ways that best encapsulate their embodied realities using different forms of language, narration, and action that disrupt and break typical storytelling conventions of the form of the novel. Keeping this theory, as well as Bérubé's theory of "disability as motive.....as the condition for possibility for the text and its apprehension by readers" (Kindle Location 1116) in mind, the initial introduction of the show serves to demonstrate to both able-bodied and disabled audiences alike that the program is leveraging the apprehension caused by JJ's disabilitiesspecifically, the fact that he is non-speaking - to assert that, in fact, the opposite is true. JJ has a voice; yet, in keeping with a cripped narratological framework, he is not always its vessel, which complicates audiences' understandings of JJ's wants and needs, as well as his agency and identity.

In this way, Speechless takes great pride in toying with Beth Haller's observation that disabled people often do not have control over their own voices in the media on a narratological level, as viewers must question the extent to which JJ's voice is his voice and not, say, Maya's or Kenneth's (Representing Disability in an Ableist World: Essays on Mass Media, 1-25, 115-136). Narratology aside, however, Speechless widens this conflict about voice and agency to include the rest of the Dimeos, as their needs are often put front and center in storylines throughout the 
series, such as Ray's unwillingness to move in the pilot; the burdens of being a "special needs" mom; and Dylan's career as an athlete. I would not term this choice as being a novel onestories about parents and siblings who have a disabled child or sibling are greatly visible in the media. But my point is that for a show about (dis)ability, starring a disabled actor whose character is the protagonist, the pilot demonstrates the complexity of the discourses they are conveying about (dis)ability. Therefore, Speechless, even in the pilot, conveys the notion that there are multiple points of entry to (dis)ability discourse, with different aims. One of the points of entry within these discourses is clearly geared towards a more macro view, as the show highlights how (dis)ability, as a system, affects multiple persons and institutions at once, which is evidenced by the aforementioned centering of non-JJ storylines in the show. This particular (dis)ability discourse is also conveyed throughout the series through focusing on the lack of social and physical access that JJ experiences, mostly at school, as a result of being disabled. However, to go back to the issue of voice and agency for a moment, the show also indicates that JJ's understanding of these systems and institutions, and their social environments, is just as complex, if not more, than his family's is. This facet of Speechless demonstrates how cripped narratological frameworks can contribute to rhetorical and narrative situations that more complexly imagine disabled bodyminds, and as such, these frameworks already include disabled audiences, in ways similar to those found in the previous chapter on Turtles All the Way Down. Furthermore, this kind of inclusion is drastically different from the kind espoused by Rowling in the Harry Potter series, and that Elizabeth Wheeler details in Handiland, because it allows disabled audiences to more freely participate in the various levels of (dis)ability discourse, as well as have more control over them from the outset. Yet, while disabled audiences' improved control over the entry points to and types of (dis)ability discourse may exist as a result of 
Speechless' cripped narratological framework, the show does not immediately emphasize JJ's reaction to and control over them, choosing instead to more fully center and combat the general, pervasive able-bodied (dis)ability discourses in order to prepare (and educate) its audience for entering into disabled (dis)ability discourse later in the series.

The show's pilot almost immediately begins to break down the multiple points of entry to (dis)ability further by highlighting the ways that (dis)ability is seen as cultural Otherness through explicit references to JJ's embodied reality, such as the opening scene where he gives teenagers "the finger"- a more micro, individual approach to (dis)ability and disability identity. This moment makes concrete JJ's otherness through the action of the shot, as the teenagers stare at him in his wheelchair, which prompts "the finger." However, the use of this gesture is also impacted by the woman who tries to take the disabled parking spot from the Dimeos; she only backs off when she, too, realizes that JJ is in a wheelchair. The wheelchair, which is a signifier of JJ's disabilities, along with JJ's embodiment of disability, creates the impression of Otherness, even though Maya's exclamation to the teenagers tries to downplay the situation. Yet, the unpacking of (dis)ability discourse, specifically disability as cultural Otherness, is further explored when Maya drops JJ and the kids at school.

Maya brings JJ around the back of the school since there is no wheelchair access in the front. There, she proceeds to have a chat with the principal and Kenneth, the school janitor, about the lack of access that JJ is experiencing. During the conversation between Maya, Kenneth, and the principal, Kenneth uses the word "crippled" to refer to JJ. Immediately, Maya reacts, saying "Let's play a game that I like to call Human or Trash" (0:8:24). She then compares a series of objects and people to trash, all to make the rhetorical argument that the word "crippled" is not okay to use. Here, Maya attempts to establish the "humanity" of JJ through an impromptu 
analysis of the language that is used to describe him and related (dis)ability issues. Kenneth's reaction to JJ fits into the larger narrative of "disability as other" that American (dis)ability discourse has largely centered on according to Grue (37), and establishes a trend in the series, which goes back to James Charlton's notion of "nothing about us, without us": JJ is ultimately left out of these kinds of discussions, while Maya or another member of the Dimeo family takes up the position of disability educator and activist to combat similar ableist narratives.

The "educating about (dis)ability" part of the show therefore develops into its own kind of (dis)ability discourse due to its history of repetition throughout the series, but it is sometimes unclear as to who this education is for. The repetition of this discourse suggests that the show is trying to serve able-bodied audience members and disabled audience members alike without necessarily doing the work to analyze how such discourses fail each group as singular entities. It is telling that the able-bodied members of the Dimeo family are almost always the ones doing this work, and not JJ or the other disabled characters that appear in the series-because of this, much of show's energy is spent on performing (dis)ability education, which altogether, is a progressive achievement. Still, in routinely leaving out the disabled voice(s) at the heart of the show, the audience, especially the disabled viewers, are kept from knowing how those characters (like JJ in the school scene) might contribute to, and change, those narratives. In this way, Speechless achieves what I think is its aim very well, which is to demonstrate that disability is normal. However, this aim sometimes involves the conflation of disabled and able-bodied audiences as one entity, an outcome that may change the fundamental meanings of the (dis)ability discourse the show is trying to promote. Audience members are supposed to be outraged that $\mathrm{JJ}$ does not have equal physical access to the school, in addition to identifying with Maya's response to the situation. But if you are disabled (as I am), you would know many public 
buildings, much less schools, are not ADA compliant. In fact, even if they are, such access is often treated as a privilege rather than as a right. This scene is therefore a good example of how the show tries to reach its audience(s) and expects them to respond.

The show's level of dedication to its (dis)ability education discourse at times gets lost in its quest to prove (dis)ability and disability identity as a normal part of American life. This point is exemplified in the school scene when Kenneth gets the opportunity to respond to Maya's analysis, as he says, "Speaking as the black man in Newport, a person who gets pulled over twice before he pulls out of the parking lot, the irony of being called intolerant is not lost on me" (0:08:30). As Kenneth suggests, the show's attempts to subvert cultural paradigms ends up minimizing issues that have a much larger scope. The show makes it clear that it is willing to take on some issues, such as Kenneth's experience of racism, but only in instances that serve its narrative: there is rather little discussion of racism, classism and gender, in the series and their relation to (dis)ability. Thus, While this type of rhetoric is effective in spelling out the collective harm these paradigms do, it is ultimately not effective as an education tool, as it neglects to consider (dis)ability in any complex way: for instance, some disabled folks use the term "cripple" to refer to themselves in an act of reclamation. This exchange reveals how the show imagines disabled bodies and disability identity to function within a larger (dis)ability discourse, and who that discourse is for, by highlighting Maya and Jimmy's reaction to the word, rather than JJ's. While Maya's point is generally correct, and somewhat informed by a disabled (dis)ability discourse approach, it is telling that the reactions of her and her husband—both ablebodied people - are what is mediated to the audience. In this moment, it becomes clear that the series' mixed (dis)ability discourse will largely be filtered through the able-bodied members of the Dimeo family, whether by their own actions, or actions taken by JJ in reaction to them. 
A prominent example of the series' mixed (dis)ability discourse being conveyed in reaction to the able-bodied members of the Dimeo family occurs in "S-S-Silent Night," the tenth episode of the second season. In this episode, Dylan expresses her desire for a dog, and almost immediately, the family tries to convince JJ that they should get a dog for Christmas. Dylan (in tandem with Maya) negotiates that the Dimeo children will forgo other presents if they can get a dog instead. But JJ "wants presents"; Maya responds, "Well you are a b-u-buzzkill," mocking his speech pattern (0:01:36). JJ pushes back against Maya and Dylan, and advocates he should get presents, specifically a camera, so that he can succeed in film school (0:01:43). The catch, however, is that the dog must be a service dog because the Dimeo's lease otherwise forbids pets, according to Ray (0:02:00). The family pesters JJ to give in, but he ultimately vetoes their collective request, citing that other people need a service dog more than he does (0:02:40). Dylan takes this especially hard, and becomes upset at JJ for his actions, so much so that Dylan applies for a service dog anyway despite JJ's protestation. JJ becomes upset with Dylan after he finds out about the application, telling her "You ignored what I wanted and you used me" (0:05:30). In response, Dylan says, “JJ, please don't be mad at me-you're never mad at me. I don't even know what that would be like" (0:05:30).

This interaction highlights the mixed (dis)ability discourse employed in this episode through the juxtaposition of JJ's agency and identity and Dylan's. The show positions Dylan's desire for a dog as simply being about getting a "normal" pet after a series of odd pets. Yet, through the inclusion of the caveat in the lease, Dylan's desire (and the family's, by extension) for a dog becomes entangled with (dis)ability as it is implied that they need the dog — not for its assistive care, but rather, as a general coping mechanism for being impacted by (dis)ability. Furthermore, however, Dylan's agency and identity as the youngest, able-bodied sibling is 
specifically rhetorically positioned against JJ's agency and identity as the oldest sibling because of his disabled identity: JJ holds a great deal of power here. In structuring the dynamic between $\mathrm{JJ}$ and Dylan in this way, the show comments on how adolescents must negotiate power, not only in relation to adult authority, but also, in relation to each other. Speechless further complicates this issue by envisioning a scenario in which a disabled adolescent is given more choice and control than their able-bodied counterpart. It is a testament to articulating how (dis)ability discourses come into conflict with one another in material ways, as Dylan's desire for normalcy is in conflict with JJ's desire for normalcy: "normalcy," however, is distinctly different for each of them while still tied to (dis)ability. A similar point can be made about JJ and Dylan's agencies and power in this conflict, as they are both tied to their ability status.

"S-S-Silent Night" therefore provides an in-depth look at the nexus between childhood and (dis)ability—including how childhood references a larger family unit, and the interplay between the wants and needs of a disabled child and the wants and needs of the rest of the family, the latter of which may sometimes be communicated through unintended, but still ableist, means. JJ's power in the episode, as well as within the insular conflict with Dylan, is undermined at every turn by his family's constant reminders of how great it would be to have a dog. Yet, the conflict between him and Dylan is escalated by Dylan to an ableist exercise when she takes a vow of silence in an effort to understand what it is like to be $\mathrm{JJ}(0: 08: 20)$. This act greatly angers JJ, and Dylan quickly realizes that this act will not help her to better understand what it is like to be JJ. Eventually, Dylan writes JJ an apology letter and gives him the camera he had originally wanted for Christmas. This interaction further underscores the power dynamics at play between the siblings, for Dylan resorts to the rather extreme and ableist measure of simulating a disability to resolve the conflict between her and JJ. Yet, such measures read as a performance of disabled 
identity rather than a true examination of it — which is perhaps why Dylan ends this charade so quickly. Moreover, Dylan's performance of silence, and of disabled identity, reminds viewers of the fact that "able-bodied audiences want to feel pain, but not experience it for themselves" (Freeman 5) - and such is the case with Dylan's character, too. But instead of interrogating why Dylan makes this choice and its effect on JJ, the show instead pivots in a sort of sideways direction, as JJ ends up applying for the service dog himself and surprises the family with it on Christmas day, but only after they watch his first feature film. This decision renders no real closure or unpacking of what occurred between Dylan and JJ. The show, through JJ's film, gives the audience JJ's response to Dylan's actions, but within the larger context of how JJ's family impacts his freedom, individuality, and identity.

The film centers on JJ's identity and expresses JJ's thoughts as closely as possible to the way in which he experiences them; he pointedly demonstrates his love for his family, but also his frustrations with how his family does not listen to him or understand all of the issues that he faces. Through this film, Speechless explicitly communicates the notion that able-bodied individuals will never truly understand disabled identity. Furthermore, the show recognizes how JJ's positioning as a disabled adolescent impacts his experience of childhood and why it is therefore imperative that JJ speak to those issues himself, rather than having someone ablebodied, not to mention an adult, do so. In this way, the film takes the discursive conflict at the heart of Dylan and JJ's fight, the competing nature of JJ's wants and needs as a disabled child and Dylan's as an able-bodied child, and makes it about something bigger in scope, namely, what it is like to live a "normal" childhood and/or adolescence.

The show's mixed (dis)ability discourse on the issue of what constitutes a "normal" childhood comes to the fore in the third and final season of the show. "N-N-New JJ," the fourth 
episode in that season, focuses on JJ continuing to develop his independence when he realizes that he can zip his sweatshirt. This newfound skill prompts JJ to start taking more control over his life, starting with his IEP meeting. He takes over the meeting from Maya, and then promptly leaves to go "try more things that he has never done before" at Kenneth's request (0:03:50). Maya is left to wonder what her purpose is if she is not caring for JJ. Ray promptly has a meltdown, and Maya puts all her energy into Ray (0:07:25). This results in Maya taking several overbearing actions to ensure that Ray succeeds in school (and other domains, such as talking to girls). JJ presciently warns Ray, however, that “Mom's help can be nice, but you need boundaries" (0:09:40). Ray shrugs off this advice; yet, when Ray has a dream that shows Maya "turning" Ray into JJ, Ray is ready to put boundaries on his care (0:15:00). This part of the episode is rather disturbing, as the audience is explicitly shown all the ways in which Maya might make this transformation occur: a movable desk is built for Ray, Ray gets glasses, and, most eerily, Ray gets his mouth taped shut. The symbolism may be heavy handed, but it is reinforced later in the episode when Maya tries to badger Ray to success in his driver's education course. However, Maya causes Ray to become so flustered that they get into an accident during Ray's driving test, and he fails the course. In this moment, Ray outright tells Maya, "I can't be your new JJ" (0:19:45).

This episode most explicitly deals with discourses of care as they relate to (dis)ability. I have already detailed how the show frequently uses the device of juxtaposing normalcy with (dis)ability to convey JJ's embodied experiences, with the expected audience outcome to be that viewers see the harmful stereotypes and practices that able-bodied people project onto disabled folk. But in this episode, that paradigm shifts to capture the idea that there is a fundamental relationship between care and disability, which is usually governed by the relationship between 
an able-bodied person and a disabled person. Speechless spends a significant portion of its runtime devoted to demonstrating how each of the Dimeos—in addition to Kenneth—act as JJ's care givers. But the show is, to a high degree, built upon the caring relationship between Maya and JJ, as JJ's identities as disabled and adolescent are so often pitted against Maya's responsibilities as both mother and primary caregiver. In some of the episodes, as is evident in this one, Maya's identity as mother to JJ, Ray, and Dylan, is separated from her identity as JJ's primary caregiver. "N-N-New JJ" unpacks the deep psychological struggle JJ's newfound independence reveals for her as a caregiver whose identity has become defined by (dis)ability, and by her ancillary function. The sudden shift in JJ's development necessitates that Maya must reconfigure her identities as caregiver and mother around JJ's new levels of confidence, assertiveness, and yes, independence. Maya struggles greatly with this task, which is why she cares for Ray in the same ways that she did for JJ, not to mention why she slowly makes Ray depend on her in similar ways to how JJ needed her care. The caring relationships that Maya develops in the episode between JJ and Ray are contrasted to great effect, highlighting how even though both boys are adolescents, their relationship to care is handled in markedly different ways, and they react differently to being cared for as well. Just as important, however, is Maya's growth in understanding how disability has intervened in JJ's relationship to her care, as well as how the absence of disability (again, as impairment) in Ray's relationship to her care has factored into their respective actions in the episode.

On a micro level, the episode points to the series' careful consideration of the ways that adolescence and (dis)ability intersect, and how being cared for his whole life has impacted JJ's adolescent and disabled identities. JJ's newfound independence complicates his aforementioned relationships with his carers—especially Maya and Kenneth—but his independence also 
complicates his understanding of himself as a disabled adolescent. This consideration of the ways that adolescence and (dis)ability intersect is most exemplified in the episode when Kenneth reluctantly invites JJ to participate in a school staff poker game during a free period. Over the episode, JJ gains more skill and confidence playing poker. Yet, JJ ends up gambling away his wheelchair in a poker game, after tricking Kenneth to leave. Kenneth asks him why he thought he could do that on his own, asking JJ to be patient with his burgeoning independence. JJ says that "I want to do things myself...All I've ever been is patient" (0:16:26). At the end of the episode, Kenneth and JJ make a deal with the janitor who won his wheelchair in order to get it back. This exchange between JJ and Kenneth underscores the larger discourse about care and disability in the episode, which is that the relationship between these two entities greatly impacts the identity development of all involved in such an exchange. To this end, JJ's use of the word "patient" has a double meaning: JJ has not only been patient, i.e. waiting without complaint, but also, his whole life he has been $a$ patient, someone to be cared for. In the context of the show, his status as the one being cared for has largely fallen under the purview of Maya's intrusive and over-protective care, which is why Ray's comment “I can't be your new JJ," coupled with JJ's growing need to be apart from his community of care, forces Maya — and by extension, ablebodied audience members who are in this position themselves - to reexamine their own relationships to disability and its functioning as a system.

On a more holistic level, throughout this series, Maya's level of care is recalled time and again to highlight the ways in which discourses on (dis)ability—especially in the United Statesare also tied to notions of freedom, individuality, work, worth, and productivity. The former issues (freedom and individuality) are concepts that, within the context of the show, are often conveyed to the audience through JJ's embodied experiences (i.e. a disabled discourse on 
(dis)ability). The latter issues (work, worth, and productivity), are almost exclusively conveyed through able-bodied discourses on disability. One of the starkest examples of this idea occurs toward the end of "C-h-Cheater!," when Ray and Jimmy start talking about money and what plans are to be made for JJ, i.e. who will he live with, where will he live, who will pay for it, etc. This leads to a whole discussion on the topic by everyone except $\mathrm{JJ}$, who then promptly happens upon the conversation (0:19:15). JJ overhears Maya say, "Realistically, is your brother ever going to be able to live on his own? Probably not" $(0: 20: 22)$. JJ then tries to run away to Kenneth's house, but Kenneth takes him back; Maya is the only one of the family to apologize. This scene starkly discusses issues of work, worth, and productivity as they relate to (dis)ability, as a system, and disability as impairment. The fact that JJ will not be able to live on his own is not contextualized within an ability framework, but rather, a financial one, as Ray even makes a comment about wanting to make a lot of money for precisely the reasons they are discussing, with Dylan echoing her brother. This snippet of the episode reaffirms some existing beliefs and attitudes about disability—namely, that disabled people cannot work or, even more disingenuously, that disabled people do not want to. While this scene does not imply the latter, as $\mathrm{JJ}$ is shown throughout the series trying to become a director, the show once again pivots to using the rest of the Dimeos as the only mouthpiece for these issues. The audience never gets a chance, as with the pilot episode, to understand what JJ has to say about him working and/or living on his own.

Speechless dabbles in many different discourses on (dis)ability throughout its threeseason run. In the moments where it engages in (dis)ability discourse from a disabled perspective, it is often overtly didactic to what the show must presume is an able-bodied audience. Conversely, when the show engages in (dis)ability discourse from an able-bodied 
perspective, it is often to place emphasis on the needs and experiences of able-bodied people immediately impacted by disability. This distillation of the discourses around disability in Speechless serve as the foundation of the show throughout its history. Moreover, these discourses work simultaneously to combat negative stereotypes and narratives about both disabled people and able-bodied individuals impacted by (dis)ability. Yet, as my analysis highlights, the show is not always successful in framing their work in this manner, as the ablebodied (dis)ability discourse that is put forth in the program routinely fails to do much of this work: at times Speechless even reaffirms existing, able-bodied worldviews and narratives about (dis)ability. Still, for the larger socio-cultural and socio-historical systems in which this show was being produced - as well as the (dis)ability discourses that it was entering in 2016Speechless presents narratives about disability identity that challenge both disabled and ablebodied people to think more critically about (dis)ability as Otherness, and about the concept of normality as it relates to the family, individual lives, and other social structures such as school, romantic relationships, and work. Speechless demonstrates that disability identity is influenced by many factors within these spheres, and ultimately, is an embodied experience that warrants more representation on television and in popular culture.

\section{Social Media Engagement with Speechless}

To gauge how the audience engaged with the (dis)ability discourses discussed above, I looked at the following social media platforms: Facebook, Twitter, and YouTube. For Facebook and YouTube, I specifically looked at the TV show's official pages/accounts. I specifically examined user comments to posts from the show on both platforms. At the time of this writing, 
the Twitter account for the show no longer exists. However, I looked at tweets referencing the show's former account handle, as well as the account handles of actors Minnie Driver and Micah Fowler, who portray Maya and JJ, respectively. I also searched for any tweets mentioning "Speechless tv show" or tagged with a similar phrase (i.e. \#speechlesstvshow).

\section{Facebook}

The official Speechless TV Facebook page mostly consists of short clips and pictures from the show, which users are then able to comment on and react to with likes, hearts, or other emojis. In the recent posts, most users are concerned with the show's cancellation — in fact, so many users posted about this under the "community" tab in the page that I could not adequately search that tab for this paper (more on this in the limitations section). To this end, comments about the cancellation of the series are not my focus, but they do show a level of engagement with the show that is relatively wide-reaching. At the time of this writing, the page has approximately 250,000 likes and followers (the latter meaning they receive notifications for content posted on the page) ("Speechless Facebook").

The comments can largely be defined as being in one of two categories: ${ }^{10}$ underscoring Speechless as "the right type" of inclusive for able-bodied audiences and commenters identifying with the show (either themselves doing this work, or someone they know and/or care(d) for). One of the things I noticed as I sifted through the comments was that many of the users engaged with the show's content in a way like what David Kociemba found when looking at user

\footnotetext{
${ }^{10}$ These categories are significant subsets of a much greater number of responses, and to that end, they do not encompass all the user engagement on the show's Facebook page.
} 
comments related to Glee's representation of disability. Kociemba noted that viewers seemed to lack the knowledge about disability to have a critical debate about the show's handling of the topic (para 3.3.). While many users on the Speechless community page claimed to have firsthand knowledge of disability (either embodied or as a caregiver), I found a type of rhetorical distance that is directed at the show's portrayal of (dis)ability. That is, the users often talk about (dis)ability without typically referencing the precise representations and narratives of (dis)ability that are mediated by the show to its audiences. This finding is interesting as it is consistent with the research I did for social media engagement with (dis)ability discourse in the Harry Potter series. In the first chapter, I noted how fans speak about (dis)ability and disability identity without the input and experiences of disabled readers, as well as how the discourse is about them, yet happening without them, and therefore, the exclusion of disabled voices allows for able-bodied discourses of disability to take hold. Sami Schalk states that "[her] method of reading black women's speculative fiction grounds analysis within the constructed reality of the individual text and not by current cultural or personal standards of the real or unreal" (Kindle Location 621). While none of the texts I have analyzed in this project are written by black women, nor may be categorized as speculative fiction (although Harry Potter may debatably qualify as such), Schalk's method of analysis points to the significance of story-world context. Moreover, Schalk's approach suggests that the erasure of such story-world context in fan responses to these texts, but especially, Speechless, works to "uphold and define (as well as be upheld and be defined by)" the ideas we culturally keep about (dis)ability (Kindle Location 615). There were many comments on Facebook that reified the ideas we culturally keep about (dis)ability, with one of the "types" of these comments being those that underscored Speechless as "the right type" of inclusive for able-bodied audiences. As scholars such as Jay Dolmage, 
Lennard Davis, and Rosemarie Garland-Thomson (among others) have shown, normalcy is always construed in relation to the able-body. Thus, the types of comments that underscored Speechless as "the right type" of inclusive generally did so by using non-story-world specific examples and vague language that gestures at (dis)ability, but does not explicitly mention it to talk about why the user enjoyed it so much. To this end, one user wrote: "Once in a while a TV show hits all the notes. More importantly it teaches us something about human nature and ultimately ourselves. Every episode I've watched makes me want more of the Dimeo's and Kenneth. I love this show. The last episode they hit it out the park. This show embodies why we live in the golden age of TV" (Alteme). This comment demonstrates the degree to which users are non-specific about the show and the kind of vague language that they employ to talk about (dis)ability, without really discussing it. Alteme states that "it teaches us something about human nature and ultimately ourselves" with "it" referring to the show; still, "it" can also be coded as standing in for (dis)ability, as Alteme's use of "teaches" references the show's didactic tactics. In this way, this user is engaging with is the able-bodied discourses on (dis)ability that the show cultivated, particularly, how (dis)ability reframes normalcy for able-bodied people. The show reframes normalcy for able-bodied individuals by making (dis)ability normal for those who already consider themselves to be so; yet, in turn, as my episode analysis shows, the show also reaffirms how this incremental education—while worthwhile and needed—ultimately is geared toward able-bodied audiences and frequently is presented through the able-bodied characters on the show. Alteme's comment plays into this idea, as the show represents a (dis)ability education that often dismisses the value of (dis)ability and disability identity.

Other comments work to similar ends, using phrases like "inclusive social value" (Hammond) to point to the show's acceptable, able-bodied discourses on disability. One user 
even comes right out and says as much, writing that " $\mathrm{ABC}$ has so many shows that are "social justice' in nature and I get it. It's 2019, but the thing is sometimes the issue feels a bit pushed and that happens all over tv these days. This show speechless is so real and it's funny..." (Elovitz). This comment reveals multiple things occurring at once, as three different claims about the show are made. Elovitz appears to be agreeing with the shows' premise of inclusivity when stating that the show, by virtue of appearing on $\mathrm{ABC}$, is “"social justice' in nature". However, Elovitz also claims that such shows "push" social justice agendas, and that Speechless, by association, fits this bill as well. Elovitz then makes the claim that Speechless "is so real," going on to state that "[i]t does a really great job of showing us what people like JJ go through, what their family and friends experience and that no matter how hard or challenging things are, that humor is a great part of life that helps us understand each other" (Elovitz). Elovitz's comment talks about (dis)ability without naming it, referring only to "people like JJ," which qualifies JJ's Otherness in a subtle way; but Elovitz's connection to the show ultimately stems from its humor and not its discussion of the so called "social justice" issues at its core. In this way, users make clear that Speechless is the "right type" of inclusive for able-bodied audiences, as (dis)ability is Othered, but not too Othered so as to make able-bodied viewers uncomfortable. Also, this category of comments is noticeably vague about what makes Speechless so palatable, as users generally refrain from naming the story-world context that promotes inclusivity. The lack of naming this context thereby omits (dis)ability from that conversation, and in doing so, creates the impression that disability representation is what is to be celebrated more so than the show's actual discussions of (dis)ability.

While the majority of comments on the show's Facebook page laud the show for its humor, inclusivity, and inspiring notes, there are a handful of comments by self-identifying 
disabled viewers that explain what the show means to them, as well as others that talk about how the show's (dis)ability discourse reminds them of someone they know with a disability, usually a family member. These comments typically engage in a mixed (dis)ability discourse, as usersboth able-bodied and disabled — contextualize the show's disability discourses in ways not only specific to Speechless's story-world, but also, in ways specific to how (dis)ability functions in "real life." This work, done by audience members, for audience members, allows for new imaginings of disabled identity to come to light as they reflect upon the "normal" boundaries that Speechless breaks, and how this makes them think about themselves or others who are disabled. For disabled users, the comments exemplify an attitude of relatability to JJ's character, usually around the topics of mobility, freedom, and achievement: "This was so emotional. I've been in a wheelchair my whole life and recently moved out on my own for the first time in my life. So, to watch JJ start to adjust to doing things himself hit close to home" (Bender). Also: "Reminded me of when I was dating my then girlfriend, now my wife of 27 years, and her apartment was on [the] 2nd floor. I scooted up the stairs and my wife carried my manual chair up. Of course, I wasn't so bold as to enter her bedroom. I watched this episode twice" (Hammond). These comments illustrate that the show resonates with disabled viewers for almost the opposite reason that it does for able-bodied viewers - (dis)ability being showcased and discussed in complex ways. Likewise, these comments are further evidence of the material effects of the show's cripped narratological framework, and how that framework allows disabled viewers to access their past and/or present disabled identity. Disabled users' comments therefore reveal the magnitude of quality representation, but moreover, they highlight the unique set of problems that become apparent when thinking about (dis)ability and childhood, and how those experiences influence identity development down the line. 
For (what appear to be) able-bodied users, self-identifying comments often center the able-bodied person's experiences doing working/caring for disabled individuals and how the show presents that narrative as relatable content:

As a former special needs mom, I love this show!...As an Executive Assistant for a nonprofit organization that helps people with developmental disabilities live life to their fullest, I love this show. You show that everyone can contribute to society. I love that you show everyone that special needs can make people really well, special. (Crawford Kern)

My son was a brain damaged spastic quadriplegic after an accident when he was eleven. We were told to put him in an institution, but we brought him home where he lived a full life even though totally disabled and speechless. This show touched my heart...I was given no hope for him, yet our [love] and encouragement enabled him to laugh, move one arm and leg, and enjoy life. This has been a great show." (Predny)

These comments are indicative of the many others that appear to be posted by able-bodied viewers of the show on Facebook, as they fixate on disabled bodies' ability to work, worth, and capability for productivity. Such underlying ideas about (dis)ability are routinely addressed by the show but in ways that may ultimately reaffirm these kinds of viewer reactions (such as Maya and Jimmy being seen reacting to $\mathrm{JJ}$ being called a cripple, but not $\mathrm{JJ}$ ). Both of the above quotes illuminate how carers (teachers, parents, aides, etc.) for disabled children not only speak for (and about) them, but also, how they think about their children and these issues - there is not even a passing consideration of whether the disabled children these people cared for may have found the show representative of themselves. Such differences among able-bodied and disabled viewers in their responses to the show's mixed (dis)ability discourse suggests that viewers' identities, in 
tandem with the preexisting existing (dis)ability discourses that they, as individuals, and the show, as a media object, have engaged with and/or promoted, inform their understanding of how Speechless mediates disabled identity.

\section{Twitter}

After Facebook, Twitter is the platform that most engaged Speechless audience members. Like its Facebook page, most of the more recent mentions of the show on Twitter are in reference to its recent cancellation. Again, while these sentiments show a broad level of support for Speechless, an analysis of these comments lies outside the scope of this paper. While the same general comment categories found in the Facebook page comments are applicable to users' responses to the show's narratives on Twitter, a third category emerged on this platform. This category I will deem “(dis)ability discourse awareness.”

This category is separate from the others in that users' comments directly address the socio-cultural structures at play that produce the show's disability narratives, namely the larger media landscape and its portrayal of (dis)ability issues. This type of comment directly situates Speechless within a discourse that acknowledges the contributions of (dis)ability narratives to media in a manner that does not usually reference able-bodied discourses of (dis)ability. An example of this type of comment lies in the post of this user, "We need more shows like this on TV, not less! Though we're talking about disability representation more, @ Speechless_ABC was still one of the only shows depicting disability w/ actors who actually had disabilities. J.J. DiMeo \& gang will be missed!” (@KrystalDownie). As seen here, the focus in these comments is rather to highlight how the industry has historically handled these issues, and to what extent Speechless 
managed to change the conversations happening around them. Another comment similarly details how the show covers (dis)ability's systemic reaches and implications for developing a disabled identity: "I have CP. Your show [is] the first one to ever include topics that I've always struggled talking about - the inspiration porn, how to navigate high school with a 504, the hospital visits, disability milestones vs. someone who’s able-bodied. Representation matters!” (@conjurewithrisk). This comment strikes at the crux of this project, which is demonstrating how media creates specific discourses around (dis)ability and how these discourses then affect the way that we, collectively, imagine disabled identity, as the reader/viewer recognizes how negotiating (dis)ability systems and ideologies has impacted their life. A third comment that fits this category straightforwardly addresses the show's contribution to (dis)ability discourse, building upon the second comment mentioned in this paragraph: “@Speechless_ABC is a transformative show. It gave the viewers an opportunity to challenge their views of people w/disabilities, everyone's innate desire for independence and how it shapes the family dynamic" (@JimWyler). This tweet underscores the mixed (dis)ability discourse approach that Speechless takes in addressing its content and audience; it also focuses our attention on (dis)ability discourse itself, as it names "challenging [audience] views of people w/disabilities" as a central aim of the show. Whose views are to be challenged is unclear in the original tweet, but the comment implies that it is able-bodied viewers' ideologies around (dis)ability that the show is attempting to challenge and change; at the same time, the inclusion of "how [(dis)ability] shapes the family dynamic" is an interesting parallel to this idea, as I would argue that one of the other central aims of the show is to capture the carer response to (dis)ability, as well as familial/carer identity in relation to (dis)ability: "N-N-New JJ" is a great example of this. 
In this way, these comments all exhibit a greater awareness of the myriad of actors and systems that contribute to how individuals experience and negotiate (dis)ability and disability identity. From my personal experience, many disabled people use Twitter. And while I have no statistical evidence to back up this claim, perhaps this is why the conversation surrounding Speechless and (dis)ability looks different on this platform. Another reason why the responses may look different is due to the differences between Facebook and Twitter users, as a younger and more diverse group of individuals is responding to the show's messaging on the topic on the latter platform. Therefore, the types of comments in this category suggest an engagement with the show's (dis)ability discourses from a disabled person's perspective, as disabled people (and their allies) seek to take control of the larger discourse in media about (dis)ability and shift its narrative, as JJ does many times in the series.

\section{YouTube}

Out of the three social media platforms examined in this paper, YouTube was the least fruitful for seeing how the audience engaged with the show's disability narratives. For one thing, the official Speechless YouTube (the ABC channel) seems to be suffering from organizational issues, as far less content is posted there than is on their Facebook page. Similarly, the content that $i s$ there is not arranged in chronological fashion, and there are many gaps in what content is available. That said, this platform was chosen due to YouTube's colloquial history of having contentious comment sections - I was interested if this forum would provide responses in this line of thought. However, as I conducted my research across the content that was posted, I came across a trend on the show's videos: very low user engagement in the comment section. The 
highest number of comments, 624, on any one video is for the show's initial trailer. On later videos, most of the comment sections max out around the ten to fifteen range, while there are outliers, such as the video entitled "JJ Has a Voice," which has 30.

That said, most of the comments on this platform across the channel's videos do not engage in any of the categories mentioned earlier. But in the comments on the video for the show's trailer, users have posted comments in all three categories of comments. There are comments about the general inclusivity of the show, about seeing images of themselves or others in the show, and about disability discourse awareness. Interestingly, many of the comments on this video have a high combination of likes and replies. This finding suggests that viewers are not only engaging in (dis)ability discourse as consumers of the show, but also participating in the creation of new (dis)ability discourse that builds upon what Speechless already communicates. Such interaction did not readily exist on the other platforms I examined for this chapter, as most users did not reply to other users on the show's Facebook page, and most of the inter-fan interaction on Twitter involved merely likes. The combination of likes and replies therefore suggests a deeper kind of engagement with the show's (dis)ability discourse, as fans actively contribute to (dis)ability discourse, much in the same way that Nerdfighters have done within their responses to vlogbrothers videos that John and Hank Green make about (dis)ability and illness.

As such, one of the best examples of this type and/or level of engagement with (dis)ability discourse from Speechless fans occurs within the replies to the show's initial trailer. In the comment section, viewers discuss their reactions to the trailer and even converse about how (dis)ability is portrayed from various angles. A comment that generated a high level of response amongst other viewers was posted by Tim De Visser: "I love that JJ is rude and 
ungrateful. I still have difficulty expressing displeasure at anything because of internalized ableism. It's so cathartic to see a disabled kid openly tell people he's not satisfied. This show is gold" (“Speechless", 2016). De Visser's comment generated a long discussion of internalized ableism that included one commenter's reluctance to accept internalized ableism as something that disabled individuals experience:

What the heck is 'internalized ableism'?... For a disabled person to live in denial and pretend that they are exactly like someone who isn't disabled is just as bad. (Especially with the condescending, nasty term, "ableism." It doesn't mean you're less valuable as a human being. It does mean that perhaps you can't do the same exact things as a nondisabled person. That's just obvious common sense. (u/Yesica1993).

The conversation on internalized ableism that De Visser initiates here is an interesting extrapolation of issues not explicitly explored in the show's trailer. In fact, the episodes that deal with this topic do not occur in the series until much later in the first season. Thus, what De Visser's comment is suggesting is that seeing JJ's disabled identity being presented in this way by the show has made them rethink their own embodied experiences not only of (dis)ability, but also, childhood and adolescence. In De Visser's response to Yesica1993, they explain further all the ways that, as a society, the United States has perpetuated ableism, and how Yesica1993's response to De Visser's initial post actually proves the point. But what is interesting is that this back-and-forth is then joined by other viewers, such as sabserab, who builds upon De Visser's claims, but also reframes them — again — as an issue of identity: "Do you also tell others how to be black? How to be a chemo patient? [I'd] rather [be] disabled then to be an ignorant fuck like you. Remember, it's the largest minority group in the world, and you could become a member anytime! During your lifetime is a chance of 1:3." 
This addition to the (dis)ability discourse that De Visser's comment initiated speaks to the idea that the representation of disability identity evoked by media such as Speechless and Turtles gives disabled viewers, especially, the opportunity to express to able-bodied viewers that the conventional ways of speaking, writing, and otherwise discussing/ showing disabled bodies have harmed the development of disabled identity in youth and adults who are disabled. Moreover, sabersab's response suggests that because disabled voices have historically been kept from creating (dis)ability discourse, their voices have also been left out in conversations about what "being disabled" means. On this issue, De Visser's comment also had other types of responses that focused on reframing what disability identity looks like, such as another commenter's sense of pride in seeing JJ be "rude and ungrateful":

I always disliked the idea that I must be some humble, nice, polite or saintly person because of my disability. That somehow, it's unacceptable to be a person who's sarcastic, can express displeasure, or can get annoyed. It feels like being held to contradictory standards. People expect less of me, but expect me to be some kind beacon of human decency. Being under and overestimated because people want to go to some feel good movie view of disability annoys me. Seeing a boy giving people the finger in his own way? Now that puts a smile on my face. (u/TerminalCarrion).

TerminalCarrion's comment demonstrates how viewers of Speechless participate in the creation of (dis)ability discourse that goes beyond what is conveyed by the show, especially as it relates to disabled identity. This comment in particular - through the use of the past tense and the word, "boy"- also attempts to conjure a new imagining and understanding of disabled adolescent identity, as TerminalCarrion seems to be asking themselves what it might have meant to them if they had more outrightly rejected this version of disabled identity—-the version prescribed 
largely by able-bodied individuals to disabled individuals. Furthermore, TerminalCarrion's acknowledgement of JJ's "own way" of "giving people the finger" reaffirms the usefulness of cripped narratological frameworks in more fully expressing disabled identity. This point of TerminalCarrion's post, in particular, also suggests that discourse about disabled adolescent identity—as well as about the disabled adolescent bodymind—requires further interrogation by individuals who have insight into these experiences, as "own way[s]" of cultivating disabled identity are capacious, highly contextual, and individualized. In turn, media that features disabled adolescents must be careful to include stakeholders (including creators, writers, actors, etc.) that value such experiences, as several comments mentioned their hopes that the series would have a long run on television.

Speechless included stakeholders that valued the experiences of disabled individuals to great effect, and like John Green's work in the previous chapter, utilized the input from disabled individuals to create (dis)ability discourse that combatted dominant, ableist (dis)ability discourses. Yet, as this chapter has also detailed, the level to which those disabled (dis)ability discourses can be executed and conveyed to what are "mostly" able-bodied audiences sometimes necessitates a shift in that discourse to take place, which is why Speechless has many moments in the series that apply an able-bodied (dis)ability discourse to appeal to the identities of family members/ carers of someone with a disability, as well as the more general discourse on (dis)ability in the United States. Because Speechless interweaves both of these types of discourses into its narrative, audiences - as shown by the responses from Facebook, Twitter, and YouTube - are met with a mixed (dis)ability discourse that allows for them to think about (dis)ability as a system, and how that system thus affects the identity development not only of those who care for someone with a disability, or have a disabled family member, but also, a 
disabled adolescent themselves. Speechless is an extremely important piece of media for this reason, as viewers watch $\mathrm{JJ}$ struggle with the plights and pitfalls of adolescence, while simultaneously being given insight as to how the trials of adolescence become complicated by (dis)ability, primarily in ways that focus on issues of independence, agency, and power in relation to the expectations of what constitutes as a normal childhood/adolescence and family. Speechless goes far beyond just dispelling the notion that there is such a thing as a normal adolescence and family, however, as the show demonstrates the ways that (dis)ability can intervene on multiple levels and in myriad ways to disrupt and dislodge - even for a momentthe choices that are given to both disabled individuals and children/adolescents by a society and systems in which both identities are considered as not independent, agential, powerful, or normal. Speechless's complex imagining of disabled adolescent identity is therefore a radical achievement, as it emphasizes how embodied experience informs narratives about disabled children as well as attendant (dis)ability discourse about such issues. 


\section{CHAPTER V: CONCLUSION}

I have spent much of my life trying to decode and unpack what it means to be disabled. Although I am approaching my thirties, I am, more than ever, preoccupied by what it meant to be a disabled adolescent. How did this shape my interactions with others - peers, family, teachers, etc.? How did this shape my own sense of self? I offer these questions now, at the end of this work, to offer insight as to why I chose this topic for my thesis: I was a disabled kid who loved to read. In many ways, I still am that kid. Still, I would be lying if I said that my views and understanding of (dis)ability_ — on societal and self-levels—-have not changed since I was younger. Moreover, I would be lying if I said that my growth, as a scholar and as a regular human being, has not also reshaped my relationship to each of these texts. What does it mean to be a disabled adult reading YA literature about disabled adolescents? I'll try to answer that question using some of the answers I found in my analysis of these works.

Melissa Anelli already wrote the book I would want to write about my relationship to Harry Potter. It is a series that has fundamentally shaped who I am. Yet, in recent years, as I have re-read these works for various academic projects, I have been increasingly concerned with the series' systemic ableism. Moreover, on the read-through for this project, I finally grasped what bothered me the most about this facet of the Wizarding world: where are disabled fans supposed to see themselves in the books? Rowling never makes explicit that Harry_or Neville,

for that matter - has a disability, although scholars such as Elizabeth Wheeler have made the strong argument that he can be read that way. But unless casual fans are reading such scholarship, they may only recognize disability in the novels through Rowling's decrees on social media, which explicitly state that Moody and Lupin are the "true" disabled characters in 
the books. Fan reactions on social media and in fan forums confirmed this line of thinking, as very few fan-generated discussions in online, Potter-community spaces existed. Furthermore, even when these conversations did exist, they almost always did so in ways that supported the status quo of the books, as well as real-world, ableist thinking about (dis)ability. However, there were exceptions to this occurrence, as some fans took it upon themselves to imagine a cripped Hogwarts experience for students, as well as what living accessibly might have looked like for Lupin. This disconnect points to larger concerns about fandom, and specifically, the extent to which disabled fans can participate in it, if (dis)ability discourse is constructed for readers in such a limited way. Such (dis)ability discourses have real-world implications on material interactions as well as ideological ones; and as the Potterverse continues to grow as a global and multi-generic conglomerate, I am concerned for the continued participation of disabled fans in material spaces as well. I never thought I would be questioning this in an academic essay, but how am I supposed to ride the new Hagrid's motorbike roller coaster at Universal Studios if my Cerebral Palsy prevents me from doing so? Of course, this is quite the extrapolation from the text, but when the text becomes part of reality, it is imperative that we recognize the actors and systems at play and name them so that we can more faithfully align our embodiments and identities with them, should we choose to do so.

This point is what I believe is at the heart of my past and present engagement in Nerdfighteria, the fan community devoted to John and Hank Green's work. Both Greens make a concerted effort to recognize the myriad ways in which we are influenced by various actors and systems, and how these affect our understandings of our environments, relationships, and identities. Nerdfighters, therefore, are exposed to creators who model ways of thinking and being that challenge existing worldviews on a host of subjects, allowing fans to consider more complex 
imaginings of their own relationships to these actors and systems - including literature and media. John has been exceptionally forthcoming as to how his OCD has impacted his work; and it is this openness about illness and (dis)ability that allows for readers/fans to enter the conversations about disabled identity that he carefully puts forth in Turtles All the Way Down. This openness by Green is in direct contrast to Rowling's wielding of power over the (dis)ability discourse that she puts forth in the Potter books and on social media, as Green advocates for a deeper understanding of (dis)ability, which he leverages in the narratology of Turtles. This text, which I have studied many times, continues to surprise me in that its very core is centered on conveying an embodied experience that is almost impossible to convey through conventional storytelling norms. Yet, when the text is combined with additional conversation about the forces impacting the storytelling, it is easy to tell that fans/readers/etc. are more equipped than Potter fans, but also in general, to recognize and evaluate individual understandings of our environments, relationships, and identities as they relate to a text—especially with regard to (dis)ability and disability identity. Moreover, the fan responses to the novel made clear the extent that the text is geared toward the disabled adolescent and thus greatly affects how it is read and understood. One of my main takeaways from the chapter is the feeling of "what if": what if more picture books, middle grade, and especially YA books framed their discussions of (dis)ability and disabled identity in such frank terms?

Speechless attempted to do similar work, yet at times was competing against itself in how it was portraying (dis)ability. Speechless's mixed discourse of (dis)ability sought to satisfy both able-bodied and disabled viewers alike. However, the needs and wants of these audiences were/are very different. These differences show up in the audience response to the show's framing of disability identity—especially as it pertains to Maya and JJ's characters respectively. 
Furthermore, the mixing of able-bodied (dis)ability discourse and disabled (dis)ability discourse undercuts the show's otherwise progressive views on disabled adolescence, agency, and power. Speechless was, to me, a show constrained by the dominant discourses of (dis)ability, even though its intent was to subvert these discourses and their associated expectations. While Speechless employed, at times, a cripped narratological framework to get its audience thinking more critically about disabled identity, it was ultimately a text that dared not to disturb the status quo too much. It was a show about (dis)ability for able-bodied folks, even though the main protagonist of the show was an adolescent, disabled boy. As I read audience responses, I was reminded of my own journey of coming to terms with my disabled identity, including the extent to which it was influenced by literature and media such as the works examined in this project; furthermore, it became clearer to me how my lack of connections as a disabled adolescent to other disabled kids informed my understanding of (dis)ability and disability identity. Specifically, this chapter made me think more critically about the value that social media brings to existing fanbases/texts and media, as readers/viewers can connect with others who share their identities and more fully explore the ways that such imaginings hit home with them.

Thus, in each chapter, it became clear how social media has redefined the relationship between authors, texts, and audiences, and how this continually changing relationship influences (dis)ability discourse to various degrees. Yet, in each chapter, it also became clear that the generic qualities of each text also contributed to the resultant (dis)ability discourse as well as the ways that authors and fans alike think, write, and talk about disabled identity. Speechless and Turtles All the Way Down, and their creators, both had orientations toward (dis)ability that allowed for, and in many instances, modeled the use of cripped narratological frameworks, a disabled (dis)ability discourse and view of disability identity for its respective consumers to 
engage with; still, the differences in genre, as well as intended audience, heavily affected the manners in which individuals took up and responded to each text's promotion of these topics. Even intra-genre (if we consider Harry Potter as YA, and YA as one genre), there were significant differences between Harry Potter and Turtles All the Way Down-including how the texts generated affective responses in their readers to (dis)ability and disability identity.

The proliferation of social media has allowed for disabled voices to come forth and, in real time, participate in the creation of counter narratives to dominant, ableist (dis)ability discourses espoused not only in and by texts, but also by outside forces that influence our reading practices. Thus, a central tenet of this project has been breaking down the ways that (dis)ability discourse informs the mediation of disability identity, and how this specific relationship informs our imaginings and understanding of disabled adolescents. One of the aims of childhood studies, in my opinion, is to similarly understand how the representations of children and adolescents might contribute to an aetonormative society and aetonormative attitudes. However, as put forth in this project, the disabled adolescent bodymind compounds the unique challenges and conditions of each separate identity, and able-bodied people and adults alike rethink their identities in relation to them. This rethinking, and ultimate continuance of, the status quo becomes reproduced in literature and media through the apparent positioning of fictional disabled adolescents to create their own systems of choice in regard to their disabled identity development, but they typically wind up fulfilling a disabled identity that is chosen for them by someone else, rather than by themselves. The use of social media to engage in (dis)ability discourse and fandom addresses this problem precisely, as new choices are created for authors and creators to follow by disabled individuals, based on embodied experiences. Similarly, as I discover, social media offers fans and audience members exposure to these new 
avenues for thinking, writing, and talking about disability identity. Fans can rapidly participate in the discourse around these choices: that is, they can easily participate in the co-creation of meaning, creating counter narratives to ableist, dominant (dis)ability discourse, and in the process, challenge the choices made about (dis)ability — and adolescence - that individuals make on a day-to-day basis.

This project was largely concerned with the authorial choices of Rowling, Green, and Silvestri (and other Speechless writers) in regard to how they thought, wrote, and talked about (dis)ability and disability identity within and outside the story-world of their respective fictions, especially where they aligned their (dis)ability discourse with and within larger ideological systems. Yet, what became apparent through my analysis, and ultimately, much more important to understanding the nexus of identity, media, and literature, were the choices that individuals make about these systems, identities, and ideologies in their own day-to-day lives. Social media has given individuals the power, agency, and voice to assert their ideas about (dis)ability and disability identity to the world. And as disabled voices grow in number and grow in their use of technology that infinitely expands most disabled persons' lives, I believe we should start listening to how they imagine themselves; likewise, we should start listening to how they feel about the way they are imagined. We have been given the tools to do so-and now is as good a time as any to start doing that work across social media platforms, but also, in person too. How else are we to change the narrative? 


\section{Limitations}

There were several limitations that impacted the findings of this project. First, the ephemeral nature of the Internet presented numerous roadblocks to my collection of reader/viewer responses to both the Harry Potter series and Speechless, as fan-forum sites and other creator/studio-sponsored online material has been deleted, removed, or changed from their original states. It should likewise be mentioned that some author-created content, like tweets, has similarly been removed from social media; moreover, John Green has been on a social media hiatus for much of the past two years. Thus, this led me to doing the majority of my research with what information was still available to me, even if the content had transformed into something slightly different, such as was the case with the Leaky Cauldron fan-forum site, as well as searching for topic-adjacent hashtags and key terms for Speechless, as the show's Twitter account no longer exists. Second, the search functions of the social media platforms that I used also presented challenges. This research limitation was very much exclusive to Facebook, however, as there is no way to search for posts from a specific time period or posting date within a Facebook page's “Community tab”. Facebook's Community pages was initially where I wanted to conduct my research, but out of necessity for time, I chose to instead analyze users' responses to content posted only for my chapter on Speechless, which was searchable by keywords. Third, unless the user specifically mentioned they were disabled either in their comment or their public social media profile, there was no way to tell if the users themselves were disabled. 


\section{Directions for Future Research}

Disability representation in media is a growing field of study—and it should be. Much more representation of disabled people is needed in popular culture. As this change starts to happen, perhaps the discourses on (dis)ability that have become engrained in our culture will too. Already, however, as my analysis shows, the ways that we write, talk about, and imagine disabled adolescents are changing, and those changes are bringing about new kinds of conversations that consumers and fans of media that feature disabled adolescent protagonists are able to have as a result. These changes also include the growing number of disabled individuals—especially disabled teens—-who are being included in these conversations, and thus, are actively shaping and participating in the (dis)ability discourse mediated by the texts themselves, as well as those that are mediated by authors, creators, and producers.

Future research into the arguments made in this project might look at a larger set of texts and media to continue to trace how audiences engage with (dis)ability discourse-especially in online settings. Another approach to this idea might be combining a theoretical lens that adds social cognitive theory to the mix, as Lingling Zhang and Beth Haller use in their 2013 study of disability identity and television. Like these scholars, I also call for a more ethnographic approach to be taken so that more data can be collected on how viewers perceive the mediation of disabled identity to audiences, and how media and texts featuring disabled adolescents alters viewers' interactions with (dis)ability discourse and disability identity in real life. It would be especially useful if ethnographic data could be collected from disabled adolescents themselves, as their voices have been largely left out of such academic — and public — conversations. Specifically understanding how disabled audiences respond to texts and media depicting disabled 
adolescents is paramount to contextualizing the ways in which counter narratives of disabled adolescence are created and constructed. This type of work would be a massive interdisciplinary undertaking, as it would continue the trend in literary, media, and disability studies of studying disability representation, but it would contribute new theoretical insights to reader response theory and childhood studies as well. I would even suggest coupling this kind of research with disability identity development theory, to collectively gauge the relationship between text, identity development, and (dis)ability discourse.

Additional lines of research could also include further exploration into what my theory of cripped narratology might entail and look like in practice when applied to texts and other media. Susan Lanser suggests in Fictions of Authority: Women Writers and Narrative Voice (1992) that traditional narratological moves have historically and culturally developed distinct discourses about certain populations, such as women; but the same is true of disabled folk, too, as these discourses have also developed specific types of narratives, and importantly, specific ways of imagining disability identity that largely fail to account for bodyminds that experience the world differently. Conventional narratological theory likewise fails to capture the embodied experience of disabled bodyminds and their need or desire to tell stories in ways that best encapsulate their embodied realities using different forms of language, narration, and pursuing actions that disrupt and break typical storytelling conventions of the form of the novel. As such, more research is needed in the vein of narratological work done by Mitchell and Snyder, Quayson, Schalk, and Bérubé that considers the full impact of the bodymind and (dis)ability on not only the novel and its storytelling functions, but also, the construction of narratives and characters in other forms and media, such as television and film. 


\section{WORKS CITED}

“Speechless_-Official Trailer.” YouTube, uploaded by ABC. 17 May 2016.

https://youtu.be/4u55WK6AbaM Accessed May 28, 2020

Adams, Rachel, and Benjamin Reiss, editors. Keywords for Disability Studies. NYU Press, 2015.Alcoff, Linda. “The Problem of Speaking for Others.” Cultural Critique, no. 20, 1991, pp. 5-32. JSTOR, www.jstor.org/stable/1354221.

Alteme, Patrick. Once and a while a show hits all the notes. Facebook. 12 April 2019. https://www.facebook.com/OfficialSpeechlessTV/posts/2090572941235530 Accessed 28 May 2020

Anelli, Melissa. Harry, A History. Pocket Books, 2008. Aronsson, Robin. Making the Muggle: A Study of Processes of Othering in J.K. Rowling's Harry Potter and How Teachers Can Use the Novels to Work with Issues of Ableism. 2016,http://urn.kb.se/resolve?urn=urn:nbn:se:su:diva-138716.

Asher, Jay. Thirteen Reasons Why. New York: Razorbill, 2007. Print.

@Avivafae. “@jk_rowling Sometimes I wonder if Remus Lupin could have gotten get disability for chronic illness/pain. Fibromyalgia feels like turning into a werewolf but it happens more often then not and there's nothing good that comes with it." Twitter. 28 September 2018. https://twitter.com/Avivafae/status/1045696695214985219

Bakhtin, M. M. (Mikhail Mikhailovich), 1895-1975. The Dialogic Imagination: Four Essays. Austin: University of Texas Press, 1981.

BALENCIAGA. "Re: What OCD is Like (For Me." YouTube. https://youtu.be/jNEUz9v5RYo Accessed 27 May 2020.

Barratt, Bethany. The Politics of Harry Potter. First edition, Palgrave Macmillan, 2012. 
Bender, Toni. I've been in a wheelchair my whole life. Facebook. 13 April 2019. https://www.facebook.com/OfficialSpeechlessTV/posts/2090568041236020 Accessed 28 May 2020.

Bérubé, Michael. "Disability and Narrative." PMLA, vol. 120, no. 2, 2005, pp. 568-576. JSTOR, www.jstor.org/stable/25486186.

Bérubé, Michael. The Secret Life of Stories: The Secret Life of Stories: From Don Quixote to Harry Potter, How Understanding Intellectual Disability Transforms the Way We Read. NYU Press, 2016. Kindle Edition.

Bond, Bradley. "The Invisible Minority: Portrayals of Physical Disability on Children's Television Programming." Conference Papers -- National Communication Association, Jan. 2008, p. 1. EBSCOhost, search.ebscohost.com/login.aspx $?$ direct $=$ true $\& d b=$ cms $\& A N=44852515 \&$ site $=$ edslive\&scope=site. Accessed 10 January 2020.

Bond, Ernest L., and Nancy L. Michelson. "Writing Harry's World: Children Co-Authoring Hogwarts." Critical Perspectives on Harry Potter, edited by Elizabeth E. Heilman, Routledge, 2009, pp. 309-327.

Brown, Karen A. Prejudice in Harry Potter's World: A Social Critique of The Series, Using Allport's The Nature of Prejudice. Virtualbookworm.com Pub., 2008. Print.

Brown, Keah. The Pretty One: On Life, Pop Culture, Disability, and Other Reasons to Fall in Love with Me. Atria, 2019.

Cadden, Mike. "Voice." Keywords for Children's Literature. Eds. Philip Nel and Lissa Paul. NYU Press, 2011. 225. Print. 
Cassieosaurus_."Re: What OCD is Like (For Me." YouTube. https://youtu.be/jNEUz9v5RYo Accessed 27 May 2020.

Centers for Disease Control \& Prevention. "Disability Impacts All of Us." Centers for Disease Control \& Prevention, 9 Sep 2019. https://www.cdc.gov/ncbddd/disabilityandhealth/infographic-disability-impacts-all.html . Accessed 27 May 2020.

Cercone, Marc. "Re: What OCD is Like (For Me." YouTube. https://youtu.be/jNEUz9v5RYo Accessed 27 May 2020.

Charlton, James I. Nothing About Us Without Us: Disability Oppression and Empowerment. 1st ed., University of California Press, 1998.

Cherland, Meredith. "Harry's Girls: Harry Potter and the Discourse of Gender." Journal of Adolescent \& Adult Literacy, vol. 52, no. 4, 2008, p. 273. EBSCOhost, doi:10.1598/JAAL.52.4.1.

Cheyne, R. "Introduction: Popular Genres and Disability Representation." Journal of Literary \& Cultural Disability Studies, vol. 6 no. 2, 2012, pp. 117-123. Project MUSE, muse.jhu.edu/article/480106

Clare, Eli. “The Mountain". Exile \& Pride: Disability, Queerness and Liberation. 2n ed. Cambridge. South End Press. 2009. Print. Pgs. 1-9.

Charaipotra, Sona and Zoraida Córdova. "How YA Twitter Is Trying To Dismantle White Supremacy, One Book At A Time.” Bustle. 18 August 2017. https://www.bustle.com/p/how-ya-twitter-is-trying-to-dismantle-white-supremacy-onebook-at-a-time-76946 Accessed 27 May 2020 
Chatman, Seymour Benjamin. Story and Discourse: Narrative Structure In Fiction And Film. Cornell University Press, 1978. Print.

Cohn, Dorrit. Transparent Minds: Narrative Modes for Presenting Consciousness in Fiction. Princeton: Princeton Univ. Press, 1978.

Collins, Suzanne. The Hunger Games. New York: Scholastic Press. 2008. Print. --. Catching Fire. --. 2009. ---. Mockingjay.--. 2010. --

@ conjurewithrisk. "I have CP. Your show's the first one to ever include topics that I've always struggled with talking about - the inspiration porn, how to navigate high school with a 504, the hospital visits, disability milestones vs someone who's able-bodied.

Representation matters!”. Twitter. 11 May 2019.

https:/twitter.com/conjurewithrisk/status/1127094487627571200

Crawley, Kelley. “Re: Why I haven’t Written a New Book.” YouTube. https://youtu.be/nRRJNL2D7Nc Accessed 27 May 2020.

Daniels, Jasmine. "Re: John Reads the First Chapter of Turtles All the Way Down." YouTube. https://youtu.be/D3QznppVuGU Accessed May 272020.

Daniels, Kapria. "What Teachers Never Taught and Writers Feared to Write: Disability in African American Children's Literature." Disability Studies Quarterly, edited by Beth Haller and Corinne Kirchner, vol. 24, no. 1. 2004. Web. Accessed 10 January 2020. http://dx.doi.org/10.18061/dsq.v24i1.842

Davis, Lennard J. Enforcing Normalcy: Disability, Deafness, and the Body. Verso, 1995.

Davis, Lennard J. Resisting Novels: Ideology and Fiction. Methuen, 1987. Kindle Edition. Davis, Lennard J., editor. The Disability Studies Reader. 4th ed., Routledge, 2013. 
DeadpoolIsMyPatronus. “Does Hogwarts not have any disabled students?” Reddit. https://www.reddit.com/r/harrypotter/comments/dupjez/does_hogwarts_not_have_any_di sabled_students/. Accessed May 272020.

De Visser, Tim. “Re: Speechless_-Official Trailer.” YouTube. https://youtu.be/4u55WK6AbaM Accessed 28 May 2020

dis_the_chris. "Under the Scottish Equality Act (2010), Hogwarts would likely now be wheelchair accessible. How would this affect the rotating staircases, and what other accommodations do you feel Hogwarts would make for disabled wizards." Reddit. https://www.reddit.com/r/harrypotter/comments/ewvdjk/under_the_scottish_equality_act _2010_hogwarts/. Accessed May 272020

Dolmage, Jay. Disability Rhetoric. Syracuse University Press, 2014.

Dowker, Anne. “The Treatment of Disability in 19th and Early 20th Century Children's Literature.” Disability Studies Quarterly, edited by Beth Haller and Corinne Kirchner, vol. 24, no. 1. 2004. Web. Accessed 10 January 2020. http://dx.doi.org/10.18061/dsq.v24i1.843

Downs, Douglas, and Elizabeth Wardle. "The Concept of Discourse Community: John Swales." Writing about Writing, Bedford St. Martins, 2011. pp. 466-473. Pdf. pdfs.semanticscholar.org/778e/5c87e6041903 980d25449c9a2972947a351e.pdf.

@DreaDreamings. "ladyoliviers: transremus: ladyoliviers: transremus: ahh but Remus Lupin with a disability that affects his... tmblr.co/ZwQpMxy7-Ytm.” Twitter. 20 October 2013. https://twitter.com/DreaDreamings/status/391839855065706496

Dunn, Patricia A. Disabling Characters: Representations of Disability in Young Adult Literature. Peter Lang, 2015. 
Easterseals (Interviewer) and Scott Silveri (Interviewee). "Speechless Writer and Producer Scott Silveri Shares His Inspiration.” Easterseals.org. 2016. https://www.easterseals.com/explore-resources/living-with-disability/scott-silverispeechless-producer.html Accessed 27 May 2020

Ellcessor, Elizabeth, and Bill Kirkpatrick, eds. Disability Media Studies. NYU Press, 2017.

Ellis, Katie. and Gerard Goggin. Disability and the Media. Palgrave Macmillan London; New York, NY. 2015

Elman, Julie Passanante. Chronic Youth: Disability, Sexuality, and U.S. Media Cultures of Rehabilitation. New York University Press, 2014.

Elovitz, Jamie Mic. Speechless is so real and so funny. Facebook. 8 April 2019. https://www.facebook.com/OfficialSpeechlessTV/posts/2092219581070866 Accessed May 282020

Fenske Jill N, and Ketti Petersen. "Obsessive-Compulsive Disorder: Diagnosis and Management." American Family Physician. https://www.aafp.org/afp/2015/1115/p896.html. Accessed 12 October 2019

Flood, Allison. "JK Rowling under fire for writing about 'Native American wizards"'. The Guardian. 9 March 2016. https://www.theguardian.com/books/2016/mar/09/jk-rowlingunder-fire-for-appropriating-navajo-tradition-history-of-magic-in-north-americapottermore Accessed 27 May 2020

Fludernik, Monika. An Introduction to Narratology, Routledge, 2009. ProQuest Ebook Central, https://ebookcentral.proquest.com/lib/ilstu/detail.action?docID=411009. 
Freeman, Daniel. "Issues of Authorship, Ableism, and Reader Identity in Young Adult Fiction”. Unpublished Manuscript, Department of English, Indiana University, Bloomington, Indiana. 2014.

Freeman, Daniel. “Ableism in Adaptation: Young Adult Sick Lit and other Representations of Disability” Midwest Modern Language Association Conference, 16 November 2018, Marriott Hotel, Kansas City, MO. Conference Presentation.

Garland-Thomson, Rosemarie. Extraordinary Bodies: Figuring Physical Disability in American Culture and Literature. Columbia University Press, 1997.

GlintTheStrong. "Re: What OCD is Like (For Me." YouTube. https://youtu.be/jNEUz9v5RYo Accessed 27 May 2020.

Green, John. The Fault in Our Stars. New York, New York: Dutton. 2012. Print.

Green, John. "John Reads the First Chapter of Turtles All the Way Down.” YouTube. https://youtu.be/D3QznppVuGU Accessed May 272020.

Green, John. Turtles All the Way Down. Dutton, 2017.

Green, John. "Turtles All the Way Down”. JohnGreenBooks. http://www.johngreenbooks.com/turtles-all-the-way-down-book. Accessed 12 October 2019.

Green, John. "What OCD is Like (For Me).” YouTube, uploaded on 25 July 2017. https://youtu.be/jNEUz9v5RYo Accessed 27 May 2020

Green, John. "Re: What OCD is Like (For Me)." YouTube, uploaded on 25 July 2017. https://youtu.be/jNEUz9v5RYo Accessed 27 May 2020

Green, John. "Why I Haven’t Written a New Book.” YouTube, uploaded on 11 June 2019. https://youtu.be/nRRJNL2D7Nc Accessed 27 May 2020 
Gross, Terry (Interviewer) and John Green (Interviewee). "For Novelist John Green, OCD Is like an 'Invasive Weed' inside His Mind.” NPR, 19 Oct. 2017, www.npr.org/sections/health-shots/2017/10/19/558534128/for-novelist-john-green-ocdis-like-an-invasive-weed-inside-his-mind. Accessed 15 Dec. 2019

Grue, Jan. Disability and Discourse Analysis. Routledge, 2015. ProQuest Ebook Central, https://ebookcentral.proquest.com/lib/ilstu/detail.action?docID=1869304. Accessed 10 January 2020

H., Noelle. "Re: Why I haven't Written a New Book." YouTube. https://youtu.be/nRRJNL2D7Nc Accessed 27 May 2020.

Hall, Kim Q, editor. Feminist Disability Studies. Indiana University Press, 2011. Kindle Edition.

Haller, Beth A. Representing Disability in an Ableist World: Essays on Mass Media. The Advocado Press, 2010.

Hammond, Eric. Inclusive social value. Facebook. 12 April 2019. https://www.facebook.com/OfficialSpeechlessTV/posts/2090572941235530 Accessed 28 May 2020

Hammond, Eric. GREAT EPISODE. Facebook. 8 April 2019. https://www.facebook.com/OfficialSpeechlessTV/posts/2086438161649008 Accessed May 282020

@ harrypotteran13. "The way Remus Lupin is treated in \#HarryPotter is very similar to how those with chronic illness or disability are treated in the workforce. Unwell, discriminated against for something they can't control, struggling to find \& maintain employment. @jk_rowling was that intentional?" Twitter. 21 July 2019. https://twitter.com/harrypotteran13/status/1152924266582536194 
Hemingways-kitten. “Re: Does Hogwarts not have any disabled students?” Reddit. https://www.reddit.com/r/harrypotter/comments/dupjez/does_hogwarts_not_have_any_di sabled_students/. Accessed May 272020.

Hintz, Carrie, and Eric L. Tribunella. Reading Children's Literature: A Critical Introduction. Broadview Press, 2019.

Hockeypuckbt15p. "Re: 'Why is there little to no physical disability in the wizarding world?'” Reddit.

https://www.reddit.com/r/harrypotter/comments/1vd40a/why_is_there_little_to_no_physi cal_disability_in/ Accessed May 272020

Horne, Jackie C. "Harry and the Other: Answering the Race Question in J. K. Rowling's Harry Potter." The Lion and the Unicorn, vol. 34 no. 1, 2010, p. 76-104. Project MUSE, doi:10.1353/uni.0.0488.

Hunt, Sally. "Representations of Gender and Agency in the Harry Potter Series." Corpora \& Discourse Studies, Jan. 2015, p. 266. EBSCOhost, search.ebscohost.com/login.aspx?direct $=$ true $\& d b=$ edb $\& A N=118773223 \&$ site $=$ edslive $\&$ scope $=$ site

Jameson, Frederic. The Political Unconscious: Narrative as a Socially Symbolic Act. Cornell University Press. 1981. Print. Pgs. 103-150.

@JimWyler. “@Speechless_ABC is a transformative show. It gave the viewers an opportunity to challenge their views of people w/ disabilities, everyones inate desire for independence and how it shapes the family dynamic. @ABCTVShows should reconsider its decision. This show brought joy to many." Twitter. 11 May 2019. https://twitter.com/JimWyler/status/1127222924279197697 
Jinxx. "Re: John Reads the First Chapter of Turtles All the Way Down." YouTube. https://youtu.be/D3QznppVuGU Accessed May 272020.

@jk_rowling. “There is no retcon re: Remus Lupin. The so-called 'revelation' now circulating is recycled from interviews given 17 years ago in which 1/4.” Twitter. 9 Sep 2016. https://twitter.com/jk_rowling/status/774370155757535232

@jk_rowling. "I was asked whether Lupin's treatment by others could be seen as a metaphor for (then) stigmatised conditions. I agreed that it could. 2/4.” Twitter. 9 Sep 2016. https://twitter.com/jk_rowling/status/774370269402107905

@johngreen. "Books belong to their readers.” Twitter, 1 Feb 2014. https://twitter.com/johngreen/status/429797089569439744

Kafer, Alison. Feminist, Queer, Crip. Indiana University Press, 2013.

Keen, Suzanne. Narrative Form. Palgrave McMillian. 2003.

Keplinger, Kody, Corinne Duyvis and Kayla Whaley. Disability in Kidlit. Web. 9 January 2020. https://disabilityinkidlit.wordpress.com/ Accessed 27 May 2020

Kern, Crawford Regina. Special needs mom who loves Speechless. Facebook. 12 April 2019. https://www.facebook.com/OfficialSpeechlessTV/posts/2090572941235530 Accessed 28 May 2020

Kociemba, David. “'This Isn’t Something I Can Fake': Reactions to Glee's Representations of Disability." Transformative Works and Cultures, 2010. EBSCOhost, doi:10.3983/twc.2010.0225. Accessed 10 January 2020

Koss, Melanie D., and William H. Teale. "What's Happening in YA Literature? Trends in Books for Adolescents." Journal of Adolescent \& Adult Literacy, vol. 52, no. 7, 2009, pp. $563-$ 572. JSTOR, www.jstor.org/stable/20468410. Accessed 9 Jan. 2020. 
@KrystalDownie "Nooo!! We need more shows like this on TV, not less! Though we're talking about disability representation more, @Speechless_ABC was still one of the only shows depicting disability w/ actors who actually had disabilities. J.J. DiMeo \& gang will be missed! Twitter, 10 May, 2019.

https://twitter.com/KrystalDownie/status/1127030613549178883

Lacalle, Charo, and Núria Simelio. "Television Fiction and Online Communities: An Analysis of Comments on Social Networks and Forums Made by Female Viewers." Critical Studies in Media Communication, no. 5, 2017, p. 449. EBSCOhost, search.ebscohost.com/login.aspx?direct=true \&db=edsbl\&AN=vdc.100049636151.0x000 001\&site $=$ eds-live $\&$ scope $=$ site.

“Toward a Feminist Poetics of Narrative Voice." Fictions of Authority: Women Writers and Narrative Voice, by Susan Sniader Lanser, Cornell University Press, Ithaca; London,1992, pp. 3- 24. JSTOR, www.jstor.org/stable/10.7591/j.ctt207g6vm.4.

The Leaky Cauldron. “About The Leaky Cauldron.” TheLeakyCauldron.org. n.d. http://www.the-leaky-cauldron.org/info/siteinfo/ Accessed 27 May 2020

Lee and Low Books. “2015 Diversity Baseline Survey Results” Lee and Low Books Blog. 26 January 2016. https://blog.leeandlow.com/2016/01/26/where-is-the-diversity-in-publishing-the2015-diversity-baseline-survey-results/ Accessed May 272020

Lee and Low Books. “2019 Diversity Baseline Survey Results” Lee and Low Books Blog. 28 January 2020. https://blog.leeandlow.com/2020/01/28/2019diversitybaselinesurvey/ Accessed May 272020

McEvoy-Levy, Siobhán. Peace and Resistance in Youth Cultures: Reading the Politics of Peacebuilding from Harry Potter to the Hunger Games. Palgrave MacMillan. 2018. 
McRuer, Robert. "Compulsory Able-Bodiedness and Queer/Disabled Existence". The Disability Studies Reader, $4^{\text {th }}$ edition. Edited by Lennard J. Davis. Taylor \& Francis Group, 2013. $369-\quad 378$.

McRuer, Robert. Crip Theory Cultural Signs of Queerness and Disability. TPB, 2006.

Mitchell, David T. and Sharon L. Snyder. Narrative Prothesis: Disability and the Dependencies of Discourse. The University of Michigan Press. 2001.

Moe, Peter Wayne. "Revealing Rather Than Concealing Disability: The Rhetoric of Parkinson's Advocate Michael J. Fox." Rhetoric Review, vol. 31, no. 4, 2012, pp. 443460. EBSCOhost, doi:10.1080/07350198.2012.711200. Accessed 10 January 2020

Murray, Stuart, and Clare Barker, editors. The Cambridge Companion to Literature and Disability. Cambridge University Press, 2018.

Napolitano, Marc. “'So Tough, So Brave, the Consummate Survivor': War, Trauma and Disability in the Harry Potter Series." Lessons in Disability: Essays on Teaching with Young Adult Literature, edited by Jacob Stratman, McFarland \& Company Publishing, 2015, pp. 177-199.

Neithardt, Leigh A. “'Splinched': The Problem of Disability in the Harry Potter Series.” The Harry Potter Series, edited by Lana A. Whited and M. Katherine Grimes, Salem Press; Grey House Publishing, 2015, pp. 273-290.

“Online Nerdfighter Communities.” Nerdfighteria.com. n.d. https://nerdfighteria.com/onlinenerdfighter-communities. Accessed 27 May 2020.

Nikolajeva, Maria. "Beyond the Grammar of Story, or How Can Children's Literature Criticism Benefit from Narrative Theory?" Children's Literature Association Quarterly, vol. 28 no. 1, 2003, p. 5-16. Project MUSE, doi:10.1353/chq.0.1702. 
Nikolajeva, Maria. Power, Voice and Subjectivity in Literature for Young Readers, Routledge, 2009. ProQuest Ebook Central, https://ebookcentral.proquest.com/lib/ilstu/detail.action?docID=446894.

Pet_genius. "Re: Squibs and the Mentally Disabled." Reddit. https://www.reddit.com/r/harrypotter/comments/exr6ah/squibs_and_the_mentally_disabl ed/ Accessed May 282020

Pickens, Therí Alyce. "Review of Prejudice in Harry Potter's World, by Karen A. Brown”. Disability Studies Quarterly, Vol 29, issue 1, Winter 2009.

Price, Margaret. Mad at School: Rhetorics of Mental Disability and Academic Life. University of Michigan Press, 2011.

Predny, Faye. Son quadriplegic, loved the show. Facebook. 13 April 2019. https://www.facebook.com/OfficialSpeechlessTV/posts/2089798237979667:0 Accessed 28 May 2020

Pugh, Tison and David L. Wallace. "Heteronormative Heroism and Queering the School Story in J. K. Rowling's Harry Potter Series." Children's Literature Association Quarterly, vol. 31 no. 3, 2006, p. 260-281. Project MUSE, doi:10.1353/chq.2006.0053.

Quayson, Ato. Aesthetic Nervousness: Disability and the Crisis of Representation. Columbia University Press, 2007. Kindle Edition.

Ramos, Hallie. "Re: John Reads the First Chapter of Turtles All the Way Down." YouTube. https://youtu.be/D3QznppVuGU Accessed May 272020.

Rodas, Julia Miele. Autistic Disturbances: Theorizing Autism Poetics from the DSM to Robinson Crusoe. University of Michigan Press, 2018. Kindle Edition. 
Rondinelli, Morgan. "Re: What OCD is Like (For Me)." YouTube, uploaded on 25 July 2017. https://youtu.be/jNEUz9v5RYo Accessed 27 May 2020

Rosenfield, Kat. "The Latest YA Twitter Pile On Forces a Rising Star to Self-Cancel.” Vulture. 31 Jan, 2019. https://www.vulture.com/2019/01/ya-twitter-forces-rising-star-author-toself- cancel.html Accessed 27 May 2020

Rosenfield, Kat. “The Toxic Drama on YA Twitter.” Vulture. 7 August 2017. https://www.vulture.com/2017/08/the-toxic-drama-of-ya-twitter.html Accessed 27 May 2020

Rowling, J.K. Harry Potter and the Sorcerer's Stone. Scholastic Press. 1999. Print. --. Harry Potter and the Chamber of Secrets.--. 1999. ---. Harry Potter and the Prisoner of Azkaban.--. 1999.---. Harry Potter and the Goblet of Fire. --. 2000.---. Harry Potter and the Order of the Phoenix.--. 2003.---. Harry Potter and the Half-Blood Prince. --. 2005.---. Harry Potter and the Deathly Hallows. --. 2007.--

Rowling, JK. "Illness and Disability". TheWizardingWorld.com. 10 August 2015. https://www.wizardingworld.com/writing-by-jk-rowling/illness-and-disability Accessed 27 May 2020

Rowling, JK. “Remus Lupin”. TheWizardingWorld.com. 10 August 2015. https://www.wizardingworld.com/writing-by-jk-rowling/remus-lupin Accessed 27 May 2020

sabersab. "Re: Speechless—Official Trailer." YouTube. https://youtu.be/4u55WK6AbaM Accessed 28 May 2020 
Samuels, Ellen Jean. Fantasies of Identification: Disability, Gender, Race. New York University Press, 2014.

Sapiens, Canis. “Mr. Moony: Lupin's Curse and His Inspiration?”. TheLeakyCauldron.org. Scribbulus Issue 17, 2007. http://www.the-leakyauldron.org/features/essays/issue17 /mrmoony/. Accessed May 272020.

Saunders, Kathy. "What Disability Studies can do for Children's Literature.” Disability Studies Quarterly, edited by Beth Haller and Corinne Kirchner, vol. 24, no. 1. 2004. Web. Accessed 10 January 2020. http://dx.doi.org/10.18061/dsq.v24i1.849

Schalk, Samantha D. Bodyminds Reimagined: (dis)ability, Race, and Gender in Black Women's Speculative Fiction. Duke University Press. 2018. Kindle Edition.

Schalk, Sami. "Reevaluating the Supercrip." Journal of Literary \& Cultural Disability Studies, vol. 10 no. 1, 2016, p. 71-86. Project MUSE muse.jhu.edu/article/611313.

Schatz, J. L., and Amber E. George, eds. The Image of Disability: Essays on Media Representations. McFarland \& Company, Inc., Publishers, 2018.

Schutt, Russell K. Understanding the Social World: Research Methods for the 21st Century. Sage, 2017.

Shaul Bar Nissim, Hanna. "Disability Inclusion in Movies and Television: Market Research". The Ruderman Family Foundation. 2019. https://rudermanfoundation.org/white_papers/disability-inclusion-in-movies-andtelevision-market-research-2019/ Accessed May 272020

Silveri, Scott, creator. Speechless. Silver and Gold Productions, The Detective Agency, ABC Studios, 20th Century Fox Television 2016. 
Sims Bishop, Rudine. "Mirrors, Windows, and Sliding Glass Doors," Perspectives: Choosing and Using Books for the Classroom 6, no. 3 (Summer 1990): ix-xi.

“P-P-Pilot.” Speechless, season 1, episode 1, ABC. 21 September, 2016. Hulu. https://www.hulu.com/watch/0bd485f0-f96d-4a60-b6f6-6961dfad18e9

"C-h-Cheater!" Speechless, season 1, episode 19, ABC. 5 April, 2017. Hulu. https://www.hulu.com/watch/d8e04f13-0b18-4dd2-b029-76d6633a0b9b

“S-i-Silent Night." Speechless, season 2, episode 10, ABC. 13 December, 2017. Hulu. https://www.hulu.com/watch/6cd77837-ca61-4a54-b8a7-6232d6d1d234

“N-e-New J.J.” Speechless, season 3, episode 4, ABC. 2 November, 2018. Hulu https://www.hulu.com/watch/8fd86264-4949-4b10-bd2c-4a753c550f13

Speechless TV Show. Speechless Official Facebook Page. Facebook. N.d. https://www.facebook.com/OfficialSpeechlessTV Accessed May 282020

Squire, Tari Hartman, and Kristina Kopić, Daryl "Chill" Mitchell. "The Challenge to Create More Authentic Disability Casting and Representation on TV". The Ruderman Family Foundation. September, 2017. https://rudermanfoundation.org/white_papers/theruderman-white-paper-on-the-challenge-to-create-more-authentic-disability-casting-andrepresentation-on-tv/ Accessed May 272020.

Stolworthy, Jacob. “JK Rowling debunks 'new Harry Potter revelation' that Remus Lupin's condition is AIDs metaphor.” The Independent. 10 September 2016. https://www.independent.co.uk/arts-entertainment/books/news/jk-rowling-harry-pottertheory-debunked-remus-lupin-aids-david-thewlis-a7235751.html Accessed 27 May 2020 
Strimel, Courtney. "The Politics of Terror: Rereading Harry Potter." Children's Literature in Education: An International Quarterly, vol. 35, no. 1, Mar. 2004, pp. 35-52. EBSCOhost, doi:10.1023/B:CLID.0000018899.06267.11.

Team Starkid. “A Ver Potter Musical.” YouTube, Uploaded by Team Starkid, 5 July, 2009. https://youtu.be/wmwM_AKeMCk Accessed 27 May 2020

Templeton, Molly. "YA Twitter Can Be Toxic, But It Also Points Out Real Problem." BuzzfeedNews. 24 June, 2019. https://www.buzzfeednews.com/article/mollytempleton/ya-twitter-books-publishingamelie- wen-zhao-social-media Accessed 27 May 2020

TerminalCarrion. "Re: Speechless_-Official Trailer." YouTube. https://youtu.be/4u55WK6AbaM Accessed 28 May 2020

Tinyemoheart. "Squibs and the mentally disabled." Reddit. https://www.reddit.com/r/harrypotter/comments/exr6ah/squibs_and_the_mentally_disabl ed/ Accessed 27 May 2020

Thomas, Ebony Elizabeth. The Dark Fantastic: Race and the Imagination from Harry Potter to The Hunger Games. NYU Press, 2019.

Transremus and ladyoliviers. "Remus Lupin with a disability.” Tumblr. 16 October 2013. https://inkstainedchocolateeyes.tumblr.com/post/64266906245/ladyoliviers-transremusladyoliviers. Accessed 27 May 2020.

Tyner, Madeline. "CCBC 2017 Multicultural Statistics.” CCBlogC, Cooperative Children's Book Center at University of Wisconsin-Madison, 22 Feb. 2018 http://ccblogc.blogspot.com/2018/02/ccbc-2017-multicultural-statistics.html 
Turner-Vorbeck, Tammy. "Pottermania: Good, Clean fun or Cultural hegemony?" Harry Potter's World: Multidisciplinary Critical Perspectives. Edited by Elizabeth E. Heilman. Routledge Falmer, 2003. 13-24.

Vezzali, Loris, et al. "The Greatest Magic of Harry Potter: Reducing Prejudice.” Journal of Applied Social Psychology, vol. 45, no. 2, Feb. 2015, pp. 105-121. EBSCOhost, doi:10.1111/jasp.12279.

Wall, Barbara. The Narrator's Voice: The Dilemma of Children's Fiction. 1991. Kindle Edition. “Our Story”. We Need Diverse Books, n.d. https://diversebooks.org/ourprograms/ourstory/

Weaver, Roslyn. "Metaphors of Monstrosity: The Werewolf as Disability and Illness in 'Harry Potter' and 'Jatta.'” Papers: Explorations into Children's Literature, no. 2, 2010, p. 69.

Wendell, Susan. "Unhealthy Disabled: Treating Chronic Illnesses as Disabilities." Hypatia, vol. 16, no. 4, 2001, pp. 17-33. JSTOR, www.jstor.org/stable/3810781. Accessed 27 May 2020.

Wheeler, Elizabeth. Handiland: The Crippiest Place on Earth. University of Michigan Press, 2019. Kindle Edition.

Wong, Alice. "Disability Visibility Project." Disability Visibility Project, n.d., https://disabilityvisibilityproject.com/. Accessed 27 May 2020

Yesica1993. "Re: Speechless—Official Trailer.” YouTube. https://youtu.be/4u55WK6AbaM Accessed 28 May 2020

Yergeau, Melanie. Authoring Autism: on Rhetoric and Neurological Queerness. Duke University Press, 2018. Kindle Edition. 
yOu_kNoW_wHo. "Re: Why I haven't Written a New Book." YouTube. https://youtu.be/nRRJNL2D7Nc Accessed 27 May 2020.

Young, Stella. “I'm Not Your Inspiration, Thank You Very Much” TED, 9 June 2014. https://www.ted.com/talks/stella_young_i_m_not_your_inspiration_thank_you_very_mu ch/transcript?language $=$ en\#t-146456 Accessed 27 May 2020

Zhang, Lingling, and Beth Haller. "Consuming Image: How Mass Media Impact the Identity of People with Disabilities.” Communication Quarterly, vol. 61, no. 3, July 2013, pp. 319 334. EBSCOhost, doi:10.1080/01463373.2013.776988. 